UNIVERSIDADE ESTADUAL PAULISTA “JÚLIO DE MESQUITA FILHO” FACULDADE DE CIÊNCIAS AGRONÔMICAS

CAMPUS DE BOTUCATU

\title{
AVALIAÇÃO ECONÔMICA DE EUCALIPTO IRRIGADO EM \\ DIFERENTES CENÁRIOS
}

\section{HANDREY BORGES ARAUJO}

Tese apresentada à Faculdade de Ciências Agronômicas da UNESP - Campus de Botucatu, para obtenção do título de Doutor em Agronomia (Irrigação e Drenagem)

BOTUCATU - SP

Janeiro - 2010 
UNIVERSIDADE ESTADUAL PAULISTA “JÚLIO DE MESQUITA FILHO” FACULDADE DE CIÊNCIAS AGRONÔMICAS

CAMPUS DE BOTUCATU

\section{AVALIAÇÃO ECONÔMICA DE EUCALIPTO IRRIGADO EM DIFERENTES CENÁRIOS}

HANDREY BORGES ARAUJO

Orientador: Prof. Dr. Raimundo Leite Cruz

Co-Orientador: Prof. Dr. Jarbas Honorio de Miranda

Tese apresentada à Faculdade de Ciências Agronômicas da UNESP - Campus de Botucatu, para obtenção do título de Doutor em Agronomia (Irrigação e Drenagem)

BOTUCATU - SP

Janeiro - 2010 
FICHA CATALOGRÁFICA ELABORADA PELA SEÇÃO TÉCNICA DE AQUISIÇÃO E TRATAMENTO DA INFORMAÇÃO - SERVIÇO TÉCNICO DE BIBLIOTECA E DOCUMENTAÇÃ̃O UNESP - FCA LAGEADO - BOTUCATU (SP)

\footnotetext{
A663a

Araújo, Handrey Borges, 1976-

Avaliação econômica de eucalipto irrigado em diferentes cenários / Handrey Borges Araújo. - Botucatu, [s.n.], 2010. v, 84 f. : il., color., grafs., tabs.

Tese (Doutorado) - Universidade Estadual Paulista, Faculdade de Ciências Agronômicas, Botucatu, 2010

Orientador: Raimundo Leite Cruz

Co-orientador: Jarbas Honório de Miranda

Inclui bibliografia

1. Fertirrigação. 2. Viabilidade econômica. 3. Eucalipto. I. Cruz, Raimundo Leite. II. Miranda, Jarbas Honório de.III. Universidade Estadual Paulista "Júlio de Mesquita Filho" (Campus de Botucatu). Faculdade de Ciências Agronômicas. IV. Título.
} 


\section{BIOGRAFIA DO AUTOR}

HANDREY BORGES ARAUJO, filho de João Batista Murta Araujo (in memorian) e Márcia Borges da Silva, natural de Uberaba, Minas Gerais, nasceu no dia 18 de abril de 1976.

Em 1994 iniciou o curso de graduação em Engenharia Agrícola pela Universidade Federal de Viçosa, o qual concluiu em 1999, iniciando na mesma época o curso de Mestrado em Construções Rurais e Ambiência do Departamento de Engenharia Agrícola desta mesma instituição, finalizando em 2002.

Atua, desde 2003, como professor universitário nos cursos de graduação em Agronomia e Engenharia Florestal da Faculdade de Agronomia e Engenharia Florestal de Garça (FAEF), no curso de Engenharia Ambiental do Centro Universitário de Lins (UNILINS) e no curso de Pós-Graduação em Gestão Ambiental e Desenvolvimento Sustentável da Faculdade de Ciências Sociais e Agrárias de Itapeva.

Atuou como consultor em diversos projetos técnicos e econômicos no âmbito da engenharia, na área de dimensionamentos de barragens e estruturas hidráulicas para finalidades agrícolas, prognose da produção de biomassa para produção de energia e de oleaginosas para produção de biocombustíveis, para empresas e órgãos como Petrobrás, Galp, FGV, Brazilian Pellets, Governo de El Salvador, entre outros. 


\section{UNIVERSIDADE ESTADUAL PAULISTA "JÚLIO DE MESQUITA FILHO" FACULDADE DE CIÊNCIAS AGRONÔMICAS CAMPUS DE BOTUCATU CERTIFICADO DE APROVAÇÃO}

TÍTULO: "AVALIAÇĀo BCONOMICA DE BUCALIPTO IRRIGADO BM DIFERENTES CENÁRIOS".

ALUNO: HANDREY BORGES ARAUJO

ORIENTADOR: PROF. DR. RAIMUNDO LEITE CRUZ

CO-ORIENTADOR: PROF. DR. JARBAS HONORIO DE MIRANDA

Aprovado pela Comissão Examinadora

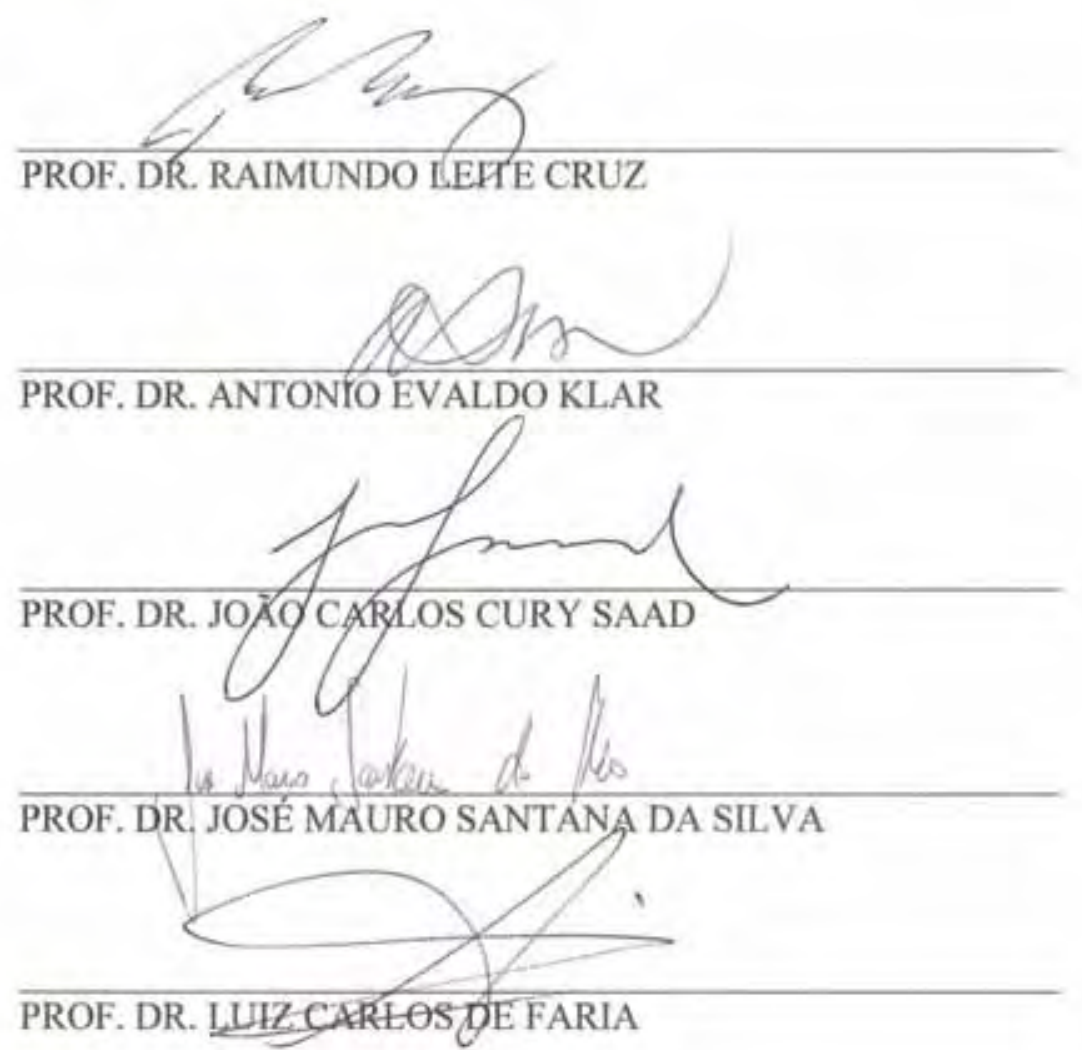

Data da Realização: 29 de janeiro de 2010. 


\section{AGRADECIMENTOS}

À Jesus, nosso irmão maior, que a cada dia nos oferece uma nova oportunidade de reconhecimento de nossos erros e restauração de nossas faltas, em busca da felicidade suprema.

À minha esposa Karina Helena da Cruz, pelo constante apoio nas horas difíceis e pela companhia agradável nos momentos de alegria, e aos nossos filhos, João Cruz Araújo Neto e Maria Luiza Cruz Araujo, que nos dão a oportunidade de descobrirmos o verdadeiro sentido da vida.

Aos meus pais, João Batista Murta Araújo (in memorian) e Márcia Borges da Silva, que há tempos vêm se dedicando ao compromisso laborioso de ajuda no crescimento de seus filhos.

Aos amigos, Pedro Paulo Diniz Epiphânio, Jozébio Estevez Gomes, Luiz Carlos de Faria e José Mauro Santana da Silva, que em especial auxiliaram no decorrer deste trabalho e a tantos outros que participam de nossa vida como verdadeiros colegas de aula, na escola da vida.

Aos Coordenadores, Diretores e alunos da UNILINS e FAEF que souberam compreender minhas negligências profissionais como professor durante estes anos de dedicação ao doutorado.

Aos mestres, que em todos os níveis, são os maiores responsáveis pelo nosso crescimento intelectual, desde os queridos professores de primário, na Escola Estadual Professor "Chaves", passando pelos professores de ginásio e colegial, no Colégio Nossa Senhora das Graças, de graduação e mestrado na Universidade Federal de Viçosa e finalmente pelos professores da Faculdade de Ciências Agronômicas da Universidade Estadual Paulista "Júlio De Mesquita Filho", que tanto contribuíram com minha formação profissional.

Ao meu orientador Raimundo Leite Cruz e co-orientador Jarbas Honorio de Miranda que sempre me apoiaram e incentivaram, embora tantos percalços pelo caminho.

À Empresa MMX Metálicos Corumbá Ltda, na pessoa de Anderson Piacezzi, Márcio Bernardi, Amilton Ferreira de Sousa e Antônio José de Souza, que numa formidável parceria, tanto colaboraram para o desenvolvimento desta tese. 


\section{SUMÁRIO}

LISTA DE TABELAS …….................................................................................... VII

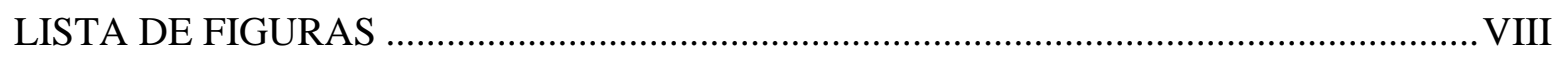

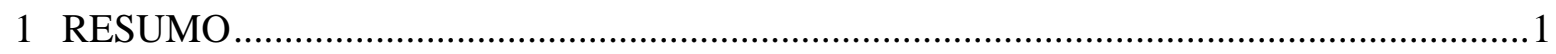

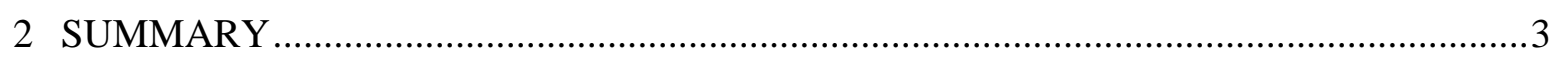

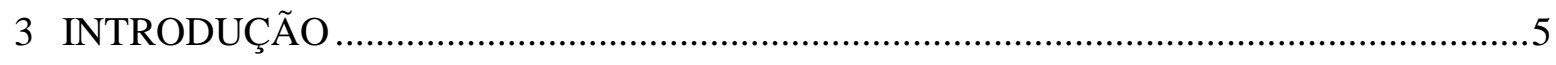

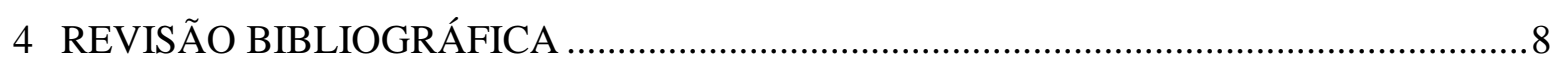

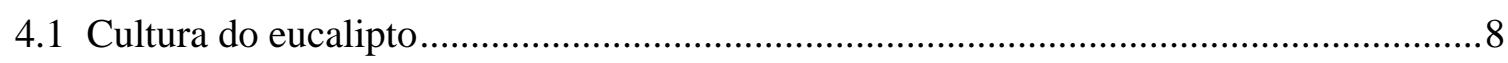

4.1.1 Curvas de crescimento e funções de prognose ...............................................10

4.1.2 Máximo Incremento Médio Anual (IMA) e Incremento Corrente Anual (ICA)

4.1.3 A relação IMA/ICA e a Rotação Econômica Ótima (REO) ...............................14

4.2 Disponibilização de água e nutrientes em plantios florestais ....................................... 15

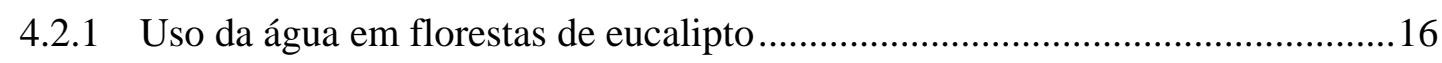

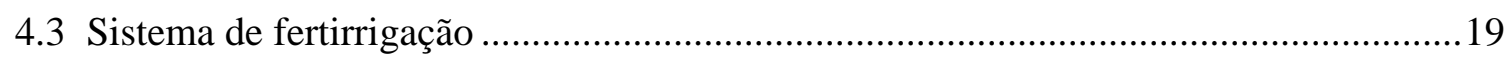

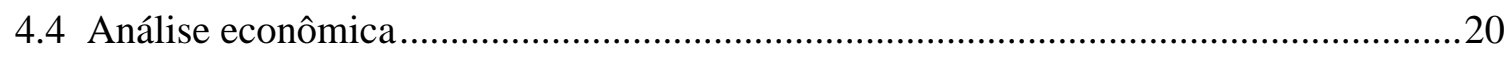

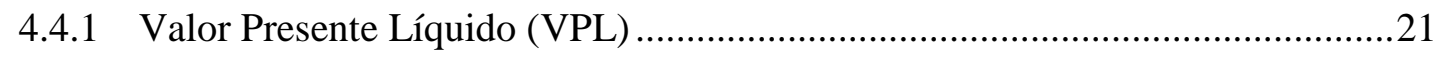

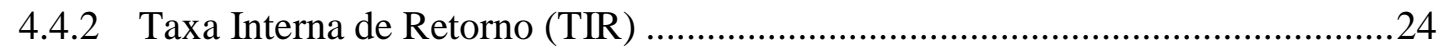

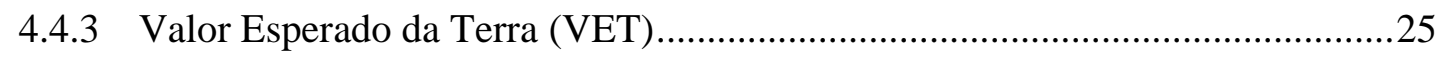

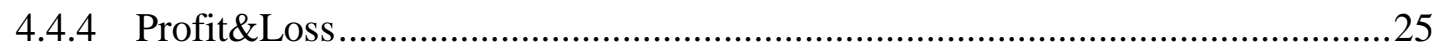

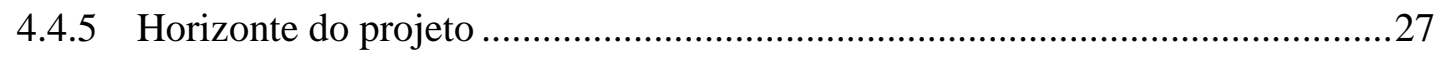

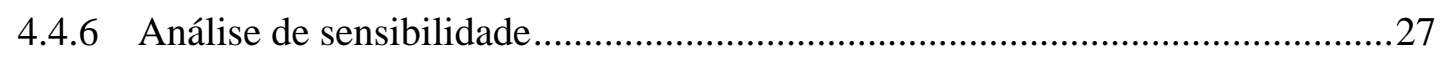

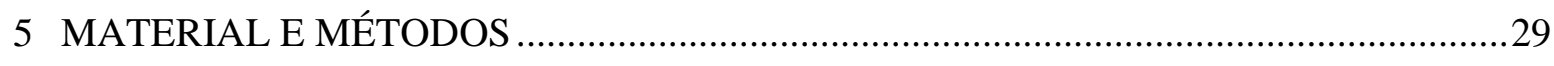

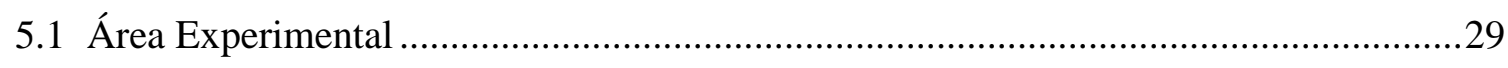

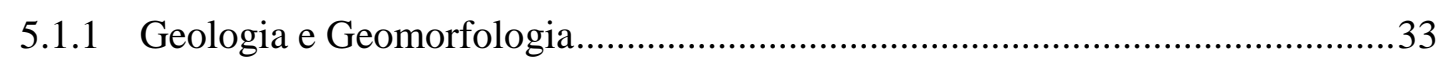

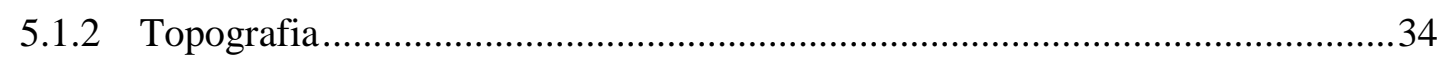

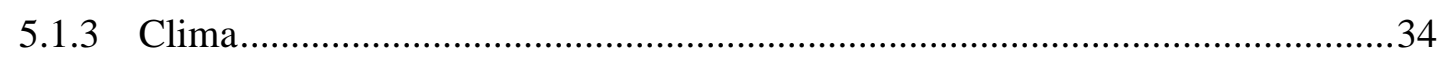

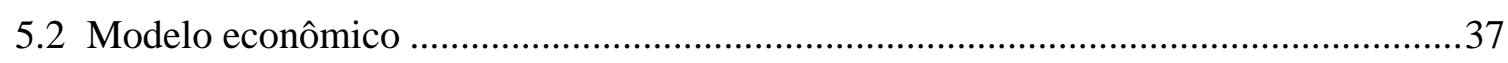

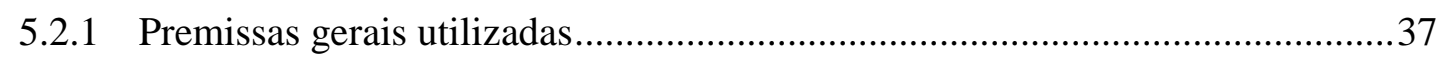




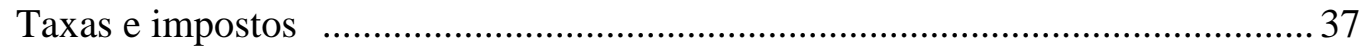

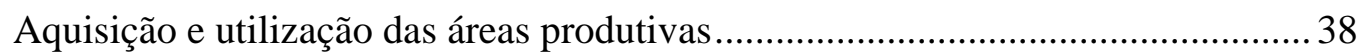

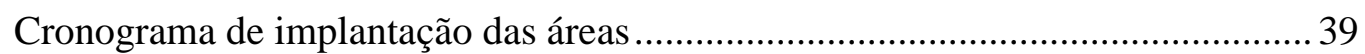

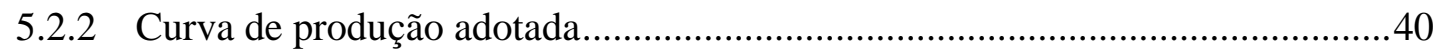

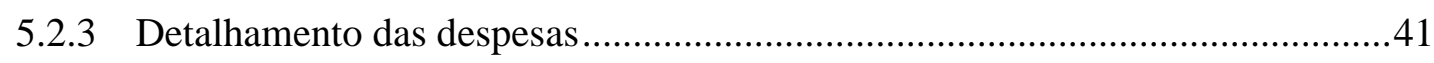

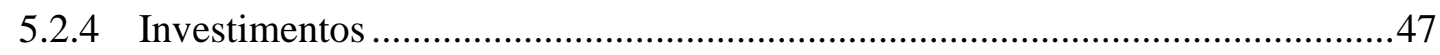

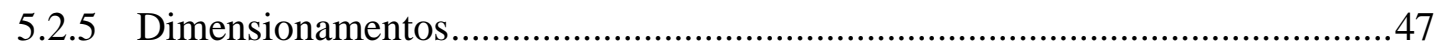

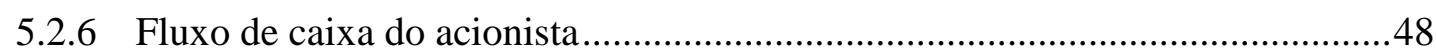

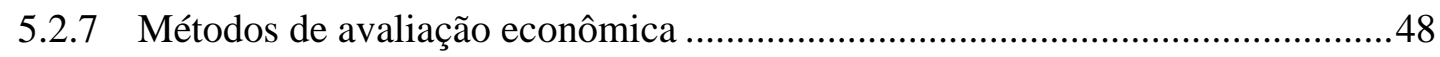

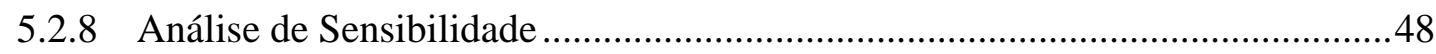

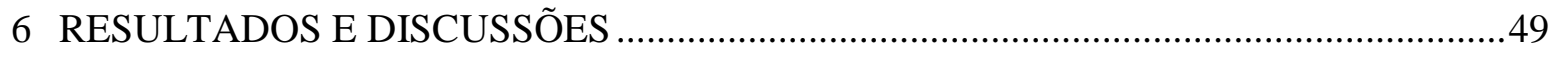

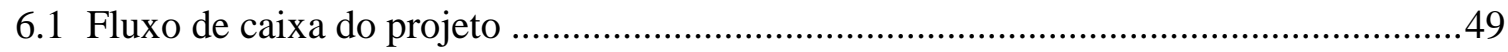

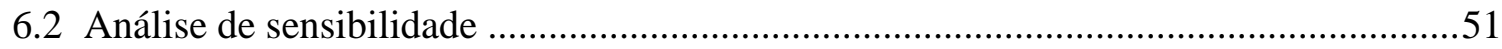

6.2.1 Sensibilidade do preço da madeira …...........................................................52

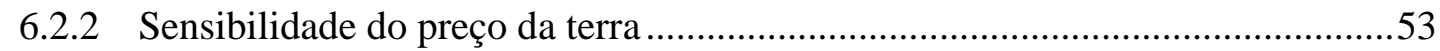

6.2.3 Sensibilidade da produtividade de madeira ...................................................55

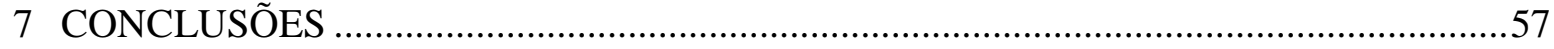

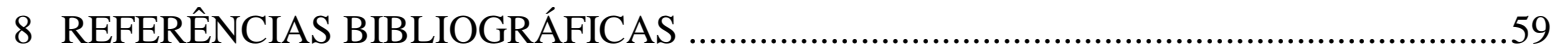

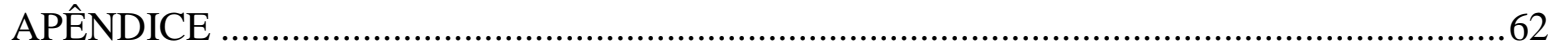




\section{LISTA DE TABELAS}

Tabela 1. Quantidade de água necessária durante um ano ou ciclo da cultura. .16

Tabela 2. Comparação entre o consumo de água do eucalipto e outras culturas.

Tabela 3. Taxas e impostos adotados em todos os cenários no modelo econômico. .38

Tabela 4. Premissas adotadas em todos os cenários para a forma de utilização e aquisição das áreas produtivas utilizadas no modelo econômico de avaliação do projeto de produção de madeira de Eucalyptus spp.

Tabela 5. Cronograma de implantação das áreas florestais utilizadas no modelo econômico de avaliação do projeto de produção de madeira de Eucalyptus spp para a Empresa MMX Metálicos Corumbá Ltda.

Tabela 6. Produtividade esperada $\left(\mathrm{m}^{3} \mathrm{ha}^{-1}\right)$ ao final de cada ano, para os cenários de produção de madeira de Eucalyptus spp em condições de sequeiro e fertirrigado.

Tabela 7. Custo unitário das operações florestais $\left(\mathrm{R} \$ \mathrm{ha}^{-1}\right)$ contratado pela Empresa MMX Metálicos Corumbá Ltda utilizado no modelo econômico de avaliação do projeto de produção de madeira de Eucalyptus spp.

Tabela 8. Custo unitário dos insumos $\left(\mathrm{R} \$ \mathrm{ha}^{-1}\right)$ de acordo com a quantidade aplicada em cada ano da cultura utilizado no modelo econômico de avaliação do projeto de produção de madeira de Eucalyptus spp para a condição de sequeiro.

Tabela 9. Custo unitário dos insumos $\left(\mathrm{R} \$ \mathrm{ha}^{-1}\right)$ de acordo com a quantidade aplicada em cada ano da cultura utilizado no modelo econômico de avaliação do projeto de produção de madeira de Eucalyptus spp para a condição de fertirrigação. 44

Tabela 10. Detalhamento do consumo mensal de energia elétrica na situação irrigante ocorridas na condição de fertirrigação utilizadas no modelo econômico de avaliação do projeto de produção de madeira de Eucalyptus spp.

Tabela 11. Recomendação de adubação solúvel para o ciclo de 6 anos com previsão de Incremento Médio Anual de $90 \mathrm{~m}^{3} \mathrm{ha}^{-1}$ ano ${ }^{-1}$ utilizadas no modelo econômico de avaliação do projeto de produção de madeira de Eucalyptus spp.

Tabela 12. Mão de obra necessária ao sistema de fertirrigação utilizadas no modelo econômico de avaliação do projeto de produção de madeira de Eucalyptus spp. 46

Tabela 13. Despesas com manutenções e reparos necessária ao sistema de fertirrigação utilizadas no modelo econômico de avaliação do projeto de produção de madeira de Eucalyptus spp. 46

Tabela 14. Outras despesas necessárias ao sistema de fertirrigação utilizadas no modelo econômico de avaliação do projeto de produção de madeira de Eucalyptus spp. 46

Tabela 15. Investimentos no sistema de fertirrigação utilizados no modelo econômico de avaliação econômica do projeto de produção de madeira de Eucalyptus spp. 


\section{LISTA DE FIGURAS}

Figura 1. Exemplo esquemático da idade ótima de corte. 14

Figura 2. Biomassa de E. globulus aos 6 anos $\left(\mathrm{Mg} \mathrm{ha}^{-1}\right)$

Figura 3. Curva de Valor Presente Líquido (VPL) em função da Taxa de Desconto demonstrando a taxa em que o VPL se torna nulo (TIR $=37 \%$ ).

Figura 4. Planta de situação da área experimental de fertirrigação por gotejamento implantado em 2007 e 2008 na Fazenda Correntes, Empresa MMX Metálicos Corumbá Ltda, município de Dois Irmãos do Buriti - MS para produção de madeira de Eucalyptus spp.

Figura 5. Sistema de captação e recalque inicial do sistema de fertirrigação para produção de madeira de Eucalyptus spp da Empresa MMX Metálicos Corumbá Ltda.

Figura 6. Reservatório do sistema de fertirrigação para produção de madeira de Eucalyptus spp da Empresa MMX Metálicos Corumbá Ltda.

Figura 7. Casa de motobombas do sistema de fertirrigação para produção de madeira de Eucalyptus spp da Empresa MMX Metálicos Corumbá Ltda.

Figura 8. Estrutura de cabeçal de controle do sistema de fertirrigação para produção de madeira de Eucalyptus spp da Empresa MMX Metálicos Corumbá Ltda. 32

Figura 9. Área fertirrigada por linha de gotejadores para produção de madeira de Eucalyptus spp da Empresa MMX Metálicos Corumbá Ltda.

Figura 10. Série histórica (1961 a 1990) da temperatura mensal e a última série anual de temperatura mensal obtida na estação meteorológica de Campo Grande. 35

Figura 11. Série histórica (1961 a 1990) da precipitação mensal e a última série anual de precipitação mensal obtida na estação meteorológica de Campo Grande. 36

Figura 12. Balanço Hídrico Climatológico Normal (1961-1990) para a cidade de Campo Grande - MS, demonstrando os períodos de Excedente hídrico, Déficit hídrico, Retirada e Reposição de água no solo.

Figura 13. Curvas de IMA e ICA, definindo a idade ótima de corte utilizadas no modelo econômico de produção de madeira de Eucalyptus spp em condições de sequeiro e fertirrigado.

Figura 14. Fluxo de caixa do projeto na situação de sequeiro para produção de madeira de Eucalyptus spp da Empresa MMX Metálicos Corumbá Ltda. 50

Figura 15. Fluxo de caixa do projeto na situação fertirrigado para produção de madeira de Eucalyptus spp da Empresa MMX Metálicos Corumbá Ltda.

Figura 16. Análise de sensibilidade da variação do preço da madeira de Eucalyptus spp em condições de sequeiro.

Figura 17. Variação do preço da madeira de Eucalyptus spp no cenário fertirrigado. 
Figura 18. Variação do custo de aquisição da terra para produção de madeira de Eucalyptus

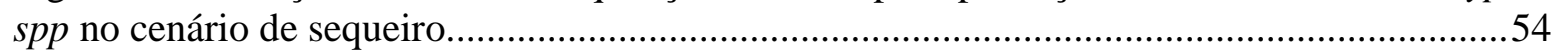

Figura 19. Variação do custo de aquisição da terra para produção de madeira de Eucalyptus

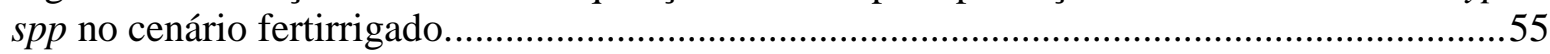

Figura 20. Variação da produtividade esperada da floresta para produção de madeira de

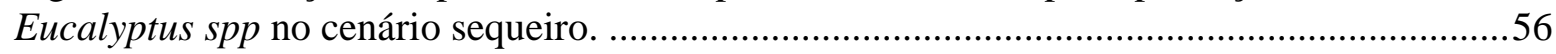

Figura 21. Variação da produtividade esperada da floresta para produção de madeira de

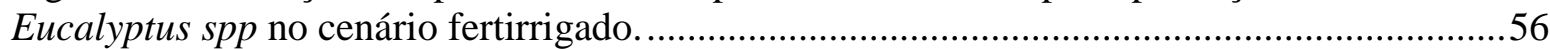




\section{RESUMO}

A análise de um modelo econômico que permita visualizar alternativas econômicas que sejam satisfatórias e compensadoras do ponto de vista do investidor para a produção de madeira de Eucalyptus spp, permitiria avaliar a implementação de reflorestamentos com altos ganhos em produtividade e com retorno econômico plausível à proposição da introdução tecnológica. Neste sentindo, objetiva-se neste trabalho a construção de um modelo econômico que possa avaliar as receitas e despesas associadas a um projeto comercial de produção de eucalipto fertirrigado implantado no município de Dois Irmãos do Buriti - MS, bem como uma simulação que defina os cenários mais adequados à implantação desta introdução tecnológica em futuros projetos. Um modelo econômico foi desenvolvido utilizando-se a planilha eletrônica de cálculos Microsoft Office Excel contendo variáveis de entrada que permitem a inserção dos dados que definem o cenário estudado, além de permitir a variação destas mesmas premissas entre um intervalo consistente, processando estas informações na ótica do projeto e culminando com as respostas que quantificam receitas e despesas no horizonte econômico do projeto. Por meio do fluxo de caixa gerado por estas receitas e despesas foi possível o cálculo de índices econômicos que permitiram a análise econômica dos cenários propostos em situação de sequeiro e fertirrigado com áreas respectivas de 855 e 500ha respectivamente. Nas condições em que os sistemas foram montados na Empresa MMX Metálicos Corumbá Ltda, o sistema de sequeiro apresentou um VPL de R\$ 4.994.275,11 e uma TIR de 11,44\% para um horizonte de planejamento de 25 anos, com custo 
da madeira de $\mathrm{R} \$ 20,47$ por $\mathrm{m}^{3}$, enquanto o cenário fertirrigado apresentou um VPL de $\mathrm{R} \$ 388.106,48$, uma TIR de 8,26\% e um custo da madeira de $\mathrm{R} \$ 28,77$ por $^{3}$ nas mesmas condições, demonstrando que ambas podem ser consideradas economicamente viáveis. Entretanto a condição de sequeiro apresentou um menor custo de transferência da madeira da unidade florestal para a unidade metalúrgica, comparada com a condição de fertirrigação, e portanto a opção de sequeiro deve ser adotada pela empresa como forma de diminuir os custos do sistema produtivo da unidade fabril, aumentando a lucratividade do setor. O sistema fertirrigado permitiu uma redução de área de floresta plantada de 41,6\% e uma redução de um ano na idade ótima de corte. Verificou-se também que o sistema de produção de madeira por meio da tecnologia de fertirrigação deve produzir um aumento no volume de madeira superior a 135\% com uma redução de um ano na idade de corte para se tornar mais vantajoso, do ponto de vista econômico, que os sistemas convencionais de sequeiro.

Palavras-chave: fertirrigação, viabilidade econômica, planilha econômica, índices econômicos, relatório de perdas e ganhos 
ECONOMIC EVALUATION OF EUCALYPTUS IRRIGATED UNDER DIFFERENT

SCENARIOS. Botucatu, 2010. 60p. Tese (Doutorado em Agronomia/Irrigação e

Drenagem) - Faculdade de Ciências Agronômicas, Universidade Estadual Paulista.

Author: HANDREY BORGES ARAUJO

Adviser: RAIMUNDO LEITE CRUZ

Co-Adviser: JARBAS HONORIO DE MIRANDA

\section{SUMMARY}

The analysis of an economic model that helps illustrate alternatives that are satisfying and rewarding from the standpoint of the investor for the production of Eucalyptus spp, would assess the implementation of reforestation with high productivity gains and economic profits to the plausible proposition introduction of technology. In this sense, the purpose of this work was to build an economic model that can evaluate the revenue and expenses related to a project's commercial production of eucalyptus fertigated deployed in the city of Dois Irmãos do Buriti - MS, as well as a simulation to define the scenarios more suitable for the deployment of this introduction of technology in future projects. An economic model was developed using the spreadsheet calculations of Microsoft Office Excel containing input variables that allow the insertion of data defining the scenario studied, besides allowing the variation among these same assumpts a consistent range, processing this information in perspective project and culminating with the responses that quantify revenue and expenditure in the economic horizon of the project. Through cash flow generated by this revenue and expenditure could be calculated based on economic indices which enabled the economic analysis of proposed scenarios in a situation of dry land and fertilized with the respective areas of 855 and 500ha respectively. Under conditions in which the systems were installed in the Company Metallic MMX Corumbá Ltda, the system presented a dryland NPV of R\$ $4,994,275.11$ and an IRR of $11.44 \%$ for a planning horizon of 25 years, at a cost of wood $\mathrm{R} \$$ 20.47 per $\mathrm{m}^{3}$, while the fertilized scenario presented a NPV of R\$388,106.48, an IRR of $8.26 \%$ and a cost of wood from $\mathrm{R} \$ 28.77$ per $\mathrm{m}^{3}$ in the same conditions, demonstrating that both can be considered economically feasible. However the upland condition showed a lower cost transfer of timber from forest unit for metallurgical unit, compared with the condition of 
fertigation, and therefore the choice of rainfeeding should be adopted by the company as a way to reduce costs of production on the unit manufacturing, increasing the profitability of the sector. The system fertigated allowed a reduction of planted forest area of $41.6 \%$ and a reduction of one year in rotation age. It was also found that the system of timber production through technology fertigation should produce an increase in timber volume over $135 \%$ with a reduction of one year at the age cutoff to make it more advantageous from an economic standpoint that conventional systems of irrigation.

Keywords: Fertigation, economic viability, economic spreadsheet, economic indicators, profit\&loss 


\section{INTRODUÇÃO}

O Brasil está presenciando uma forte expansão do setor florestal, principalmente na cultura de eucalipto, alavancada em especial, pelos segmentos de papel e celulose, de siderurgia e de painéis reconstituídos. Este cenário favorável pela demanda nacional e internacional faz com que os setores que consomem eucalipto invistam ainda mais em novas unidades de processamento.

Apesar do momento crítico em que passa a economia mundial, a percepção do mercado é que a retomada do plantio de eucalipto deverá ser suficiente para afastar o país do risco de "apagão florestal", desde que se invista satisfatoriamente em aumento de produção e produtividade.

A demanda tende a continuar aquecida por conta da expansão do consumo para diversos fins e das pressões ambientais sobre a utilização de madeira nativa. Além disto, a implantação de florestas como alternativa econômica e o desenvolvimento de novas tecnologias dos produtos madeireiros devem atender a uma crescente demanda por produtos derivados das florestas pelas indústrias, na geração de produtos e subprodutos madeireiros.

Do ponto de vista social e ambiental, esta expansão florestal fixa o homem no meio rural e reduz a sua migração para as cidades, por meio da viabilização econômica de pequenas e médias propriedades e contribui para a preservação das florestas nativas e ecossistemas remanescentes. 
Portanto, o uso de tecnologias que tornem a implantação de florestas uma atividade cada vez mais atraente e ambientalmente correta, com um aumento de produtividade que justifique os investimentos na atividade passa pelo conhecimento do comportamento silvicultural das espécies nativas e exóticas, como condição primordial na implantação de estratégias e de projetos de reflorestamentos.

A implantação florestal tem o objetivo de promover a adequada proteção, preparo de solo, fertilização e plantio para que haja alta sobrevivência, rápido crescimento inicial e elevada produtividade final das florestas plantadas. Por isto, as operações de implantação são as de maiores custos e as mais importantes para o sucesso do empreendimento florestal. Sua execução de forma adequada propicia facilidade de manutenção, aumento de produtividade, com conseqüente diminuição do custo da madeira produzida.

A introdução da fertirrigação na implantação do gênero Eucalyptus, surge como grande expectativa de aumento de produtividade, além é verdade, de um acréscimo no custo da implantação e manutenção da floresta. Tal fator introduzido no processo produtivo deve melhorar a produtividade, mas o ganho resultante deste, ainda não permite uma avaliação completa do quadro, quando se compara a produção e viabilidade econômica, a qual permitirá o sucesso do empreendimento florestal. Quanto melhor este retorno, menor será a pressão ambiental sobre as florestas nativas. De acordo com Duerr (1972), a implantação florestal depende da finalidade a que se pretende dar ao produto obtido e pode ser que o ganho no produto florestal não seja tão importante, quanto ao destino final deste, que é a geração de subprodutos, onde o custo inicial é diluído no produto final e no ganho obtido com este.

Desta forma, torna-se necessário a construção e análise de um modelo econômico que permita visualizar as alternativas econômicas que sejam satisfatórias e compensadoras do ponto de vista do investidor. O que permitiria a implementação de reflorestamentos com altos ganhos em produtividade e com retorno econômico plausível à proposição da introdução tecnológica.

Neste sentindo, objetiva-se neste trabalho a construção de um modelo econômico que possa avaliar as receitas e despesas associadas a um projeto comercial de produção de eucalipto fertirrigado, com base nos dados obtidos de um projeto implantado no 
município de Dois Irmãos do Buriti - MS, bem como a simulação de diferentes cenários, definindo os mais adequados à implantação desta introdução tecnológica em futuros projetos. 


\section{REVISÃO BIBLIOGRÁFICA}

A avaliação econômica de um projeto consiste na determinação das receitas e despesas inerentes ao processo produtivo e objetiva encontrar informações relevantes ao empresário, que irá investir dinheiro para obter retornos financeiros de seu empreendimento.

Neste sentido, um modelo econômico de produção florestal que pretenda ter íntima relação com os fenômenos naturais associados ao plantio e condução de uma floresta necessitará embutir em seus princípios informações de clima, solo, fertilidade, produtividade, cultivar, etc.

\subsection{Cultura do eucalipto}

De acordo com Anuário Estatístico da ABRAF (2009), em 2008 no Brasil, as áreas de florestas plantadas com eucalipto e pinus acumularam um total estimado de 6.126.000 ha. Representando um acréscimo de cerca de 282.000 ha plantados em relação a 2007 (5.844.367 ha). Dentre as espécies mais plantadas continua se destacando o eucalipto, com um crescimento de 7,3\% na área plantada em relação ao ano anterior. Mais de $80 \%$ desta área está na região de cerrado, cuja característica é a baixa fertilidade do solo, e para que haja um ganho significativo de crescimento dos povoamentos florestais, é necessária a aplicação de fertilizantes. 
A necessidade de se obter florestas cada vez mais produtivas, objetivando uma ou outra característica da madeira, seja uma maior densidade, baixos teores de extrativos ou outras características, tem levado as empresas brasileiras a investimentos cada vez maiores em programas de melhoramento genético, e técnicas que possibilitem uma maior homogeneidade da matéria prima, permitindo um aumento da qualidade final do produto (TONINI et al., 2006).

Para se prover matéria prima a uma indústria, é necessário planejar e implantar povoamentos florestais que possibilitem um contínuo suprimento desta. Para isto, é necessário conhecer a dinâmica de crescimento das florestas plantadas. Portanto, o estudo do crescimento e produção florestal é a ferramenta mais utilizada para a compreensão dessa dinâmica. A análise da medida de produção florestal em relação a variáveis como a idade, o sítio e a densidade é fundamental no processo de se conhecer esta dinâmica (TONINI et al., 2006).

Com esta dinâmica de crescimento, busca-se a redução da idade de corte das florestas de eucalipto. Seguramente isto acarretará alterações na dinâmica de nutrientes minerais do sistema.

Macdonald (1994) destaca que para avaliação dos efeitos do manejo de determinado recurso faz-se necessário o monitoramento deste para justificar os investimentos planejados a um dado empreendimento, bem como, alternativas de produção, onde se busca otimizar a alocação de recursos entre manejos alternativos. Consequentemente, aumentará o conhecimento dos sistemas monitorados, especificamente, sua variação temporal e espacial (RODRIGUEZ, 1998).

E ainda conforme Macdonald (1994), os passos essenciais para um plano e execução de um projeto de monitoramento são resumidos em: proposição dos objetivos gerais; definição de um limite de orçamento e equipe; revisão dos dados já existentes; definição de hipóteses e objetivos específicos; determinação de quais variáveis serão monitoradas, os locais e procedimentos de amostragem, e ainda as técnicas analíticas; avaliação hipotética ou comparação com um banco de dados reais; reavaliação dos objetivos específicos e compatibilidade com os recursos disponíveis; iniciação de monitoramento em uma base piloto; análise e avaliação de dados do projeto piloto; reavaliação dos objetivos do projeto de monitoramento e compatibilidade com os recursos disponíveis e modificação do 
projeto se necessário; uma continuidade do monitoramento; e por fim, a publicação periódica de relatórios e recomendações pertinentes.

Este autor sugere ainda que na prática, os passos não são dados necessariamente, em ordens seqüenciais. Por isto, as decisões tomadas em um determinado passo podem repercutir para um ou mais componentes do projeto de monitoramento, levando à reavaliações de passos anteriores.

Como parte de um projeto de monitoramento, métodos precisam ser usados na avaliação deste. Citam-se neste caso, métodos de determinação da prognose de crescimento da floresta. Clutter et al. (1983 apud TONINI et al., 2006), afirmam que os métodos para prognose do crescimento de florestas são baseados no conceito de que o crescimento e a produção de povoamentos de uma determinada espécie, ou composição de espécies, são influenciados pela idade do povoamento ou a distribuição da idade em povoamentos inequiâneos; pela capacidade inata de produção da área envolvida; pela suposição de que a capacidade inata de produção do sítio tem sido e é plenamente utilizada pelos tratamentos silviculturais aplicados.

\subsubsection{Curvas de crescimento e funções de prognose}

Cha et al. (2000) consideram que um bom modelo deve prover uma descrição acurada de comportamento, enquanto permanece matematicamente simples o suficiente para permitir cálculos fáceis. Mas, acurácia e simplicidade estão frequentemente em contraposição, e torna-se um grande desafio aliar ambas.

Utiliza-se de diferentes modelos para o mesmo sistema, dependendo mais precisamente do tipo de prognose que se quer. Uma vez que um modelo tem sido desenvolvido, procede-se a análise. Considerando que o resultado de uma análise é em geral, a prognose de um comportamento, isto pode se desdobrar em potenciais objetivos específicos:

- Para um conjunto de dados ou variáveis de entrada (inputs), quais são as de saída (outputs)?

- Para se obter um número de variáveis de saída desejado para um dado número de variáveis de entrada, quais mudanças precisam ser feitas nos parâmetros do sistema? 
- Se alguns ou todos os parâmetros do sistema não podem ser mudados, quais variáveis de entrada precisam ser utilizados para produzir os dados de saída?

O primeiro tipo de análise envolve um processo direto (embora não necessariamente fácil). Dado um modelo de sistema e a equação resultante que o expressa, o que é preciso fazer é computar a resposta do sistema para um conjunto de dados de entrada. Os últimos 2 itens, por outro lado, requerem a resolução de um problema inverso.

Especificamente, a fim de produzir um conjunto de respostas é necessário determinar quais parâmetros do sistema são requeridos ou quais tipos de variáveis de entrada são impostas aos sistemas (CHA et al., 2000).

Ainda, conforme CHA et al. (2000), este tipo de problema é muito comum nos projetos de engenharia, e geralmente é mais desafiador que cálculos diretos de dados de saídas para um conjunto de entradas e parâmetros específicos do sistema.

$\mathrm{Na}$ área florestal, funções de prognose para o incremento do DAP (Diâmetro à Altura do Peito) são fundamentais para a confecção de modelos de crescimento, assim como classes de tamanho. O componente de crescimento prediz o incremento anual em diâmetro para uma árvore individual. Os Modelos podem predizer o crescimento ou tamanho futuro do diâmetro de um tronco ou da área basal. Vanclay (1995) sugere que usando o incremento da área basal ao invés do incremento em diâmetro como resposta variável provê valores mais altos de $\mathrm{R}^{2}$ e descreve como um modelo de crescimento pode ser integrado a um sistema de relatórios de inventários de maneira que parcelas possam ser reportadas nas datas das medidas ou após as simulações em uma data futura e reportadas como parcelas individuais ou sumarizadas dentro de um estrato ou relatos do estado de uma floresta.

Moore e Lockwood (1990 apud VANCLAY, 1995) descreveram um sistema de prognose de colheita ligado a informação geográfica que permite a produção pelas prescrições de gerenciamento. A otimização dos modelos de estudos de crescimento podem ser utilizados para exploração florestal e permitem maximizar a receita ou outros benefícios.

O aumento do diâmetro do tronco pode ser expresso como uma função de produção a qual estima o ganho ou incremento em um dado período. As funções de incremento do DAP podem ser empíricas ou teóricas. As equações teóricas são funções matemáticas com similaridades ao crescimento observado, sem qualquer associação com hipóteses de causas ou fenômenos observados. Conforme Vanclay (1995), muitas destas 
equações são desenvolvidas empregando-se a análise de regressão do tipo stepwise para relacionar as variáveis correlacionadas com a variável resposta.

Callliez (1980) afirma que não é fácil conhecer a correlação entre a variância do volume e as variáveis de entrada; por isto é necessário uma grande quantidade de dados.

Para Santana et al., (2005) o planejamento das atividades de manejo precisa estar fundamentado pela obtenção de informações confiáveis do crescimento e da produção dos povoamentos florestais. E para uma ação clara e estratégica de manejo, faz-se necessário a obtenção de equações de prognose do crescimento e da produção, aliados a dados econômicos de custos e receitas.

Clutter (1963 apud SANTANA et al., 2005), fez derivações de modelos analíticos compatíveis para descrever o crescimento e a produção em volume de Pinus taeda, afirmando que a definição algébrica do modelo de produção pode-se derivar pela integração matemática do modelo de crescimento. Tais técnicas foram aperfeiçoadas, sendo possível estimar a produção e o crescimento cumulativo como uma função da idade inicial do povoamento, da área basal inicial, do índice de local e da idade futura. Afirma ainda que quando a idade futura se equivale à idade atual, o modelo de projeção reduz-se a um modelo convencional de produção. Desta forma, para as condições atuais comporta-se como um modelo de produção ao mesmo tempo em que para condições futuras, comporta-se como modelo de projeção ou de crescimento.

Assim, ele é simultaneamente um modelo de produção para condições atuais e um modelo de projeção ou crescimento para condições futuras.

Conforme Scolforo (1998), as decisões gerenciais florestais são baseadas em informações sobre condições de recursos presentes e futuros. Como as florestas constituem sistemas biológicos dinâmicos que estão em contínuas mudanças, os modelos de crescimento e produção são necessários para projetar estas mudanças e fornecer dados significantes para as tomadas de decisões.

A maioria dos sistemas de predição de crescimento e produção florestal é expressa na forma de equações matemáticas ou sistemas de equações interrelacionadas. Desta maneira, os computadores podem ser usados para gerar predição para qualquer combinação de "inputs" (idade, sítio e densidade) do povoamento. O uso destas 
estimativas juntamente com modelos de análise econômica apropriada gera decisões relativas a idades ótimas de colheita, níveis de densidade de plantio, níveis de desbaste e outras atividades de manejo.

Conforme Scolforo (1998), a integração de prognoses de produção com critérios de análise de investimento possibilita a tomada de várias decisões, tais como o momento de efetuar desbastes, qual é a rotação econômica ótima por sítio, detectar a escassez ou excedente de produção da madeira, aquisição ou não de novas áreas para produção em função do raio de transporte do produto e ainda inferir acerca da utilização dos múltiplos produtos de madeira, por exemplo.

\subsubsection{Máximo Incremento Médio Anual (IMA) e Incremento Corrente Anual (ICA)}

Inventários contínuos implementados desde o primeiro ano do povoamento florestal, permitem a geração de modelos de produção que possibilitam gerar a prognose.

Os tipos mais usuais de crescimento florestal são o Incremento Médio Anual (IMA) e o Incremento Corrente Anual (ICA). O IMA é a produção até uma idade particular dividida por esta idade, ou seja, a taxa média do aumento da produção desde a implantação do povoamento até uma idade particular, enquanto que ICA corresponde ao valor do aumento de produção no período de um ano, geralmente expressos por hectare (CAMPOS; LEITE, 2002).

Desta forma uma curva de crescimento possibilita definir o máximo incremento e consequentemente a rotação com base na máxima produção em volume, denominada de rotação técnica ótima, exemplificado na Figura 1. Enquanto o ICA é maior que o IMA, não se atingiu o máximo Incremento Médio Anual. Quando o ICA torna-se menor que o IMA, significa que este último começou a decrescer (SCOLFORO, 1998). 


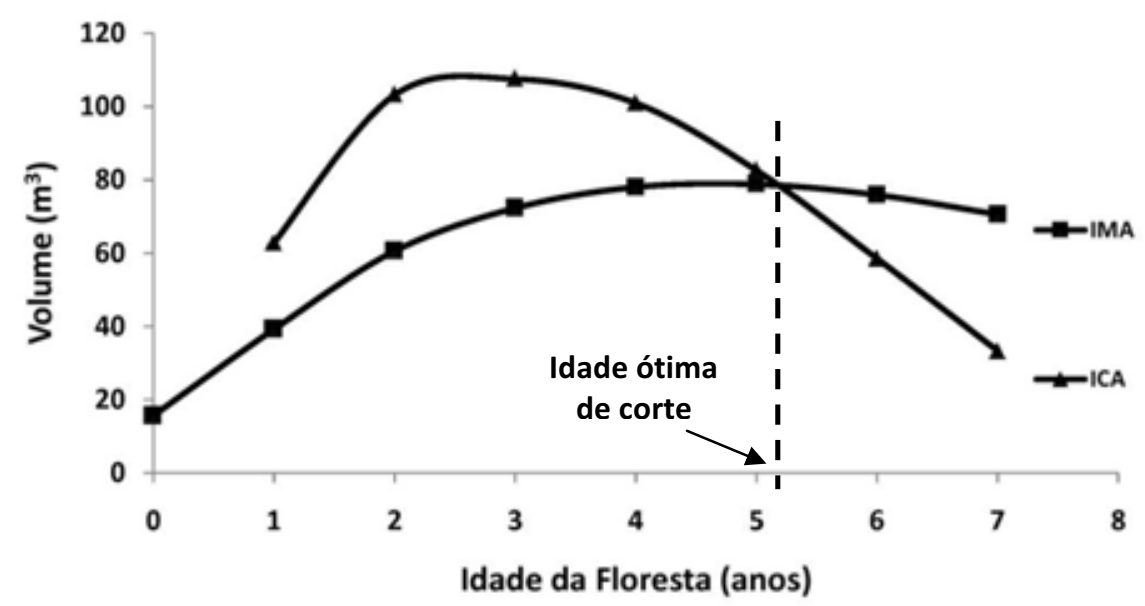

Figura 1. Exemplo esquemático da idade ótima de corte.

\subsubsection{A relação IMA/ICA e a Rotação Econômica Ótima (REO)}

Considerando-se os custos, a dimensão dos produtos florestais, a renda e a taxa de juros, define-se estratégias de ocupação dos sítios florestais. Pode se considerar ainda a definição da Rotação Econômica Ótima (REO), onde se utilizam os critérios de investimento, maximização do Valor Presente Líquido (VPL), Taxa Interna de Retorno (TIR), Benefício Periódico Equivalente (BPE), razão Benefício/Custo (Ri) e Custo Médio de Produção (CMPR) para a definição da idade econômica que deve ser realizado o corte.

A consideração destes fatores, IMA e ICA, e a Rotação Econômica Ótima, permitem uma avaliação dos critérios de investimentos, viabilidade econômica de um projeto, e melhor momento para a rotação do povoamento florestal (SCOLFORO, 1998).

A produtividade de um determinado sítio florestal está vinculada ao seu resultado econômico, sendo assim, se o custo de produção se tornar tão alto de forma que o produto extraído deste sítio não atingir ganhos econômicos condizentes, o projeto é inviável. Assim, os dois fatores (IMA/ICA e REO) precisam ser avaliados em conjunto. Portanto, o comportamento dos critérios de análise de investimentos em função das diversas idades de rotação indicará a antecipação ou prorrogação da idade de corte (SCOLFARO, 1998).

Também, conforme Scolforo (1998), com os modelos de prognose pode-se avaliar a pertinência de investir em sítios menos produtivos ou na utilização de 
tecnologias para um aumento significativo de produtividade, como é o caso da irrigação e fertirrigação, garantindo maior produção ainda que com maior investimento.

\subsection{Disponibilização de água e nutrientes em plantios florestais}

Segundo Du Toit (2006) o aumento na disponibilidade de água e de nutrientes no solo permitirá uma elevação do nível de eficiência de absorção ativa de radiação, ou seja, a quantidade de radiação ativa absorvida fotossintéticamente pelo dossel da floresta. A interceptação de radiação está limitada basicamente a florestas situadas em locais de baixa latitude, mas também, locais que apresentam quantidades adequadas de radiação a sua absorção pelas florestas podem ser limitadas a níveis abaixo do padrão dos índices de área foliar devido a deficiências de água ou de nutrientes. De fato, a disponibilidade de água, nutrientes e a interação entre estes dois fatores determinam eficazmente a amplitude das respostas aos suplementos adicionais de fertilizante (LINDER, 1987; MCMURTRIE e LANDSBERG, 1992; GONÇALVES et al., 1997 apud DU TOIT, 2006). Diversas pesquisas com a otimização de nutrientes e água têm mostrado (em escala experimental) a importância de se compreender tal interação. O grande desafio está em extrapolar esta compreensão à escala de produção.

Ainda, Du Toit (2006) ressalta que as operações silviculturais realizadas durante a rotação (tais como desbastes e/ ou podas) afetarão a área foliar e a dinâmica do nutriente no solo. É fato que a disponibilidade de água e nutriente no solo, sofrerá alteração para as árvores restantes após uma operação de raleio ou poda. Esta mudança na disponibilidade do recurso pode afetar a quantidade e a composição dos suplementos de fertilizante necessários para o crescimento ótimo do indivíduo arbóreo e possivelmente, afetará seu nível de resposta. Mesmo em face dos efeitos das operações silviculturais na disponibilidade do recurso para os plantios, é necessário reconhecer que em escala produtiva, são observadas variações entre sítios, gradientes de temperatura, podendo compartimentalizar as respostas para os mesmos tratamentos. 


\subsubsection{Uso da água em florestas de eucalipto}

As espécies do gênero eucalipto possuem um crescimento muito mais rápido do que as espécies nativas, e consequentemente, a sua demanda por água é maior, embora a eficiência no aproveitamento da mesma seja melhor. Da mesma forma que qualquer outra espécie vegetal, o eucalipto utiliza água para atender suas demandas fisiológicas, promovendo assim o seu crescimento (Tabela 1).

Tabela 1. Quantidade de água necessária durante um ano ou ciclo da cultura

\begin{tabular}{l|c}
\hline \multicolumn{1}{c|}{ Cultura } & Consumo de água $(\mathrm{mm})$ \\
\hline Cana-de-açúcar & $1000-2000$ \\
\hline Café & $800-1200$ \\
\hline Citrus & $600-1200$ \\
\hline Milho & $400-800$ \\
\hline Feijão & $300-600$ \\
\hline Eucalipto & $800-1200$ \\
\hline
\end{tabular}

Fonte: CALDER et al., 1992 apud INSTITUTO DE PESQUISAS E ESTUDOS FLORESTAIS, 2009.

De acordo com Lima (1996), vários estudos mostram que o eucalipto não difere sistematicamente das demais culturas. Na verdade, comparando-se a geração de biomassa por litro de água utilizado, o eucalipto é um dos mais eficientes produtores de biomassa (Tabela 2).

O consumo absoluto de água pelo eucalipto está entre os mais altos, pelo seu rápido crescimento. Mas quando a comparação é feita considerando o consumo relativo da água, ou seja, o número de litros de água utilizados para a formação de $1 \mathrm{~kg}$ de biomassa, ele está entre os menores, mostrando a grande eficiência da espécie na produção de biomassa (Tabela 2). Essa eficiência na produção de biomassa faz com que o eucalipto cresça rapidamente, conferindo-lhe um avançado grau de competitividade para a indústria de celulose e papel (LIMA, 1996). 
Tabela 2. Comparação entre o consumo de água do eucalipto e outras culturas.

\begin{tabular}{l|c}
\hline \multicolumn{1}{c|}{ Cultura/Cobertura } & Eficiência uso de água \\
\hline Batata & $1 \mathrm{~kg}$ de batata / 2.000 L \\
\hline Milho & $1 \mathrm{~kg} \mathrm{de}$ milho / 1.000 L \\
\hline Cana-de-açúcar & $1 \mathrm{~kg}$ de açúcar / 500 L \\
\hline Cerrado & $1 \mathrm{~kg} \mathrm{de} \mathrm{madeira} \mathrm{/} \mathrm{2.500} \mathrm{L}$ \\
\hline Eucalipto & $1 \mathrm{~kg}$ de madeira / 350 L \\
\hline
\end{tabular}

Fonte: NOVAIS et al., 1996 apud INSTITUTO DE PESQUISAS E ESTUDOS FLORESTAIS, 2009.

Madeira et al. (2002), realizaram experimentos com Eucalyptus globulus Labill., plantados na região central de Portugal os quais foram submetidos a tratamentos com irrigação mais uma completa solução de fertilizante para simular o ponto ótimo nutricional. Foram alocadas parcelas para averiguação somente com irrigação, somente com a adição de fertilizantes e fertirrigados (água mais fertilizante). A parcela testemunha não recebeu água nem fertilizantes. Como resultados, houve um incremento significativo na produção de biomassa onde água e/ou nutrientes foram aplicados em comparação a testemunha. A quantidade de carbono acumulada no sistema após 6 anos de plantio foi respectivamente: $8.22,10.22,11.23$ e $13.76 \mathrm{KgC} \mathrm{m}^{-2}$ (testemunha, fertilizada, irrigada e fertirrigada), conforme Figura 2.

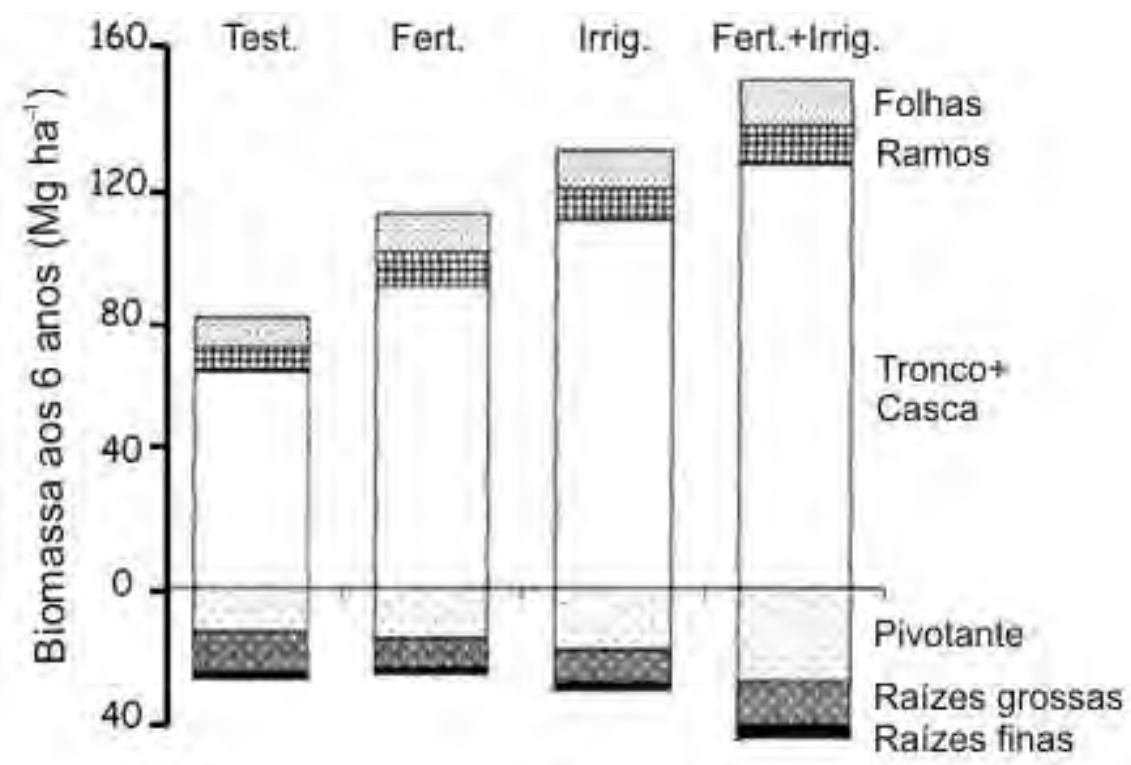

Figura 2. Biomassa de E. globulus aos 6 anos $\left(\mathrm{Mg} \mathrm{ha}^{-1}\right)$

Fonte: Adaptado de Madeira et al., 2002 
Observou-se também, um aumento da quantidade de carbono estocado no solo, tanto na serrapilheira como nas raízes, etc. durante o período de avaliação (4.2, 4.7, 4.8 e $6.3 \mathrm{KgC} \mathrm{m}^{-2}$ respectivamente).

Miranda et al. (2006) observaram a qualidade da madeira de árvores de Tasmanian bluegum (Eucalyptus globulus Labill.) aos 18 anos. As árvores foram avaliadas com relação ao conteúdo de cerne, ao acúmulo de extrativos, e o rendimento da polpa usando duas condições do crescimento: controle e crescimento otimizado pela irrigação e pela fertilização nos 6 primeiros anos de crescimento. Houve uma correlação positiva entre conteúdo de cerne com o crescimento da árvore, enquanto que o conteúdo de alburno permaneceu constante. O cerne continha mais teor de extrativos do que o alburno (5.3\% contra $4.0 \%)$ e o rendimento da polpa era mais baixo no cerne em relação ao alburno (58.0\% contra $56.0 \%)$. Houve uma correlação negativa quanto ao rendimento da polpa e o conteúdo de extrativos. A correlação positiva entre o crescimento das árvores e o percentual de cerne indica que a fertirrigação induz um aumento na sua taxa de formação.

Wimmer (2001) discute que a formação da madeira é um processo fisiológico dinâmico, e que qualquer mudança no ambiente imediato em que a árvore está crescendo pode afetar o seu crescimento e assim os padrões de crescimento das propriedades da madeira. Uma compreensão dos fatores que influenciam a formação das propriedades da madeira no câmbio em um nível secundário-anual pode ser somente delineada se o processo e as condições de crescimento puderem ser relacionadas à madeira formada. Os resultados da pesquisa mostram as propriedades de madeira (densidade da madeira, ângulo das microfibras) sendo observadas em etapas diárias de tempo durante a formação de madeira. Ele demonstrou como a irrigação, o déficit de água no solo, a temperatura e outros fatores influenciam a formação da madeira das árvores o que ajuda em muito melhorar a compreensão de como a qualidade da madeira é determinada.

No intuito de alcançar uma maior produtividade em florestas plantadas, universidades e instituições de pesquisa, associadas às empresas florestais, têm desenvolvido pesquisas para o aumento da produtividade das plantações florestais. Investimentos têm sido aplicados no melhoramento genético e clonagem, preparo do solo e nutrição das árvores e, mais recentemente, com a introdução experimental da prática de fertilização associada à irrigação, como é o caso da Empresa MMX Metálicos Corumbá Ltda. 
No ano de 2000, iniciou-se no Brasil um projeto chamado Brasil Eucalyptus Produtividade Potencial - BEPP. Este projeto demonstra que clones de Eucalyptus, considerando o manejo tradicional, apresentam uma produtividade média de $49 \mathrm{~m}^{3} \mathrm{ha}^{-1}$ ano $^{-1}$. Sem a fertilização, a produtividade de madeira se reduz em 30\% (34 $\left.\mathrm{m}^{3} \mathrm{ha}^{-1} \mathrm{ano}^{-1}\right)$. Os fertilizantes, quando aplicados em doses maciças, induzem um aumento para $51 \mathrm{~m}^{3} \mathrm{ha}^{-1} \mathrm{ano}^{-1}$, o que não é significativo em relação a produtividade obtida pelas empresas. A introdução da prática da irrigação eleva a produtividade das plantações para $63 \mathrm{~m}^{3} \mathrm{ha}^{-1} \mathrm{ano}^{-1}$, ou seja, em 29\%. Associando-se a irrigação com a fertilização a produtividade atinge $68 \mathrm{~m}^{3} \mathrm{ha}^{-1} \mathrm{ano}^{-1}$, representando um acréscimo de $38 \%$ em relação ao sistema atualmente adotado pelas empresas. Ficando evidente que os tratamentos de irrigação e de fertilização aumentam consideravelmente as taxas de crescimento das árvores de eucalipto (TOMAZELLO FILHO, 2006).

\subsection{Sistema de fertirrigação}

O método de irrigação por gotejamento tem como principal vantagem a economia de água, aliado ainda a um aumento na produção das culturas. Segundo Ollita (1982), este sistema é antigo e vem sendo utilizado no Brasil há muitos anos. O gotejo foi desenvolvido em Israel utilizando canalizações de aço perfuradas sistematicamente. $\mathrm{O}$ surgimento do material plástico, mais econômico, proporcionou uma maior flexibilidade do sistema e impulsionou de forma acentuada as pesquisas neste sentido, principalmente com o aparecimento dos gotejadores idealizados para este fim, na década de 60 (GUSTAFSON, 1971 apud OLLITA, 1982).

Ollita (1982) afirma que este o sistema de irrigação por gotejamento tendo sido idealizada para condições específicas de uma agricultura altamente intensiva, exige um sofisticado sistema de filtragem da água e de aplicação de fertilizantes e outros produtos químicos.

Keller e Bresler (1973, apud Ollita 1982), apresentam objetos técnicos e agronômicos na escolha deste método de irrigação, os quais são:

- A possibilidade de obtenção de altos valores no conteúdo de umidade ou baixos valores de potencial de água no solo, sem problemas de aeração do solo; 
- Flutuações mínimas no conteúdo de umidade do solo, durante o ciclo de irrigação;

- Fornecimento de água para somente aquelas partes do solo onde a absorção de água pelo sistema radicular das plantas é mais eficiente.

- Reduzir o problema de salinidade nas plantas por: translocação dos sais para além do volume ocupado pelo sistema radicular; diminuição da concentração dos sais por manter altos conteúdos de umidade de solo; evitar a queima de folhas devido à acumulação de sais em sua superfície, através do contato com a água de irrigação;

- Suprir diretamente a parte mais eficiente do sistema radicular com nutrientes;

- Economizar água pela redução na evaporação, escorrimento superficial e percolação profunda.

Um sistema de irrigação por gotejamento é baseada na pequena vazão através de orifícios de diâmetro reduzido, situados em estruturas especiais denominadas gotejadores, adaptadas em tubulações de plástico, localizadas sobre ou imediatamente abaixo da superfície do solo. Assim, de forma sucinta, um sistema completo de irrigação por gotejamento constitue-se das seguintes partes: cabeçal de controle; canalização de polietileno ou PVC flexível; e gotejadores.

\subsection{Análise econômica}

A análise econômica é fundamental no planejamento e seleção de projetos que permitem maior rentabilidade e menores riscos. É extremamente útil quando usada para identificar pontos fracos de um determinado projeto, sendo uma ferramenta essencial para determinar se é possível prosseguir com o projeto (BELLI et al., 2000). Quando usado para calcular somente uma medida sumária, tais como Valor Presente Líquido (VPL), ou Taxa Interna de Retorno (TIR), esta análise serve a um propósito limitado.

Brigagão (2006) menciona a necessidade da criação de instrumentos econômicos como mecanismos importantes para orientar as atividades produtivas, revelando seus custos ambientais e determinando as atividades de produção, de forma mais racional e eficiente no aproveitamento dos recursos naturais disponíveis, neste caso, se refere a recursos hídricos. A utilização deve ser racional e com valoração econômica. 
As ferramentas de análise econômica podem ajudar a responder várias questões sobre o impacto do projeto em um empreendimento. Identificando possíveis riscos e avaliando sua viabilidade. Belli et al. (2000), afirmaram que estas ferramentas podem ajudar a determinar se o setor público ou privado deverá se encarregar do projeto; a estimar seu impacto fiscal; a determinar se os arranjos feitos para reposição dos custos são eficientes e justos; e avaliar o seu potencial de impacto ambiental e a contribuição para a redução da pobreza.

Ainda de acordo com Belli et al. (2000), o primeiro passo na análise econômica de um projeto é definir claramente seus objetivos. Uma clara definição é essencial para a redução dos números de alternativas a serem consideradas, para a seleção das ferramentas de análise e o comportamento dos indicadores ou critérios de avaliação.

A ferramenta apropriada de análise também dependerá do horizonte do projeto.

Projetos de investimentos são avaliados considerando-se pelo menos uma alternativa de uso para o recurso financeiro, caso contrário não faz sentido à avaliação. Normalmente a avaliação econômica é realizada entre dois ou mais projetos concorrentes.

\subsubsection{Valor Presente Líquido (VPL)}

O Valor Presente Líquido (VPL), também referido como Valor Presente Atual, tem como sinônimo patrimônio presente (present worth), que representa um valor útil para se decidir se um bem do ativo fixo, de longa duração, vale o preço presente que se pede por ele. Os valores futuros são descontados pela taxa de juro compatível com o risco do investimento (MIAN, 2002).

Quando o VPL de um investimento a uma determinada taxa de desconto é positivo, paga o custo de financiamento do investimento ou custo do uso alternativo dos fundos. $\mathrm{O}$ investimento gera receita que é igual ao valor presente positivo (MIAN, 2002). Também implica que a taxa de retorno do investimento é no mínimo igual à taxa de desconto. Inversamente, um VPL negativo, indica que o investimento não está gerando ganhos equivalentes àqueles esperados pelo uso alternativo dos fundos, assim gerando a 
possibilidade de perda. O método para avaliação da atratividade dos investimentos é matematicamente representado pela seguinte equação:

$$
\mathrm{VPL}=\sum_{\mathrm{t}=0}^{\mathrm{n}} \frac{\mathrm{R}_{\mathrm{t}}}{(1+\mathrm{i})^{\mathrm{t}}}+\sum_{\mathrm{t}=0}^{\mathrm{n}} \frac{\mathrm{C}_{\mathrm{t}}}{(1+\mathrm{i})^{\mathrm{t}}}
$$

onde:

$\mathrm{VPL}=$ Valor Presente Líquido $\left(\mathrm{R} \$ \mathrm{ha}^{-1}\right)$;

$\mathrm{R}_{\mathrm{t}}=$ Receita ao final do ano $\mathrm{t}\left(\mathrm{R} \$ \mathrm{ha}^{-1}\right)$;

$\mathrm{C}_{\mathrm{t}}=$ Custo ao final do ano $\mathrm{t}\left(\mathrm{R} \$ \mathrm{ha}^{-1}\right)$;

$\mathrm{i}=$ taxa de juros ou taxa mínima de atratividade (decimal); e

$\mathrm{n}=$ duração do projeto (anos).

Quando da comparação de dois ou mais projetos concorrentes será tanto melhor aquele que apresentar maior VPL. Um VPL nulo, igual a zero, significa que o investimento foi remunerado a uma taxa igual à utilizada nos cálculos. Nesse caso, para o investidor é indiferente implementar ou não o projeto de acordo com suas preferências pessoais ou riscos associados (DUERR, 1972).

Quando se considera apenas um projeto de investimento, a alternativa para o recurso financeiro considerada na avaliação de viabilidade é a taxa de juros, ou a taxa mínima de atratividade, a qual é considerada para cálculo dos critérios de avaliação econômica. Assim quando se obtém um Valor Presente Líquido (VPL) nulo não significa que este seja um mau investimento, mas que sua remuneração é exatamente igual a taxa de juros utilizada. Por isso na avaliação econômica consideram-se taxas adequadas que realmente reflitam uma alternativa para o recurso financeiro ou uma expectativa de retorno desejado pelo investidor (CLUTTER et al., 1983).

Todos os critérios de avaliação econômica utilizam-se de fórmulas de matemática financeira de juros compostos para descapitalizar (trazer para o presente um valor ocorrido no futuro) ou capitalizar (levar para o futuro um valor ocorrido no presente) os valores do fluxo de caixa do projeto (REZENDE; OLIVEIRA, 2001).

Planilhas são construídas para cálculos do VPL, e softwares são utilizados para a construção de planilhas de cálculo, como o EXCEL (Microsoft). Uma vez 
que o VPL do investimento alternativo é calculado, as seguintes regras de decisão podem ser aplicadas:

- Se o VPL do investimento é positivo: aceita-se a proposta;

- Se o VPL é negativo: rejeita-se a proposta;

- Se o VPL é nulo, o analista será indiferente porque a proposta de investimento gera o mesmo retorno que o uso alternativo dos fundos (assumindo que ambas alternativas tenham os mesmos riscos).

O critério de decisão VPL segue diretamente a suposição que é requerida do analista a maximização do patrimônio da empresa. Este critério resulta em uma ótima escolha dos projetos (MIAN, 2002).

Quando o VPL resultar negativo, o projeto deve ser rejeitado porque o valor presente dos seus custos supera o valor presente das suas receitas, isto é, resulta em prejuízo financeiro em relação a taxa de juros utilizada para a avaliação. Nesse caso diz-se que o projeto é inviável economicamente. Quando for obtido um VPL positivo, maior do que zero, significa que o projeto remunerou o investimento a uma taxa de juros maior do que a utilizada na avaliação, isto é, resultou em receita líquida ou lucro. Nesse caso diz-se que o projeto é viável economicamente.

O valor do VPL do projeto depende, entre outras coisas, da taxa de desconto. Como mostra a Figura 3.

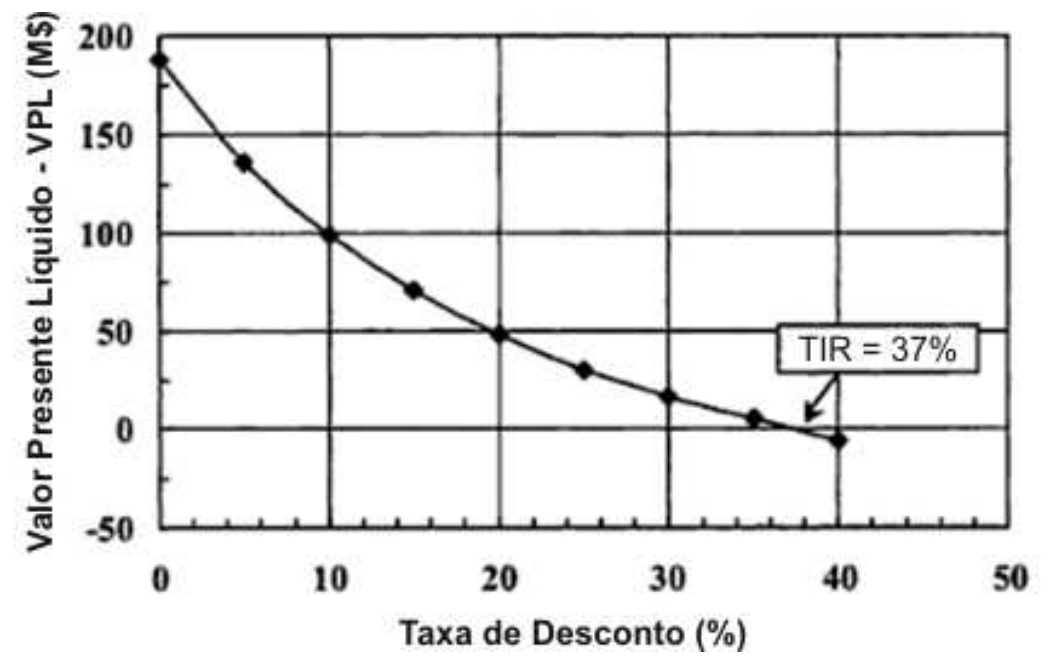

Figura 3. Curva de Valor Presente Líquido (VPL) em função da Taxa de Desconto demonstrando a taxa em que o VPL se torna nulo (TIR $=37 \%$ ).

Fonte: Adaptado de MIAN, 2002 
Observa-se que a curva de VPL mostra sensibilidade do fluxo de caixa líquido a taxa de desconto e dá o alcance em que a taxa de desconto do projeto gera um VPL positivo.

Portanto, o VPL é a primeira medida de ajuste de risco na avaliação da viabilidade econômica de um projeto (GOODPASTURE, 2003).

\subsubsection{Taxa Interna de Retorno (TIR)}

A taxa interna de retorno (TIR) como ferramenta de análise econômica, tem ampla abrangência, sendo utilizada principalmente para avaliar projetos florestais e industriais. Representa a remuneração do capital investido, em porcentagem, num determinado projeto. Esta taxa de juros faz com que o valor presente das receitas seja igual ao valor presente dos custos do projeto, sendo determinado pela seguinte equação.

$$
\sum_{t=0}^{n} \frac{R_{t}}{\left(1+(T I R)^{t}\right.}=\sum_{t=0}^{n} \frac{C_{t}}{(1+T I R)^{t}}
$$

onde:

TIR = Taxa Interna de Retorno (\%);

$\mathrm{R}_{\mathrm{t}}=$ Receita ao final do ano $\mathrm{t}\left(\mathrm{R} \$ \mathrm{ha}^{-1}\right)$;

$\mathrm{C}_{\mathrm{t}}=$ custo ao final do ano $\mathrm{t}\left(\mathrm{R} \$ \mathrm{ha}^{-1}\right) ; \mathrm{e}$

$\mathrm{n}=$ duração do projeto (anos).

A análise levando em consideração a TIR deve ser comparada com uma taxa alternativa de juros, como investimentos bancários, que mantém uma taxa mínina de atratividade (a remuneração do capital desejado pelo empreendedor). Se a TIR for menor que a taxa alternativa, ou mínima, o projeto será inviável, se maior o projeto será viável e se igual o investidor será indiferente a implementação ou não do projeto (KLEMPERER \& KLEMPERER, 1995).

GOODPASTURE (2003) afirma que gerenciadores de projetos deveriam ter grande amplitude trazendo para o processo de decisão todos os materiais relevantes.

MIAN (2002) ressalta que a Taxa Interna de Retorno é outra medida importante e informativa de rentabilidade. Também pode mostrar a eficiência marginal do 
capital. A TIR é a taxa de desconto obtida quando o VPL é igual a zero (conforme mostra a Figura $2:$ IRR $=37 \%$ ) e ainda, a taxa de juros recebida para um investimento consistindo de pagamentos (valores negativos) e entradas (valores positivos) que ocorrem em períodos regulares.

\subsubsection{Valor Esperado da Terra (VET)}

O Valor Esperado da Terra (VET) ou fórmula de Faustman, é um critério muito empregado na avaliação de projetos florestais porque elimina o problema de comparação de culturas com ciclos muito diferentes. Ele representa o valor presente líquido de uma série infinita de receitas líquidas, calculadas no final do ciclo florestal. No caso de projetos florestais, o VET normalmente é interpretado como o valor máximo a ser pago pela terra nua. A equação que calcula o VET é a seguinte:

$$
\mathrm{VET}=\frac{\mathrm{VPL} \cdot(1+\mathrm{i})^{\mathrm{t}}}{(1+\mathrm{i})^{\mathrm{t}}-1}
$$

onde:

$\mathrm{VET}=$ Valor Esperado da Terra $\left(\mathrm{R} \$ \mathrm{ha}^{-1}\right)$;

$\mathrm{VPL}=$ Valor Presente Líquido $\left(\mathrm{R} \$ \mathrm{ha}^{-1}\right) ; \mathrm{e}$

$\mathrm{i}=$ taxa de juros ou taxa mínima de atratividade (decimal).

A interpretação do resultado do VET é semelhante a do VPL. Quando o VET for negativo o projeto é inviável economicamente, se positivo é viável e se nulo o investidor é indiferente a sua implementação. No caso de comparação entre dois ou mais projetos alternativos será melhor o que apresentar maior VET (DUERR, 1972).

\subsubsection{Profit\&Loss}

A atividade financeira em um determinado período de tempo, geralmente o ano contábil, é demonstrada no relatório de Lucros e Perdas (Profit-and-Loss Statement). Contrastando com o Balancete, que mostra um quadro do negócio em um determinado momento, o relatório de Lucros e Perdas pode ser semelhante a uma pintura em movimento, mostrando o que aconteceu com o negócio, ou empresa em um período de tempo. 
É uma excelente ferramenta para avaliar a atividade comercial de uma empresa. É possível detectar onde estão as fraquezas nas operações da empresa e planejar meios de torná-la mais efetiva, além de aumentar os lucros. Uma comparação dos Profit\&Loss de diversos anos dará um quadro ainda melhor das tendências da atividade (PINSOM, 2008).

Ainda, segundo Pinsom (2008), o exame deste relatório mostra de onde o dinheiro vem e onde está sendo gasto em um período específico. Permite visualizar projeções do empreendimento para períodos futuros, permitindo traçar caminhos a se seguirem, ou melhor, as estratégias da empresa para um melhor retorno.

Os balanços considerando entrada e saídas são usados também nos relatórios de Lucros e Perdas. O relatório de despesas está onde os custos financeiros de um determinado projeto podem ser percebidos e registrados em cada período pelo administrador. Goodpasture (2003) cita um refrão que reflete o pensamento em que o relatório de despesas está sujeito mais a interpretação do GAAP ("princípios geralmente aceitos de contabilidade"), onde dinheiro em caixa é tangível e bem entendido sem ambiguidade, o qual é: "Dinheiro em Caixa é um fato, mas Profit\&Loss é uma opinião".

O que está nítido neste relatório é que todos os balancetes caminham juntos, o que os engenheiros chamam de sistema integrado, e os contadores de "balanço" ou "reconciliação".

Segundo Belli (2000), utilizam-se as análises financeiras dos projetos considerando-se as análises de Fluxo de Caixa. Para cada período durante o ciclo de vida do projeto, o analista financeiro deve estimar o caixa gerando e subtraindo o caixa da mesma forma que precisa sustentar o projeto. O fluxo de caixa resulta no perfil do projeto, porque as avaliações financeiras são feitas em base ao fluxo de caixa, omitindo importantes itens que aparecem nos demonstrativos profit-and-loss. Por exemplo, usa-se a depreciação e o desgaste como cálculos de despesas em demonstrativos de rendas e balancetes para chegar a uma estimativa dos lucros líquidos. Estes conceitos são como custos financeiros que não incluem despesas. O fluxo econômico é utilizado no cálculo do VPL e Taxas de Retorno Econômico. 


\subsubsection{Horizonte do projeto}

A análise e avaliação de um determinado projeto precisam passar por uma importante decisão que é a determinação da fronteira da análise econômica. Na estimativa interna dos custos e benefícios do projeto, o horizonte da análise torna-se claro. Se os benefícios se acumulam para o alcance do projeto ou se os custos são suportados por este alcance, isto entra na análise. A identificação das externalidades implica expandir as fronteiras físicas e conceituais da análise.

\subsubsection{Análise de sensibilidade}

Decisões de planejamento podem ser tomadas em função de fatores de crescimento e modelos de prognose. Neste sentido, os planejadores devem ter precaução pois os modelos de prognoses não são completamente acurados, requerendo que decisões de planejamento sejam razoavelmente tolerantes quanto às inacurácias dos modelos de prognose. Uma alternativa à abordagem convencional para análise dos efeitos da prognose é sujeitá-la, de alguma forma, à análise de sensibilidade (HIRSCH JUNIOR, 2006).

O desenvolvimento de qualquer prognose requer um número de suposições a serem feitas, explícita ou implicitamente. Alguns destes tipos de suposições podem ser incorporados na prognose e transportadas para análise de possíveis comportamentos futuros, como por exemplo: crescimento e produtividade; preços do produto; custos de transporte; custo final de produção; oferta do produto no mercado; e taxas de juros.

Uma análise de sensibilidade consiste em variar um ou mais destas suposições de maneira que produzam prognoses alternativas, de acordo com uma variação esperada ou suposta.

Hirsch (2006) afirma que as análises de sensibilidade podem ser produzidas adicionando-se variáveis exógenas ao sistema analisado, que representam valores médios, altos ou baixos. Alterando estes valores, será possível antever o comportamento dentro deste novo cenário de uma variável, permitindo uma avaliação econômica mais ampla e mais segura. Pode-se considerar por exemplo, uma demanda pelo produto normal, alta demanda ou baixa demanda, considerando faixas de variações, que permitem ver até que 
ponto um empreendimento está sujeito a ser viável ou não. Assim, para se obter um melhor entendimento do alcance da demanda possível num horizonte futuro, conduz-se uma análise de sensibilidade.

A análise de sensibilidade consiste em rever cada suposição implícita ou explícita na análise e, para cada suposição, gerar um par de suposições alternativas razoáveis, uma que cresce com a demanda e outra que decresce com a demanda. Esta variação proverá aos planejadores, informações apropriadas do alcance futuro de uma demanda ou variação de preço. Decisões planejadas podem então ser tomadas dentro de uma amplitude já conhecida, a qual permite não haver sobressaltos dentro de um determinado projeto (HIRSCH, 2006). 


\section{MATERIAL E MÉTODOS}

O presente trabalho foi realizado em parceria com a Empresa MMX Metálicos Corumbá Ltda, utilizando-se de informações coletadas do projeto de fertirrigação por gotejamento implantado em 2007 na Fazenda Correntes, município de Dois Irmãos do Buriti-MS.

\section{1 Área Experimental}

O projeto de fertirrigação foi estrategicamente instalado no município de Dois Irmãos do Buriti - MS, escolhida como a primeira unidade produtiva fertirrigada da empresa. Conforme a Figura 4, a área fertirrigada corresponde a 500 ha (plantios em 2007 e 2008) e a tecnologia utilizada foi o sistema de irrigação localizada do tipo gotejamento, implantado pela Empresa Netafim, com uma lâmina máxima de irrigação de 2,45 mm dia ${ }^{-1}$, correspondente a $24,5 \mathrm{~m}^{3} \mathrm{ha}^{-1} \mathrm{dia}^{-1}$. 


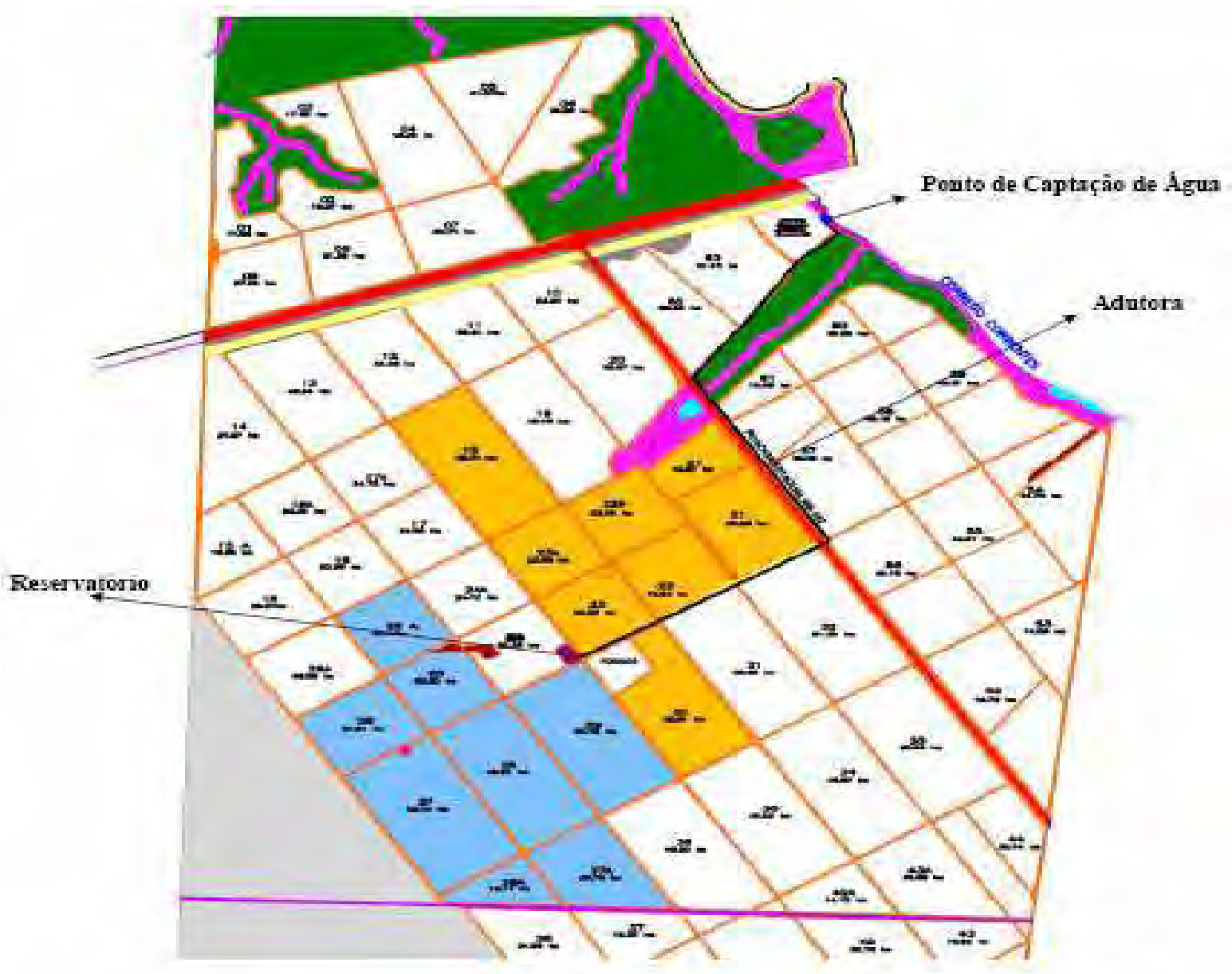

$\square$ Projeto Fertirrigado 2007

曰 Projeto Fertirrigado 2008

Figura 4. Planta de situação da área experimental de fertirrigação por gotejamento implantado em 2007 e 2008 na Fazenda Correntes, Empresa MMX Metálicos Corumbá Ltda, município de Dois Irmãos do Buriti - MS para produção de madeira de Eucalyptus spp.

O sistema de fertirrigação implantado na Empresa MMX Metálicos Corumbá Ltda é dotado de sistema de captação e recalque inicial (Figura 5), reservatório (Figura 6), casa de bombas (Figura 7), cabeçal de controle (Figura 8) e área fertirrigada (Figura 9), entre outros. 


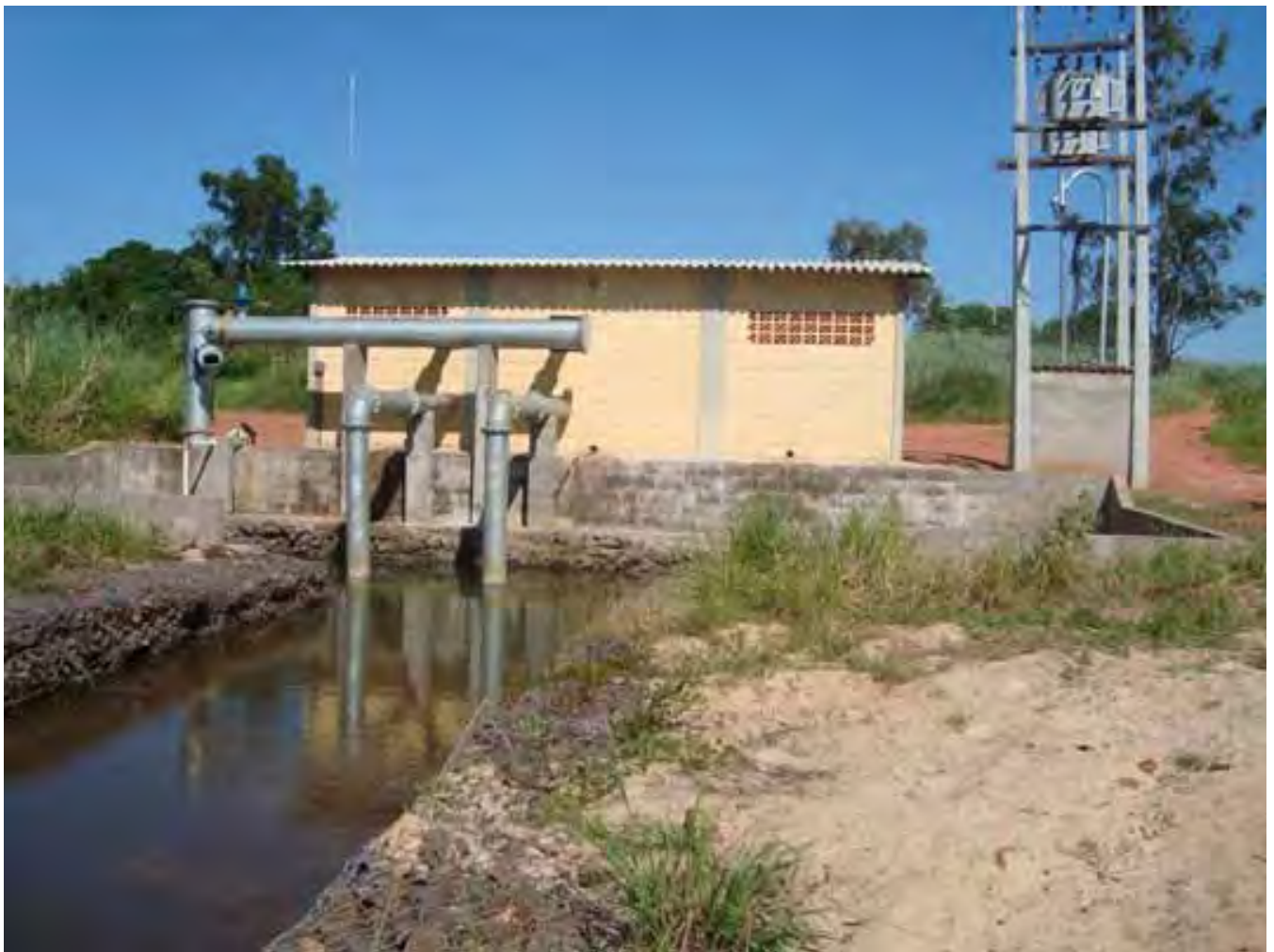

Figura 5. Sistema de captação e recalque inicial do sistema de fertirrigação para produção de madeira de Eucalyptus spp da Empresa MMX Metálicos Corumbá Ltda.

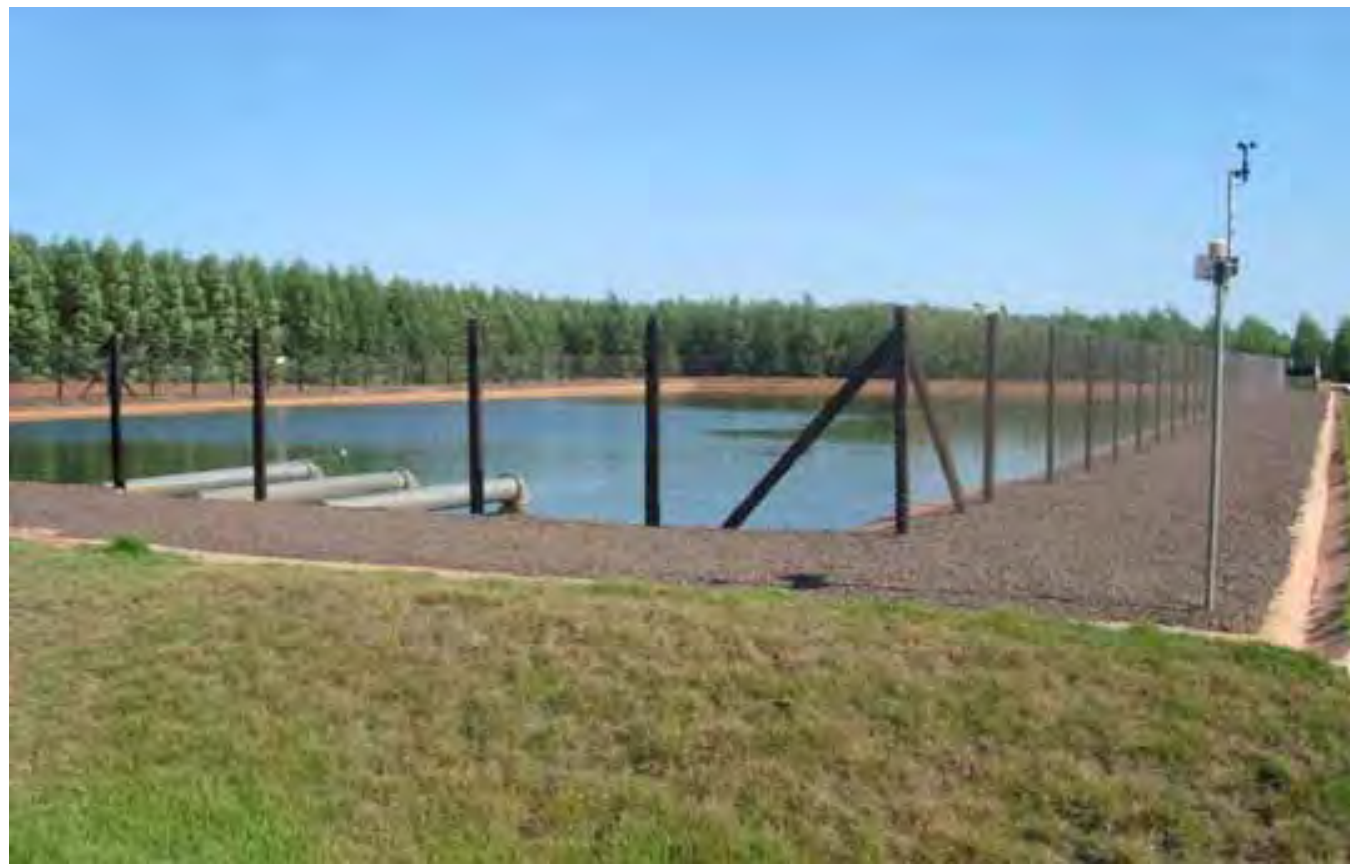

Figura 6. Reservatório do sistema de fertirrigação para produção de madeira de Eucalyptus spp da Empresa MMX Metálicos Corumbá Ltda. 


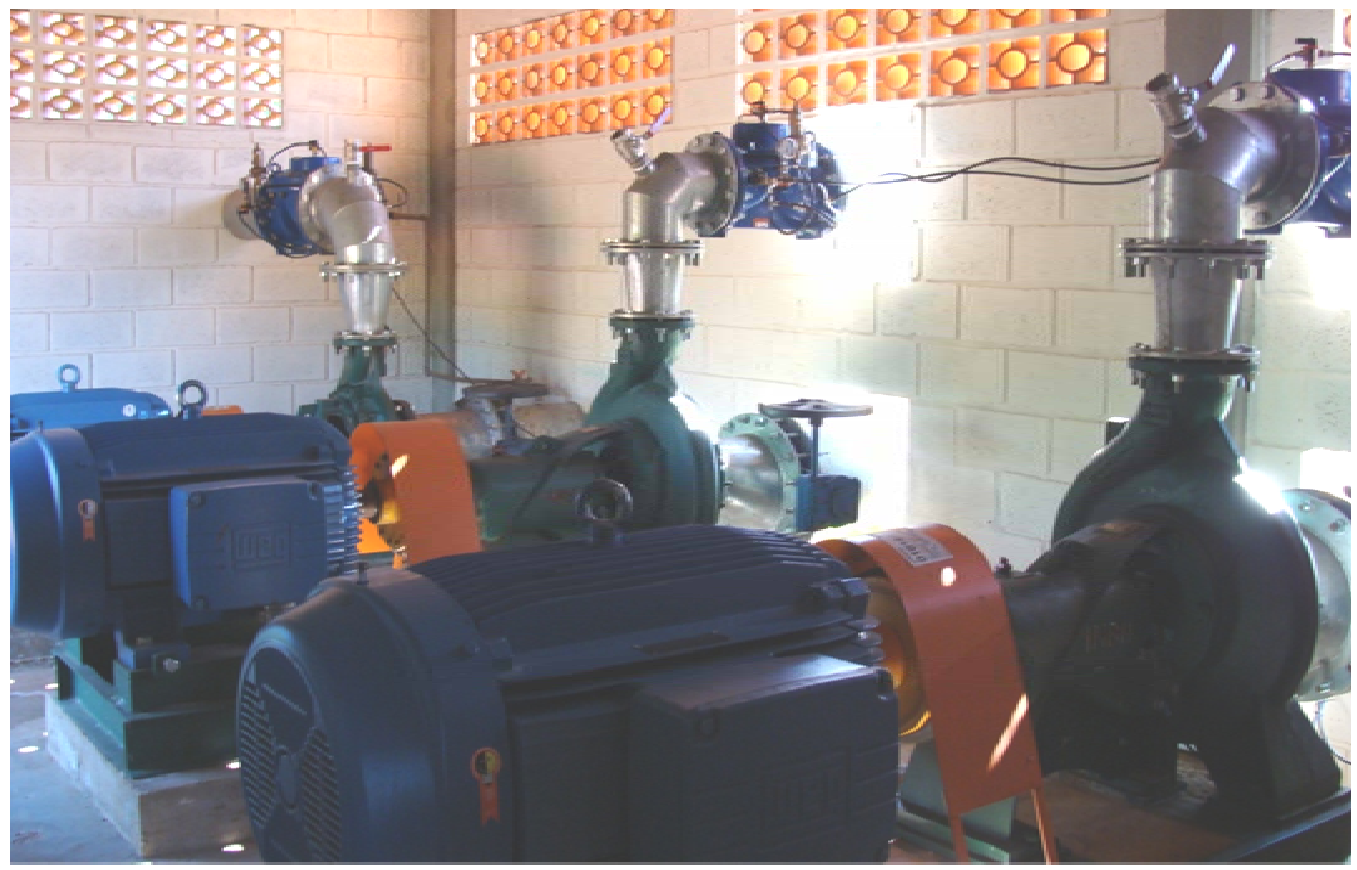

Figura 7. Casa de motobombas do sistema de fertirrigação para produção de madeira de Eucalyptus spp da Empresa MMX Metálicos Corumbá Ltda.

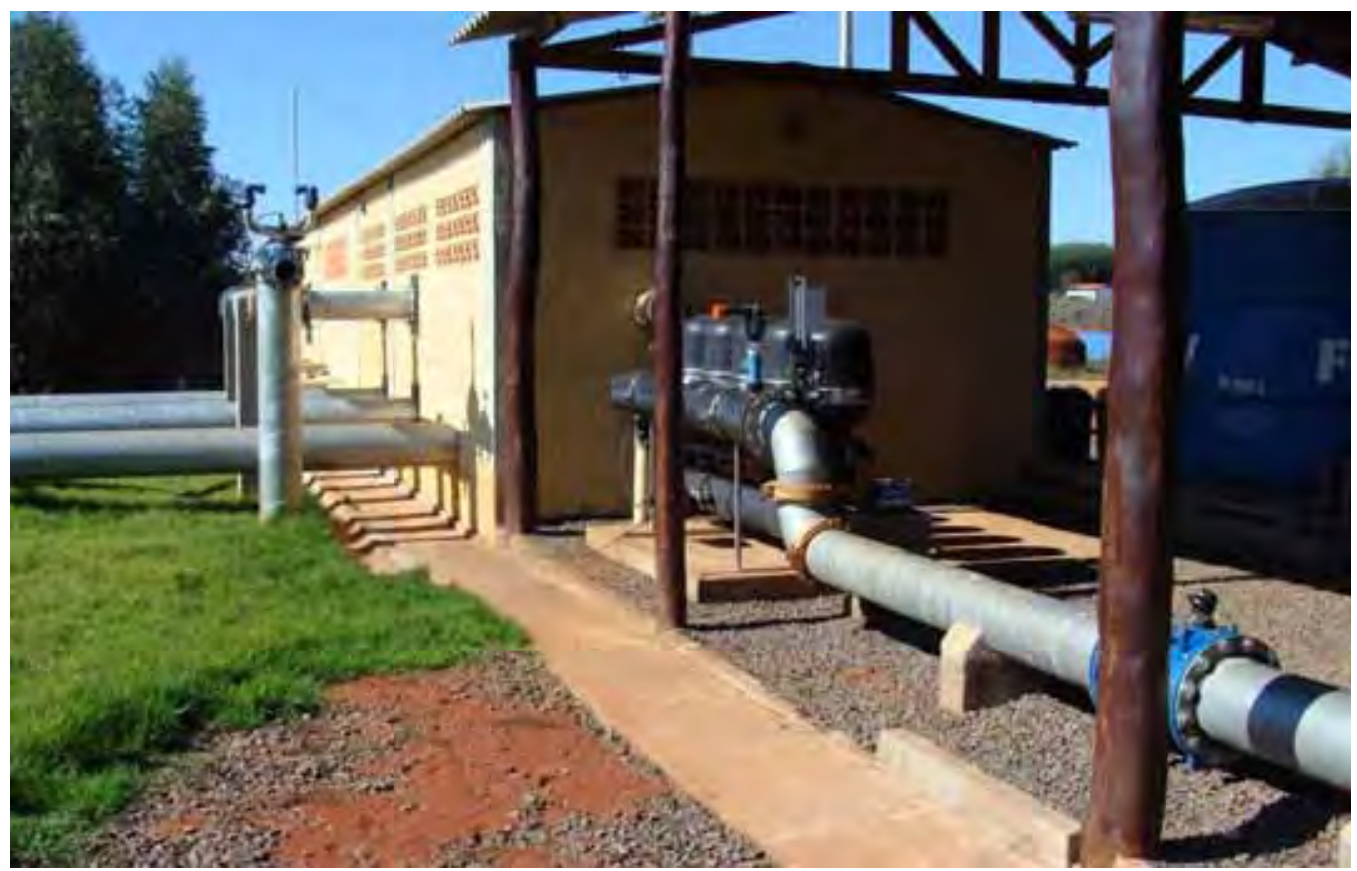

Figura 8. Estrutura de cabeçal de controle do sistema de fertirrigação para produção de madeira de Eucalyptus spp da Empresa MMX Metálicos Corumbá Ltda. 


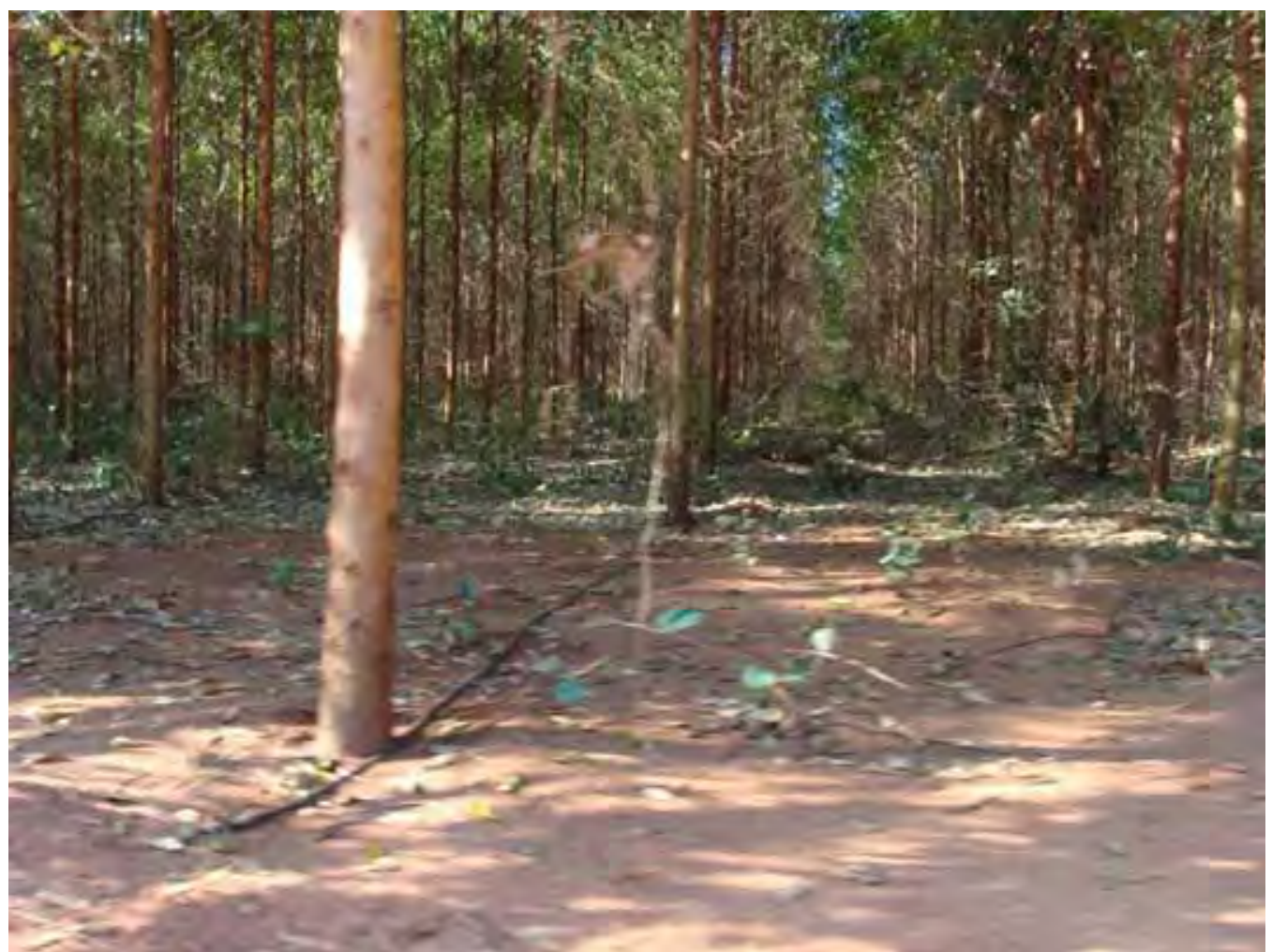

Figura 9. Área fertirrigada por linha de gotejadores para produção de madeira de Eucalyptus spp da Empresa MMX Metálicos Corumbá Ltda.

\subsubsection{Geologia e Geomorfologia}

As áreas do projeto florestal estão localizadas na Depressão Aquidauana - Bela Vista. O relevo foi esculpido em rochas areníticas permocarboníferas da Formação Aquidauana e rochas jura-cretácicas da Formação Botucatu, sem diferenças estruturais marcantes. A gênese está ligada a atividades tectônicas que favoreceram a ação erosiva, promovendo a sua escavação (BRASIL, 1982).

Litologicamente, evidencia-se a presença de arenitos com granulometria variável de fina a grosseira, cores vermelho-tijolo, esbranquiçadas, cinza arroxeadas (IBGE, 1988 apud MMX METÁLICOS CORUMBÁ LTDA, 2008). 


\subsubsection{Topografia}

As áreas sob influência do projeto florestal pertencem à unidade de Depressões do Alto Paraguai-Guaporé. As altitudes nas partes mais baixas variam entre 150 a 400 m. A Depressão Aquidauana - Bela Vista, que está a oeste dos Piemontes da Serra de Maracaju e da Depressão de Miranda e a leste da Depressão de Bonito, possui uma altitude em torno de 350 m (IBGE,1977 apud MMX METÁLICOS CORUMBÁ LTDA, 2008). Entretanto podemos ressaltar que a altitude média próxima das áreas do projeto de fertirrigação implantado é em torno de $250 \mathrm{~m}$.

\subsubsection{Clima}

Segundo a MMX Metálicos Corumbá Ltda (2008), três sistemas de circulação interferem na região Centro-Oeste: sistema de circulação perturbada de Oeste, representado por tempo instável no verão; sistema de circulação perturbada de Norte, representado pela convergência intertropical (CIT), que provoca chuvas no verão, outono e inverno no norte da região; e sistema de circulação perturbada de Sul, representado pelas frentes polares, invadindo a região no inverno com grande freqüência, provocando chuvas de um a três dias de duração.

Na classificação de Köppen o clima da região é caracterizado como Cwa.

A temperatura média anual de Mato Grosso do Sul é de $22^{\circ} \mathrm{C} . \mathrm{Na}$ primavera-verão, são comuns temperaturas elevadas, quando a média do mês mais quente varia de 24 a $26^{\circ} \mathrm{C}$, com a média das máximas do mês mais quente (setembro) oscilando entre 30 e $36^{\circ} \mathrm{C}$. O inverno é uma estação amena embora seja excessivamente seco e ocorram com freqüência temperaturas baixas, devido à influência das massas de ar frias vindas da Antártida, muito comuns nesta época do ano.

A temperatura média do mês mais frio oscila entre 15 e $24^{\circ} \mathrm{C}$, e a média das mínimas de 8 a $18^{\circ} \mathrm{C}$. Na Figura 10 pode-se observar a variação da temperatura média ao longo do ano registrada na estação meteorológica de Campo Grande. 


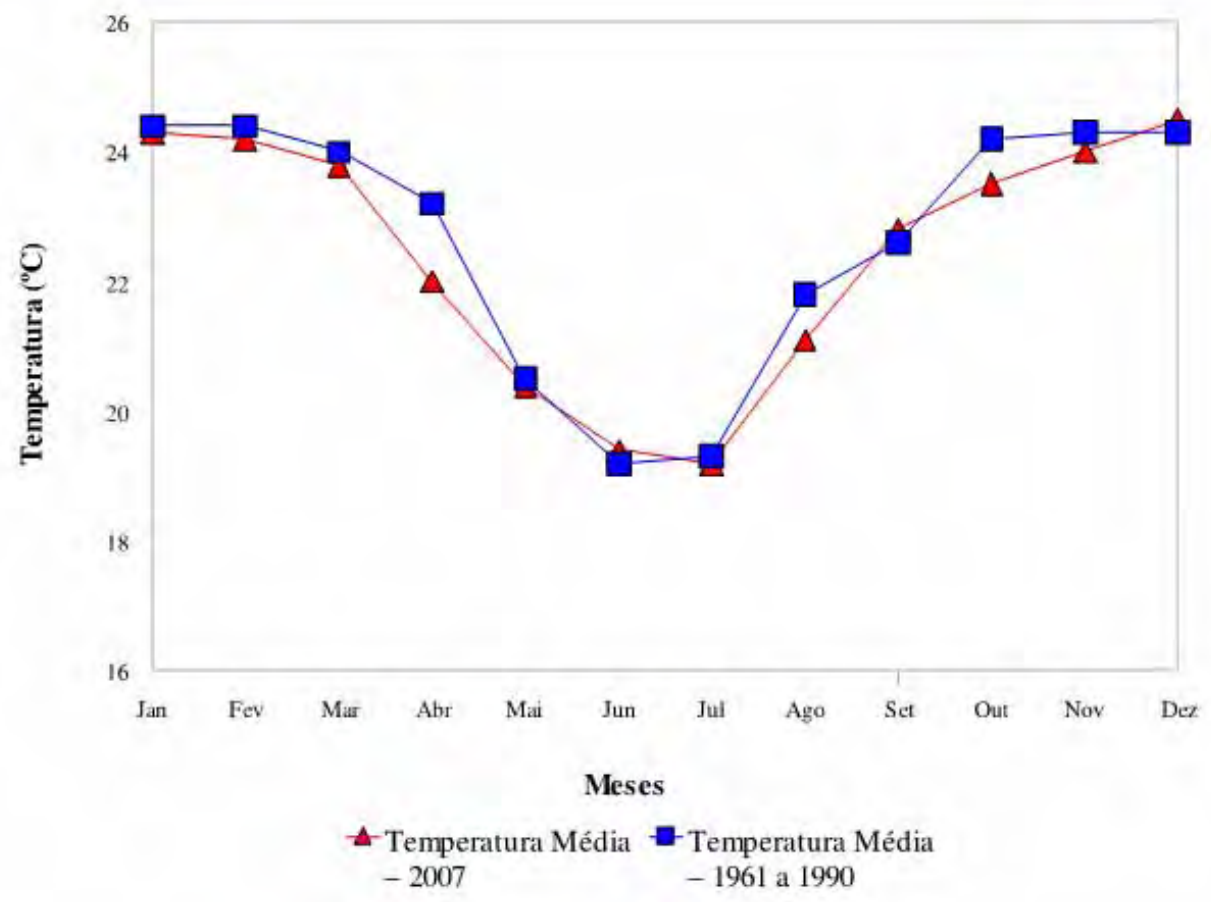

Figura 10. Série histórica (1961 a 1990) da temperatura mensal e a última série anual de temperatura mensal obtida na estação meteorológica de Campo Grande. Fonte: INMET, 2008.

Na região de Aquidauana o clima apresenta uma estação seca muito bem definida, porém com temperatura mais elevada nos meses mais frios, que podem atingir até $24^{\circ} \mathrm{C}$. As precipitações pluviométricas variam de 1.200 a $1.700 \mathrm{~mm}$ anuais, Figura 11 .

A Figura 12 apresenta o Balanço Hídrico Climatológico Normal para a série 1961 a 1990 para a cidade de Campo Grande - MS, demonstrando os períodos de Excedente hídrico, Déficit hídrico, Retirada e Reposição de água no solo para a região. 


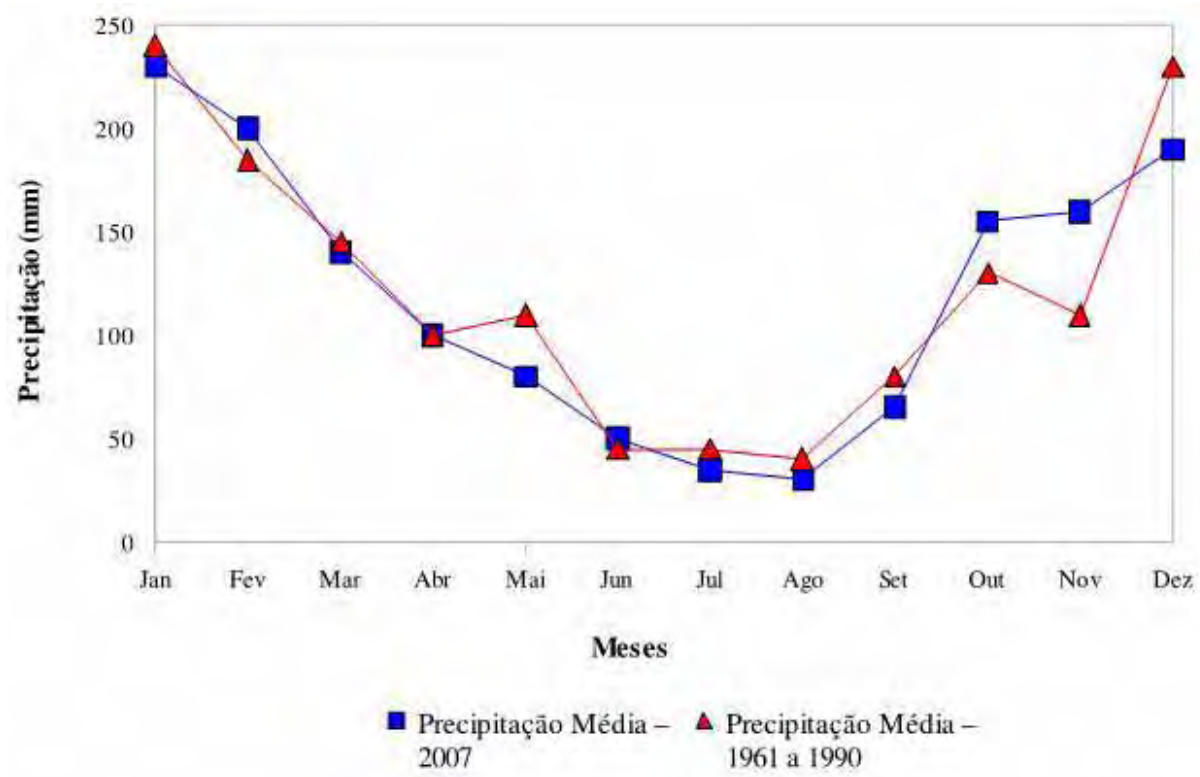

Figura 11. Série histórica (1961 a 1990) da precipitação mensal e a última série anual de precipitação mensal obtida na estação meteorológica de Campo Grande.

Fonte: INMET, 2008.

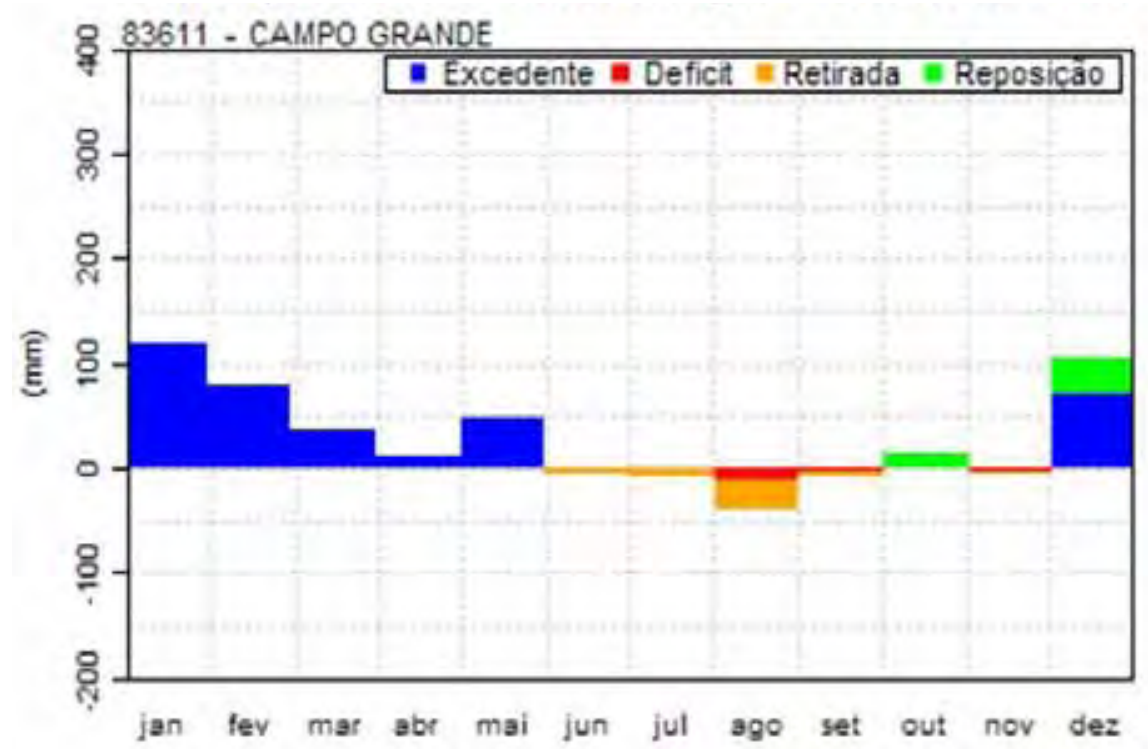

Figura 12. Balanço Hídrico Climatológico Normal (1961-1990) para a cidade de Campo Grande - MS, demonstrando os períodos de Excedente hídrico, Déficit hídrico, Retirada e Reposição de água no solo.

Fonte: INMET, 2010. 


\subsection{Modelo econômico}

Um modelo econômico foi desenvolvido utilizando-se a planilha eletrônica de cálculos Microsoft Office Excel contendo variáveis de entrada que permitem a inserção dos dados que definem os cenários estudados, além de permitir a variação destas mesmas premissas entre um intervalo consistente, processando estas informações na ótica do projeto e culminando com as respostas que quantificam receitas e despesas no horizonte do projeto. Por meio do fluxo de caixa gerado por estas receitas e despesas também é possível o cálculo de índices econômicos (VPL, TIR) que permitiram a análise econômica dos cenários propostos em situação de sequeiro e fertirrigado.

\subsubsection{Premissas gerais utilizadas}

Para o desenvolvimento do modelo foram adotadas premissas básicas que correspondem aos valores inerentes ao estudo em questão como: taxas e impostos, forma de utilização e aquisição das áreas produtivas, valor da produção, índices econômicos, bem como as definições dos módulos de produção, como: tamanho (ha) e ano de implantação de cada módulo. Também foram definidas as operações silviculturais e as variáveis de manejo da floresta, como: idade de corte e espaçamento.

\section{Taxas e impostos}

As taxas e impostos utilizadas no modelo econômico desenvolvido são apresentadas na Tabela 3. 
Tabela 3. Taxas e impostos adotados em todos os cenários no modelo econômico.

\begin{tabular}{l|r}
\hline \multicolumn{1}{c|}{ Descrição } & \multicolumn{1}{c}{ Valor } \\
\hline Encargos & $68,77 \%$ \\
\hline CSSL & $9,00 \%$ \\
\hline COFINS & $7,65 \%$ \\
\hline PIS & $1,65 \%$ \\
\hline IRPJ & $25,00 \%$ \\
\hline IRPF & $27,50 \%$ \\
\hline ISS & $5,00 \%$ \\
\hline ITR & $0,15 \%$ \\
\hline ICMS Interestadual & $12,00 \%$ \\
\hline ICMS Estadual & $17,00 \%$ \\
\hline Taxa de Desconto & $8,00 \%$ \\
\hline
\end{tabular}

\section{Aquisição e utilização das áreas produtivas}

Para as condições de aquisição e utilização das áreas produtivas do modelo econômico de avaliação do projeto de produção de madeira de Eucalyptus spp foram definidas as premissas apresentadas na Tabela 4.

Tabela 4. Premissas adotadas em todos os cenários para a forma de utilização e aquisição das áreas produtivas utilizadas no modelo econômico de avaliação do projeto de produção de madeira de Eucalyptus spp.

\begin{tabular}{|c|c|}
\hline Descrição & Valor \\
\hline Custo da Terra $\left(\right.$ ha $\left.^{-1}\right)$ & $\mathrm{R} \$ \quad 5.000,00$ \\
\hline Reserva Legal & $35 \%$ \\
\hline Estradas e Aceiros & $3 \%$ \\
\hline Valorização Anual da Terra & $5 \%$ \\
\hline
\end{tabular}

O valor de venda da produção de madeira de Eucalyptus spp foi obtido pela média dos últimos dois anos do Índice de Preços do CEPEA/ESALQ para madeira em pé, no valor de $\mathrm{R} \$ 34,23$ por estéreo. 


\section{Cronograma de implantação das áreas}

O projeto de produção de madeira de Eucalyptus spp considerou premissas atuais e condizentes com o mercado da região de implantação, considerando a implantação em dois módulos de produção de 250ha cada, implantados em 2007 e 2008, totalizando 500ha fertirrigados. Esta premissa foi adotada de forma a representar no modelo a mesma escala de produção experimental utilizada na empresa. Cada módulo possuindo o mesmo nível tecnológico adotado para o projeto como um todo. Para a análise da rentabilidade da unidade florestal, foram adotadas escalas padronizadas de plantio.

Os plantios das áreas florestais nos módulos foram realizados em duas fases até a obtenção de uma área plantada de 855ha para a situação de sequeiro e 500ha para a situação de fertirrigação, de acordo com o cronograma apresentado na Tabela 5, sendo que após esta totalização será feito um corte raso e replantio dos povoamentos florestais, a cada período de idade de corte, em cada um dos módulos até o ano de 2032, quando se encerra o horizonte de projeto.

A área de sequeiro caracteriza-se maior em função da premissa adotada de que para a mesma produção anual de madeira $150.225 \mathrm{~m}^{3}$, serão necessários uma área maior de sequeiro em comparação ao fertirrigado, em função deste apresentar maior produtividade e menor idade de corte.

Tabela 5. Cronograma de implantação das áreas florestais utilizadas no modelo econômico de avaliação do projeto de produção de madeira de Eucalyptus spp para a Empresa MMX Metálicos Corumbá Ltda.

\begin{tabular}{c|c|c|c|c|c|c}
\hline $\begin{array}{c}\text { Unidade } \\
\text { Gerencial }\end{array}$ & $\begin{array}{c}\text { Plantio } \\
\text { (Ano) }\end{array}$ & $\begin{array}{c}\text { Ano } \\
\text { Econ. }\end{array}$ & \multicolumn{2}{|c|}{ Área Útil Necessária (ha) } & \multicolumn{2}{c}{ Área Total Necessária (ha) } \\
\hline Módulo 1 & 2007 & 0 & 428 & Fertirrigado & Sequeiro & Fertirrigado \\
\hline Módulo 2 & 2008 & 1 & 428 & 250 & 678 & 397 \\
\hline Total & & & $\mathbf{8 5 6}$ & $\mathbf{5 0 0}$ & $\mathbf{1 . 3 5 6}$ & $\mathbf{7 9 3}$ \\
\hline
\end{tabular}

O cronograma de implantação (plantio) define todas as outras etapas relacionadas à produção de madeira. O processo de aquisição de mudas será simultâneo à implantação florestal nas duas condições (sequeiro e fertirrigado). 
O comprometimento da terra (compra), necessário à produção de madeira de Eucalyptus spp tanto nas condições de sequeiro quanto na de fertirrigação começaram em 2007. Isso porque a área a ser plantada no primeiro módulo foi preparada simultaneamente ao plantio.

A unidade florestal foi idealizada com cada um dos módulos possuindo uma área efetiva de plantio de Eucalyptus spp de 428ha e 250ha (sequeiro e fertirrigado, respectivamente) para produção de madeira, proveniente de compra e considerando-se a proporção de Reserva Legal de 35\% e uma perda de 3\% com aceiros e estradas, é necessária a aquisição de 678ha e 397ha (sequeiro e fertirrigado, respectivamente) de área total em cada módulo para atender a legislação florestal brasileira. Não há obrigatoriedade de a Reserva Legal ser continua a área produtiva, sendo facultada sua aquisição em outra localidade, dentro da mesma Bacia Hidrográfica da área produtiva.

\subsubsection{Curva de produção adotada}

Os dados utilizados como premissa para produção de madeira foram adaptados do modelo 3-PG de prognose de produção para as condições de sequeiro (com regime hídrico normal) e fertirrigado (com uma lâmina de 1500mm distribuída uniformemente ao longo do ano) de Borges (2009) e são apresentados na Tabela 6, em que as prognoses foram obtidas com Índice de Fertilidade igual a 1,0. Estes dados foram ajustados em função de um inventário realizado nas áreas experimentais para se tornarem mais condizentes com a realidade do empreendimento.

Tabela 6. Produtividade esperada $\left(\mathrm{m}^{3} \mathrm{ha}^{-1}\right)$ ao final de cada ano, para os cenários de produção de madeira de Eucalyptus spp em condições de sequeiro e fertirrigado.

\begin{tabular}{c|c|c|c|c|c|c|c|c}
\hline Idade da Floresta (anos) & $\mathbf{0}$ & $\mathbf{1}$ & $\mathbf{2}$ & $\mathbf{3}$ & $\mathbf{4}$ & $\mathbf{5}$ & $\mathbf{6}$ & $\mathbf{7}$ \\
\hline Sequeiro & 7,11 & 43,06 & 105,01 & 173,00 & 236,82 & 297,39 & 351,33 & 378,17 \\
\hline Fertirrigado & 19,93 & 99,80 & 230,96 & 367,63 & 495,92 & 600,90 & 675,26 & 717,63 \\
\hline
\end{tabular}

O material genético utilizado pela Empresa MMX em seu experimento fertirrigado foi o clone M13 (Híbrido urograndis) da Acesita (Fornecedor: I-144).

Por meio destas curvas de produção adotadas para a análise econômica são possíveis a determinação das curvas de Incremento Médio Anual (IMA) e Incremento 
Corrente Anual (ICA), que permitem por sua vez a obtenção das idades ótimas de corte, conforme Figura 13.

SEQUEIRO

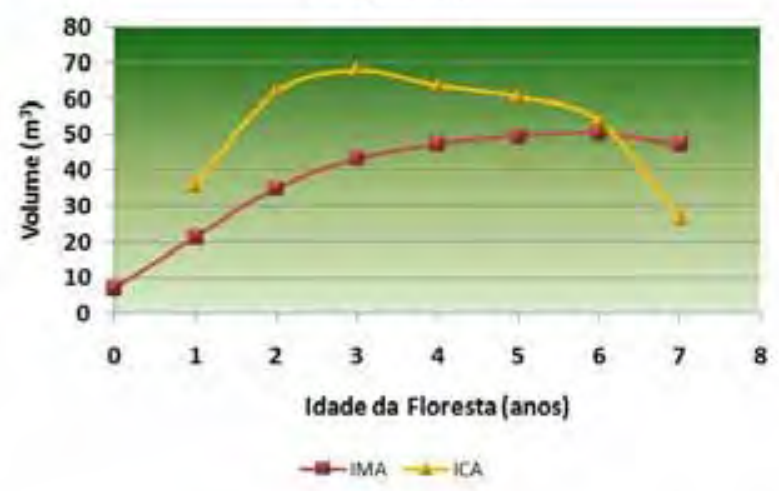

FERTIRRIGADO

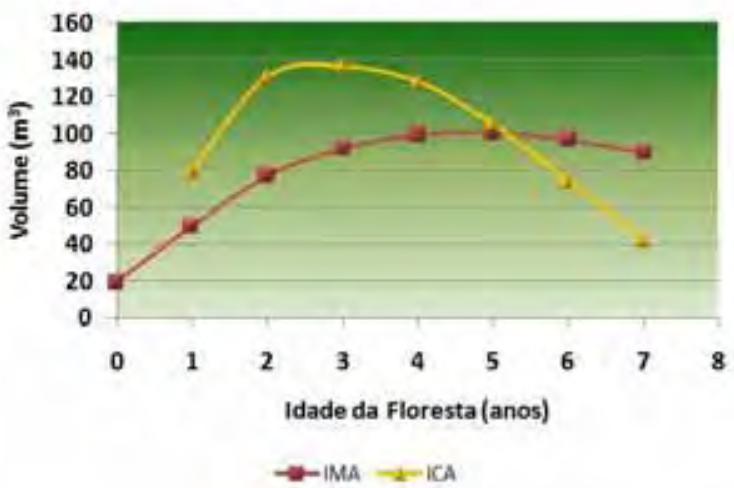

Figura 13. Curvas de IMA e ICA, definindo a idade ótima de corte utilizadas no modelo econômico de produção de madeira de Eucalyptus spp em condições de sequeiro e fertirrigado.

De acordo com a Figura 13 podemos verificar que a idade ótima de corte ocorrerá no final do ano 6, ou seja, com 7 anos de idade para a condição de sequeiro e com 6 anos de idade para a condição de fertirrigação.

\subsubsection{Detalhamento das despesas}

Todas as operações florestais necessárias ao sistema produtivo de Eucalyptus spp são apresentadas na Tabela 7, que apresenta também os custos das operações terceirizadas para uma empresa de apoio à unidade florestal que serão aplicados ao longo dos 25 anos do horizonte de produção da cultura florestal para todas as condições adotados, a não ser que a operação não seja necessária no cenário específico.

A coluna fator indica um grau de ponderação para a operação que foi atribuído ao valor completo da operação e que indica de acordo com o caso, o percentual de área a ser realizada a operação ou o número de vezes que ela ocorre na mesma área. 
Tabela 7. Custo unitário das operações florestais $\left(\mathrm{R} \$ \mathrm{ha}^{-1}\right)$ contratado pela Empresa MMX Metálicos Corumbá Ltda utilizado no modelo econômico de avaliação do projeto de produção de madeira de Eucalyptus spp.

\begin{tabular}{|c|c|c|c|c|}
\hline & OPERAÇÕES FLORESTAIS & $\begin{array}{c}\text { Valor } \\
\left(\mathbf{R} \$ . h^{-1}\right)^{2}\end{array}$ & Fator & $\begin{array}{c}\text { Custo } \\
\left(\mathbf{R} \$ \text { ha }^{-1}\right)\end{array}$ \\
\hline \multirow{6}{*}{. } & Abertura de Aceiros & $\mathrm{R} \$ 120,00$ & $100 \%$ & $\mathrm{R} \$ 120,00$ \\
\hline & Abertura mecanizada & $\mathrm{R} \$ 450,00$ & $100 \%$ & $\mathrm{R} \$ 450,00$ \\
\hline & Roçada mecanizada total & $\mathrm{R} \$ \quad 90,46$ & $50 \%$ & $\mathrm{R} \$ \quad 45,23$ \\
\hline & Talhonamento & 64,00 & $100 \%$ & 64,00 \\
\hline & Controle de Formigas & $\mathrm{R} \$ \quad 68,66$ & $100 \%$ & 68,66 \\
\hline & Controle de Cupins & $\mathrm{R} \$ \quad 26,38$ & $20 \%$ & 5,28 \\
\hline \multirow{5}{*}{ 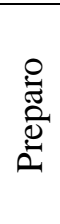 } & Aplicação de herbicida pós emergente & $\mathrm{R} \$ \quad 68,57$ & $100 \%$ & $\mathrm{R} \$ \quad 68,57$ \\
\hline & Subsolagem com fertilização & $\mathrm{R} \$ 237,71$ & $100 \%$ & $\mathrm{R} \$ 237,71$ \\
\hline & Aplicação de calcário mecanizado & $\mathrm{R} \$ \quad 80,03$ & $100 \%$ & $\mathrm{R} \$ \quad 80,03$ \\
\hline & Gradagem pesada & $\mathrm{R} \$ 170,00$ & & \\
\hline & Repasse a formiga & $\mathrm{R} \$ \quad 39,68$ & $100 \%$ & $\mathrm{R} \$ \quad 39,68$ \\
\hline \multirow{5}{*}{$\begin{array}{l}\stackrel{0}{\stackrel{\Xi}{\Xi}} \\
\frac{\vec{\Xi}}{2}\end{array}$} & Aplicação mecanizada de herbicida pré emergente & $\mathrm{R} \$ 72,48$ & $100 \%$ & $\mathrm{R} \$ \quad 72,48$ \\
\hline & Plantio mecanizado + adubação de arranque + gel & $\mathrm{R} \$ 362,28$ & $100 \%$ & $\mathrm{R} \$ 362,28$ \\
\hline & Irrigação & $\mathrm{R} \$ 148,33$ & $200 \%$ & $\mathrm{R} \$ 296,66$ \\
\hline & Replantio com gel & $\mathrm{R} \$ \quad 77,91$ & $3 \%$ & $\mathrm{R} \$ \quad 2,34$ \\
\hline & Adubação primeira cobertura & $\mathrm{R} \$ 168,36$ & $100 \%$ & $\mathrm{R} \$ 168,36$ \\
\hline \multirow{10}{*}{ 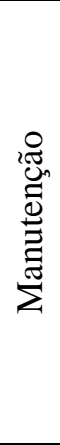 } & Ronda a formiga & $\mathrm{R} \$ \quad 39,24$ & $100 \%$ & $\mathrm{R} \$ \quad 39,24$ \\
\hline & Roçada manual na linha & $\mathrm{R} \$ 114,48$ & $40 \%$ & 45,79 \\
\hline & Roçada mecânica na entrelinha & $\mathrm{R} \$ 117,56$ & $30 \%$ & 35,27 \\
\hline & Prevenção e combate a incêndios & $\mathrm{R} \$ \quad 18,00$ & $100 \%$ & 18,00 \\
\hline & Adubação de manutenção & $\mathrm{R} \$ \quad 68,37$ & $100 \%$ & $\mathrm{R} \$ \quad 68,37$ \\
\hline & Aplicação de herbicida com pulverizador costal & $\mathrm{R} \$ 187,40$ & $250 \%$ & $\mathrm{R} \$ 468,50$ \\
\hline & Aplicação de herbicida pós emergente com proteção & $\mathrm{R} \$ \quad 82,87$ & $250 \%$ & $\mathrm{R} \$ 207,18$ \\
\hline & Capina Química Total & $\mathrm{R} \$ \quad 82,87$ & $35 \%$ & $\mathrm{R} \$ \quad 29,00$ \\
\hline & Manutenção manual de aceiros & 25,00 & $100 \%$ & 25,00 \\
\hline & Manutenção de estradas & 70,31 & $100 \%$ & 70,31 \\
\hline
\end{tabular}

Os custos das operações florestais são os mesmos para as condições de sequeiro e fertirrigado, entretanto estes valores somente são aplicados ao modelo econômico caso a operação exista em função do cenário estudado.

A Tabela 8 apresenta os custos e as quantidades dos insumos florestais utilizados em cada ano da floresta que serão aplicados ao longo dos 25 anos do horizonte de produção da cultura florestal para a situação de sequeiro. 
Tabela 8. Custo unitário dos insumos $\left(\mathrm{R} \$ \mathrm{ha}^{-1}\right)$ de acordo com a quantidade aplicada em cada ano da cultura utilizado no modelo econômico de avaliação do projeto de produção de madeira de Eucalyptus spp para a condição de sequeiro.

\begin{tabular}{|c|c|c|c|c|c|c|}
\hline $\begin{array}{l}\text { ANO } \\
\text { CULT. }\end{array}$ & INSUMOS & Un. & $\begin{array}{c}\text { Valor } \\
\left(\mathbf{R} \$ . \text { un }^{-1}\right)\end{array}$ & $\begin{array}{l}\text { Quant. } \\
\text { (un.ha }^{-1} \text { ) }\end{array}$ & Fator & $\begin{array}{c}\text { Custo } \\
\left(\text { R\$.ha }^{-1}\right)\end{array}$ \\
\hline 0 & Isca Granulada & $\mathrm{Kg}$ & $\mathrm{R} \$ \quad 3,55$ & 4 & $100 \%$ & $\mathrm{R} \$ \quad 14,20$ \\
\hline 0 & K-Otrine & $\mathrm{Kg}$ & $\mathrm{R} \$ 11,00$ & 0,2 & $20 \%$ & $\mathrm{R} \$ \quad 0,44$ \\
\hline 0 & Glifosato & $\mathrm{L}$ & $\mathrm{R} \$ \quad 11,40$ & 4 & $100 \%$ & $\mathrm{R} \$ \quad 45,60$ \\
\hline 0 & Fosfato Natural - UM 1, 2 e $2 \mathrm{E}$ & $\mathrm{Kg}$ & $\mathrm{R} \$ \quad 0,54$ & 400 & $70 \%$ & $\mathrm{R} \$ 151,48$ \\
\hline 0 & Fosfato Natural - UM 3,e 4 & $\mathrm{Kg}$ & $\mathrm{R} \$ \quad 0,54$ & 350 & $30 \%$ & $\mathrm{R} \$ \quad 56,81$ \\
\hline 0 & Calcário & $\mathrm{t}$ & $\mathrm{R} \$ \quad 70,00$ & 1,5 & $100 \%$ & $\mathrm{R} \$ 105,00$ \\
\hline 0 & Isca Granulada & $\mathrm{Kg}$ & $\mathrm{R} \$ \quad 3,55$ & 1 & $100 \%$ & $\mathrm{R} \$ \quad 3,55$ \\
\hline 0 & Isca Granulada & $\mathrm{Kg}$ & $\mathrm{R} \$ \quad 3,55$ & 0,5 & $100 \%$ & $\mathrm{R} \$ \quad 1,78$ \\
\hline 0 & Fordor & $\mathrm{Kg}$ & $\mathrm{R} \$ 620,00$ & 0,05 & $100 \%$ & $\mathrm{R} \$ 31,00$ \\
\hline 0 & Mudas & Mil un. & $\mathrm{R} \$ 270,00$ & 1,11 & $100 \%$ & $\mathrm{R} \$ 300,00$ \\
\hline 0 & Cupinicida & $\mathrm{Kg}$ & $\mathrm{R} \$ 892,00$ & 0,08 & $100 \%$ & $\mathrm{R} \$ 71,36$ \\
\hline 0 & Gel & $\mathrm{Kg}$ & $\mathrm{R} \$ \quad 12,11$ & 3 & $100 \%$ & $\mathrm{R} \$ \quad 36,33$ \\
\hline 0 & $\begin{array}{l}\mathrm{N}: \mathrm{P}: \mathrm{K} 10: 30: 10+0,4 \% \mathrm{~B}+0,2 \% \mathrm{Zn} \\
+0,1 \% \mathrm{Cu}\end{array}$ & $\mathrm{Kg}$ & $\mathrm{R} \$ \quad 1,30$ & 111 & $100 \%$ & $\mathrm{R} \$ 143,75$ \\
\hline 0 & MAP & $\mathrm{Kg}$ & $\mathrm{R} \$ \quad 2,50$ & 0,21 & $100 \%$ & 0,53 \\
\hline 0 & Mudas & Mil un. & $\mathrm{R} \$ 270,00$ & 1,11 & $3 \%$ & $\mathrm{R} \$ \quad 9,00$ \\
\hline 0 & $10-00-35+0,8 \% \mathrm{~B}$ & $\mathrm{Kg}$ & $\mathrm{R} \$ \quad 1,48$ & 128 & $100 \%$ & $\mathrm{R} \$ 189,70$ \\
\hline 1 & Glifosato & $\mathrm{L}$ & $\mathrm{R} \$ \quad 11,40$ & 1 & $250 \%$ & $\mathrm{R} \$ 28,50$ \\
\hline 1 & Glifosato & $\mathrm{L}$ & $\mathrm{R} \$ \quad 11,40$ & 3 & $250 \%$ & $\mathrm{R} \$ \quad 85,50$ \\
\hline 1 & $10-00-35+0,8 \% \mathrm{~B}$ & $\mathrm{Kg}$ & $\mathrm{R} \$ \quad 1,48$ & 255 & $40 \%$ & $\mathrm{R} \$ 151,16$ \\
\hline 1 & $15-00-20+1,0 \% \mathrm{~B}+0,3 \% \mathrm{Cu}+0,3 \% \mathrm{Zn}$ & $\mathrm{Kg}$ & 1,21 & 213 & $30 \%$ & $\mathrm{R} \$ 77,06$ \\
\hline 1 & $10-00-35+0,8 \% \mathrm{~B}$ & $\mathrm{Kg}$ & 1,48 & 213 & $30 \%$ & $\mathrm{R} \$ \quad 94,70$ \\
\hline 1 & Isca Granulada & $\mathrm{Kg}$ & $\mathrm{R} \$ \quad 3,55$ & 0,5 & $100 \%$ & $\mathrm{R} \$ \quad 1,78$ \\
\hline 2 & Glifosato & $\mathrm{L}$ & $\mathrm{R} \$ \quad 11,40$ & 1 & $50 \%$ & 5,70 \\
\hline 2 & Isca Granulada & $\mathrm{Kg}$ & $\mathrm{R} \$ \quad 3,55$ & 0,5 & $100 \%$ & $\mathrm{R} \$ \quad 1,78$ \\
\hline 2 & $10-00-35+0,8 \% \mathrm{~B}$ & $\mathrm{Kg}$ & 1,48 & 128 & $40 \%$ & $\mathrm{R} \$ \quad 75,88$ \\
\hline 2 & Borogran & $\mathrm{Kg}$ & 1,17 & 20 & $30 \%$ & $\mathrm{R} \$ \quad 7,00$ \\
\hline 2 & $\mathrm{KCl}+1 \% \mathrm{~B}$ & $\mathrm{Kg}$ & $\mathrm{R} \$ \quad 1,97$ & 100 & $30 \%$ & R\$ 58,98 \\
\hline 2 & Decis 2,5 CE & $\mathrm{L}$ & $\mathrm{R} \$ \quad 60,00$ & 1 & $2 \%$ & $\mathrm{R} \$ \quad 1,20$ \\
\hline 3 & Glifosato & $\mathrm{L}$ & $\mathrm{R} \$ \quad 11,40$ & 3 & $20 \%$ & 6,84 \\
\hline 3 & Borogran & $\mathrm{Kg}$ & $\mathrm{R} \$ \quad 1,17$ & 20 & $100 \%$ & $\mathrm{R} \$ \quad 23,32$ \\
\hline 3 & Isca Granulada & $\mathrm{Kg}$ & $\mathrm{R} \$ \quad 3,55$ & 1 & $100 \%$ & $\mathrm{R} \$ \quad 3,55$ \\
\hline 3 & Decis 2,5 CE & $\mathrm{L}$ & $\mathrm{R} \$ \quad 60,00$ & 1 & $2 \%$ & 1,20 \\
\hline 4 & Isca Granulada & $\mathrm{kg}$ & $\mathrm{R} \$ \quad 3,55$ & 1 & $100 \%$ & 3,55 \\
\hline 4 & Decis 2,5 CE & $\mathrm{L}$ & $\mathrm{R} \$ \quad 60,00$ & 1 & $2 \%$ & 1,20 \\
\hline 5 & Isca Granulada & $\mathrm{kg}$ & $\mathrm{R} \$ \quad 3,55$ & 1 & $100 \%$ & 3,55 \\
\hline 6 & Isca Granulada & $\mathrm{kg}$ & 3,55 & 1 & $100 \%$ & 3,55 \\
\hline
\end{tabular}

A Tabela 9 apresenta os custos e as quantidades dos insumos florestais utilizados em cada ano da floresta que serão aplicados ao longo dos 25 anos do horizonte de produção da cultura florestal para a situação fertirrigado. 
Tabela 9. Custo unitário dos insumos $\left(\mathrm{R} \$ \mathrm{ha}^{-1}\right)$ de acordo com a quantidade aplicada em cada ano da cultura utilizado no modelo econômico de avaliação do projeto de produção de madeira de Eucalyptus spp para a condição de fertirrigação.

\begin{tabular}{|c|c|c|c|c|c|c|}
\hline $\begin{array}{c}\text { ANO } \\
\text { CULT. } \\
\end{array}$ & INSUMOS & Un. & $\begin{array}{c}\text { Valor } \\
\left(\mathbf{R} \$ . \text { un }^{-1}\right)\end{array}$ & $\begin{array}{l}\text { Quant. } \\
\left(\text { un.ha }^{-1}\right)\end{array}$ & Fator & $\begin{array}{c}\text { Custo } \\
\left(\text { R\$.ha }^{-1}\right)\end{array}$ \\
\hline 0 & Isca Granulada & $\mathrm{Kg}$ & 3,55 & 4 & $100 \%$ & $\mathrm{R} \$ \quad 14,20$ \\
\hline 0 & K-Otrine & $\mathrm{Kg}$ & $\mathrm{R} \$ \quad 11,00$ & 0,2 & $20 \%$ & $\mathrm{R} \$ \quad 0,44$ \\
\hline 0 & Glifosato & $\mathrm{L}$ & $\mathrm{R} \$ \quad 11,40$ & 4 & $100 \%$ & $\mathrm{R} \$ \quad 45,60$ \\
\hline 0 & Fosfato Natural - UM 1, 2 e $2 \mathrm{E}$ & $\mathrm{Kg}$ & $\mathrm{R} \$ \quad 0,54$ & 400 & $70 \%$ & $\mathrm{R} \$ 151,48$ \\
\hline 0 & Fosfato Natural - UM 3,e 4 & $\mathrm{Kg}$ & $\mathrm{R} \$ \quad 0,54$ & 350 & $30 \%$ & $\mathrm{R} \$ \quad 56,81$ \\
\hline 0 & Calcário & $\mathrm{t}$ & $\mathrm{R} \$ \quad 70,00$ & 2 & & \\
\hline 0 & Isca Granulada & $\mathrm{Kg}$ & $\mathrm{R} \$ \quad 3,55$ & 1 & $100 \%$ & 3,55 \\
\hline 0 & Isca Granulada & $\mathrm{Kg}$ & $\mathrm{R} \$ \quad 3,55$ & 0,5 & $100 \%$ & 1,78 \\
\hline 0 & Fordor & $\mathrm{Kg}$ & $\mathrm{R} \$ 620,00$ & 0,05 & $100 \%$ & $\mathrm{R} \$ 31,00$ \\
\hline 0 & Mudas & Mil un. & $\mathrm{R} \$ 270,00$ & 1,11 & $100 \%$ & $\mathrm{R} \$ 300,00$ \\
\hline 0 & Cupinicida & $\mathrm{Kg}$ & $\mathrm{R} \$ 892,00$ & 0,08 & $100 \%$ & $\mathrm{R} \$ 71,36$ \\
\hline 0 & Gel & $\mathrm{Kg}$ & $\mathrm{R} \$ \quad 12,11$ & 3 & $100 \%$ & $\mathrm{R} \$ \quad 36,33$ \\
\hline 0 & $\begin{array}{l}\mathrm{N}: \mathrm{P}: \mathrm{K} 10: 30: 10+0,4 \% \mathrm{~B}+0,2 \% \mathrm{Zn} \\
+0,1 \% \mathrm{Cu}\end{array}$ & $\mathrm{Kg}$ & $\mathrm{R} \$ \quad 1,30$ & 111 & $100 \%$ & $\mathrm{R} \$ 143,75$ \\
\hline 0 & MAP & $\mathrm{Kg}$ & $\mathrm{R} \$ \quad 2,50$ & 0,21 & $100 \%$ & 0,53 \\
\hline 0 & Mudas & Mil un. & $\mathrm{R} \$ 270,00$ & 1,11 & $3 \%$ & 9,00 \\
\hline 0 & $10-00-35+0,8 \% \mathrm{~B}$ & $\mathrm{Kg}$ & $\mathrm{R} \$ \quad 1,48$ & 128 & & \\
\hline 1 & Glifosato & $\mathrm{L}$ & $\mathrm{R} \$ \quad 11,40$ & 1 & $250 \%$ & $\mathrm{R} \$ \quad 28,50$ \\
\hline 1 & Glifosato & $\mathrm{L}$ & $\mathrm{R} \$ \quad 11,40$ & 3 & $250 \%$ & $\mathrm{R} \$ \quad 85,50$ \\
\hline 1 & $10-00-35+0,8 \% \mathrm{~B}$ & $\mathrm{Kg}$ & $\mathrm{R} \$ \quad 1,48$ & 255 & & \\
\hline 1 & $15-00-20+1,0 \% \mathrm{~B}+0,3 \% \mathrm{Cu}+0,3 \% \mathrm{Zn}$ & $\mathrm{Kg}$ & $\mathrm{R} \$ \quad 1,21$ & 213 & & \\
\hline 1 & $10-00-35+0,8 \% \mathrm{~B}$ & $\mathrm{Kg}$ & 1,48 & 213 & & \\
\hline 1 & Isca Granulada & $\mathrm{Kg}$ & $\mathrm{R} \$ \quad 3,55$ & 0,5 & $100 \%$ & $\mathrm{R} \$ \quad 1,78$ \\
\hline 2 & Glifosato & $\mathrm{L}$ & $\mathrm{R} \$ \quad 11,40$ & 1 & $50 \%$ & 5,70 \\
\hline 2 & Isca Granulada & $\mathrm{Kg}$ & $\mathrm{R} \$ \quad 3,55$ & 0,5 & $100 \%$ & 1,78 \\
\hline 2 & $10-00-35+0,8 \% \mathrm{~B}$ & $\mathrm{Kg}$ & $\mathrm{R} \$ \quad 1,48$ & 128 & & \\
\hline 2 & Borogran & $\mathrm{Kg}$ & 1,17 & 20 & & \\
\hline 2 & $\mathrm{KCl}+1 \% \mathrm{~B}$ & $\mathrm{Kg}$ & $\mathrm{R} \$ \quad 1,97$ & 100 & & \\
\hline 2 & Decis 2,5 CE & $\mathrm{L}$ & $\mathrm{R} \$ \quad 60,00$ & 1 & $2 \%$ & 1,20 \\
\hline 3 & Glifosato & $\mathrm{L}$ & $\mathrm{R} \$ \quad 11,40$ & 3 & & \\
\hline 3 & Borogran & $\mathrm{Kg}$ & $\mathrm{R} \$ \quad 1,17$ & 20 & & \\
\hline 3 & Isca Granulada & $\mathrm{Kg}$ & $\mathrm{R} \$ \quad 3,55$ & 1 & $100 \%$ & \\
\hline 3 & Decis 2,5 CE & $\mathrm{L}$ & $\mathrm{R} \$ \quad 60,00$ & 1 & $2 \%$ & 1,20 \\
\hline 4 & Isca Granulada & $\mathrm{kg}$ & $\mathrm{R} \$ \quad 3,55$ & 1 & $100 \%$ & 3,55 \\
\hline 4 & Decis 2,5 CE & $\mathrm{L}$ & $\mathrm{R} \$ \quad 60,00$ & 1 & $2 \%$ & 1,20 \\
\hline 5 & Isca Granulada & $\mathrm{kg}$ & $\mathrm{R} \$ \quad 3,55$ & 1 & $100 \%$ & 3,55 \\
\hline 6 & Isca Granulada & $\mathrm{kg}$ & 3,55 & 1 & $100 \%$ & 3,55 \\
\hline
\end{tabular}

A Tabela 10 descreve o consumo mensal de energia elétrica na situação irrigante ocorridas na condição de fertirrigação, necessárias ao perfeito funcionamento do sistema de irrigação associado ao sistema de injeção de fertilizantes. 
Tabela 10. Detalhamento do consumo mensal de energia elétrica na situação irrigante ocorridas na condição de fertirrigação utilizadas no modelo econômico de avaliação do projeto de produção de madeira de Eucalyptus spp.

\begin{tabular}{|c|c|c|c|}
\hline Descrição & Consumo (KW.h) & Valor $\left(\mathbf{R} \$ . K^{-1} \cdot \mathbf{h}^{-1}\right)$ & Total (R\$) \\
\hline Cons. Fora de Ponta & 63959 & $\mathrm{R} \$ 0,023828$ & $\mathrm{R} \$ 1.524,04$ \\
\hline Cons. Ponta & 338 & $\mathrm{R} \$ 1,021327$ & $\mathrm{R} \$ \quad 345,21$ \\
\hline Demanda Contratada & 476,28 & $\mathrm{R} \$ 10,934129$ & $\mathrm{R} \$ 5.207,71$ \\
\hline Outros( Cons. Energia Reativa/Juros/Multa) & & & $\mathrm{R} \$ 2.170,64$ \\
\hline Impostos (Pis/Cofins/ICMS) & & & $\mathrm{R} \$ 6.436,70$ \\
\hline Total $(500 \mathrm{ha})$ & & & $\mathrm{R} \$ 18.903,84$ \\
\hline Total $\left(\mathbf{R} \$ . h^{-1} \mathbf{a n o}^{-1}\right)$ & & & R\$ 453,69 \\
\hline
\end{tabular}

A Tabela 11 descreve a recomendação de adubação na forma solúvel para o ciclo de 6 anos da floresta, determinada com uma previsão de Incremento Médio Anual de $90 \mathrm{~m}^{3} \mathrm{ha}^{-1}$ ano $^{-1}$ utilizadas na situação de fertirrigação, necessárias ao balanceamento de fertilidade do solo para o empreendimento.

Tabela 11. Recomendação de adubação solúvel para o ciclo de 6 anos com previsão de Incremento Médio Anual de $90 \mathrm{~m}^{3} \mathrm{ha}^{-1}$ ano ${ }^{-1}$ utilizadas no modelo econômico de avaliação do projeto de produção de madeira de Eucalyptus spp.

\begin{tabular}{|c|c|c|c|}
\hline Adubo & Preço Unitário & Quantidade (Kg.ha ${ }^{-1}$ ) & Valor Total $\left(\mathbf{R} \$ . h^{-1}\right)$ \\
\hline Calcário dolomítico & $\mathrm{R} \$ 0,06$ & 1500 & $\mathrm{R} \$ \quad 90,00$ \\
\hline Gesso & $\mathrm{R} \$ 0,06$ & & $\mathrm{R} \$$ \\
\hline MAP purificado & $\mathrm{R} \$ 3,85$ & 225 & 865,58 \\
\hline Cal & $\mathrm{R} \$ 0,38$ & 710 & $\mathrm{R} \$ \quad 269,80$ \\
\hline Uréia & $\mathrm{R} \$ 1,07$ & 1200 & $\mathrm{R} \$ 1.284,00$ \\
\hline Cloreto de potássio & $\mathrm{R} \$ 2,20$ & 900 & $\mathrm{R} \$ 1.980,00$ \\
\hline Ácido Bórico & $\mathrm{R} \$ 3,15$ & 27 & $\mathrm{R} \$ \quad 85,05$ \\
\hline Sulfato de zinco & $\mathrm{R} \$ 2,00$ & 6 & 12,00 \\
\hline Sulfato de cobre & $\mathrm{R} \$ 4,00$ & 3 & 12,00 \\
\hline Sulfato de manganês & $\mathrm{R} \$ 3,92$ & 8 & 31,36 \\
\hline Molibidato de Sódio & $\mathrm{R} \$ 12,12$ & 1,5 & 18,18 \\
\hline Cloro & $\mathrm{R} \$ 3,00$ & 35,1 & $\mathrm{R} \$ \quad 105,19$ \\
\hline Total $\left(\mathrm{R} \$\right.$ ha $^{-1}$ ciclo $\left.^{-1}\right)$ & & & $R \$ 4.753,16$ \\
\hline Total $\left(\mathbf{R} \$\right.$ ha $^{-1}$ ano $\left.^{-1}\right)$ & & & R\$ 792,19 \\
\hline
\end{tabular}

Na Tabela 12 podemos verificar de forma resumida a mão de obra utilizado no sistema de fertirrigação, necessária a seu acompanhamento e perfeito funcionamento. 
Tabela 12. Mão de obra necessária ao sistema de fertirrigação utilizadas no modelo econômico de avaliação do projeto de produção de madeira de Eucalyptus spp.

\begin{tabular}{|c|c|}
\hline Descrição & Valor Total $\left(\mathbf{R} \$\right.$ ha $\left.^{-1}\right)$ \\
\hline Terceirizada & $\mathrm{R} \$ 12.986,88$ \\
\hline Monitor Florestal & $\mathrm{R} \$ \quad 2.926,25$ \\
\hline Total & $\begin{array}{ll}\text { R } & 15.913,13\end{array}$ \\
\hline Total $\left(\mathrm{R} \$\right.$ ha $\left.^{-1} \mathrm{ano}^{-1}\right)$ & R\$ $\quad 381,92$ \\
\hline
\end{tabular}

Para despesas com manutenções e reparos foram considerados os itens da Tabela 13.

Tabela 13. Despesas com manutenções e reparos necessária ao sistema de fertirrigação utilizadas no modelo econômico de avaliação do projeto de produção de madeira de Eucalyptus spp.

\begin{tabular}{|c|c|}
\hline Descrição & Valor Total $\left(\mathbf{R} \$\right.$ ha $\left.^{-1}\right)$ \\
\hline Manutenção Equipamentos & $\mathrm{R} \$ 36.560,00$ \\
\hline Manutenção Ponto de Capitação & $3.000,00$ \\
\hline Manutenção Rede Elétrica & $5.000,00$ \\
\hline Manutenção/Combustível Moto & $7.200,00$ \\
\hline Ferramentas & 690,00 \\
\hline Peças de Reposição & $\mathrm{R} \$ 13.200,00$ \\
\hline Custo Moto & 875,00 \\
\hline Total (500ha) & $\mathrm{R} \$ \quad 66.525,00$ \\
\hline Total $\left(\mathrm{R} \$ \mathrm{ha}^{-1} \mathrm{ano}^{-1}\right)$ & R\$ 133,05 \\
\hline
\end{tabular}

Também foram considerados como outras despesas anuais os custos decorridos dos processos de licenciamento ambiental e outorga, bem como as análises, quantificações e sistema de segurança necessários à adequada implantação e operação do empreendimento fertirrigado, conforme Tabela 14.

Tabela 14. Outras despesas necessárias ao sistema de fertirrigação utilizadas no modelo econômico de avaliação do projeto de produção de madeira de Eucalyptus spp.

\begin{tabular}{|c|c|c|}
\hline Descrição & \multicolumn{2}{|c|}{ Valor Total $\left(\mathrm{R} \$ \mathrm{ha}^{-1}\right)$} \\
\hline Licenças e Condicionantes Ambientais & $\mathrm{R} \$$ & $12.100,00$ \\
\hline Análises Experimentais & $\mathrm{R} \$$ & $17.000,00$ \\
\hline Mensurações (Inventário) & $\mathrm{R} \$$ & $14.160,00$ \\
\hline Vigilância & $\mathrm{R} \$$ & $59.316,00$ \\
\hline Total (500ha) & $\mathbf{R} \$$ & $102.576,00$ \\
\hline Total $\left(\mathbf{R} \$\right.$ ha $\left.^{-1} \mathbf{a n o}^{-1}\right)$ & $\mathbf{R} \$$ & 205,15 \\
\hline
\end{tabular}


As totalizações decorrentes destas despesas inerentes à situação de produção de eucalipto fertirrigado podem ser observadas no Apêndice 13.

\subsubsection{Investimentos}

Conforme apresentado anteriormente, todas as operações realizadas para produção de madeira de Eucalyptus spp foram terceirizadas pela Empresa MMX Metálicos Corumbá Ltda a outra prestadora de serviços, que por sua vez era responsável pela aquisição e manutenção de todos os equipamentos utilizados, repassando obviamente estes custos no preço das operações contratadas. Estas também foram as premissas aqui consideradas neste modelo e ficando a cargo da Empresa MMX os investimentos associados ao sistema de fertirrigação, conforme observados na Tabela 15.

Tabela 15. Investimentos no sistema de fertirrigação utilizados no modelo econômico de avaliação econômica do projeto de produção de madeira de Eucalyptus spp.

\begin{tabular}{|c|c|c|c|c|c|}
\hline Descrição & $\begin{array}{l}\text { Referência } \\
\text { (ha) }\end{array}$ & \multicolumn{2}{|c|}{$\begin{array}{l}\text { Valor } \\
(\mathbf{R} \$)\end{array}$} & \multicolumn{2}{|c|}{$\begin{array}{c}\text { Valor Unitário } \\
\left(\mathbf{R} \$ \mathbf{h a}^{-1}\right)\end{array}$} \\
\hline Sistema de Irrigação & 500 & $\mathrm{R} \$$ & $4.588 .601,03$ & $\mathrm{R} \$$ & $9.177,20$ \\
\hline Sistema Elétrico & 500 & $\mathrm{R} \$$ & $154.000,00$ & $\mathrm{R} \$$ & 308,00 \\
\hline Total $(\mathbf{R} \$)$ & & $\mathbf{R} \$$ & $4.742 .601,03$ & $\mathbf{R} \$$ & $9.485,20$ \\
\hline
\end{tabular}

\subsubsection{Dimensionamentos}

De acordo com os cenários definido pelas variáveis de entrada foram quantificadas: a produção de madeira anual em função da produtividade esperada (em situação de sequeiro e fertirrigada), função das equações de prognose da floresta; a quantidade de área manejada em função das operações florestais necessárias em cada ano; os insumos em situação de sequeiro e fertirrigado; os investimentos com o sistema de fertirrigação; além dos custos e receitas anuais relativas a cada uma destas variáveis e podem ser melhor observados nos Apêndices. 


\subsubsection{Fluxo de caixa do acionista}

As receitas e despesas referentes ao empreendimento em situação de sequeiro e fertirrigado foram organizadas em um "Profit \& Loss" (relatório de lucros e perdas) distintos, permitindo a comparação entre os empreendimentos.

Este Profit\&Loss contem além das receitas e despesas com a operação, as produções anuais de madeira, os impostos sobre as receitas brutas e líquidas, investimentos e depreciação, formando um fluxo de caixa que permite o conhecimento das oscilações econômicas do empreendimento.

\subsubsection{Métodos de avaliação econômica}

Em função da dificuldade em se analisar economicamente um empreendimento por meio de apenas um critério econômico, a análise é realizada a partir dos seguintes critérios: Taxa interna de Retorno (TIR) e Valor presente líquido (VPL).

\subsubsection{Análise de Sensibilidade}

Para a avaliação de diferentes situações que possibilitem a identificação de condições favoráveis e limitantes para a implantação de florestas fertirrigadas, foram propostas variações em diversos itens da análise econômica de forma a identificar diferentes cenários para o estudo.

O estudo de sensibilidade do empreendimento complementa a avaliação econômica verificando os riscos a que o projeto está submetido em função das variações possíveis de ocorrer nas premissas básicas, definindo portanto diferentes cenários a serem analisados. Para tanto foram realizadas simulações de preço da madeira, preço da terra e produtividade esperada para a floresta. 


\section{RESULTADOS E DISCUSSÕES}

Neste capítulo é apresentada a avaliação econômica do projeto de produção de madeira de Eucalyptus spp utilizando-se como base os dados de investimentos e despesas do projeto de fertirrigação da Empresa MMX Metálicos Corumbá Ltda. Inicialmente serão apresentados os resultados da análise econômica realizada sobre as condições em que o experimento foi realizado, utilizando-se as premissas já identificadas e apresentadas anteriormente. Posteriormente são apresentados e discutidos os resultados econômicos das análises de sensibilidade realizadas, demonstrando situações médias e marginais para a caracterização de outros cenários possíveis.

\subsection{Fluxo de caixa do projeto}

O modelo econômico construído permitiu a identificação da cadeia de receitas e despesas ocorridas em ambas as situações propostas (sequeiro e fertirrigado) e são apresentadas a seguir:

A Figura 14 mostra o fluxo de caixa do projeto para a situação de sequeiro, contabilizando as receitas e despesas inerentes ao processo de produção de madeira de Eucalyptus spp para dois módulos implantados de 428ha nos anos 2007 e 2008, consecutivamente. 


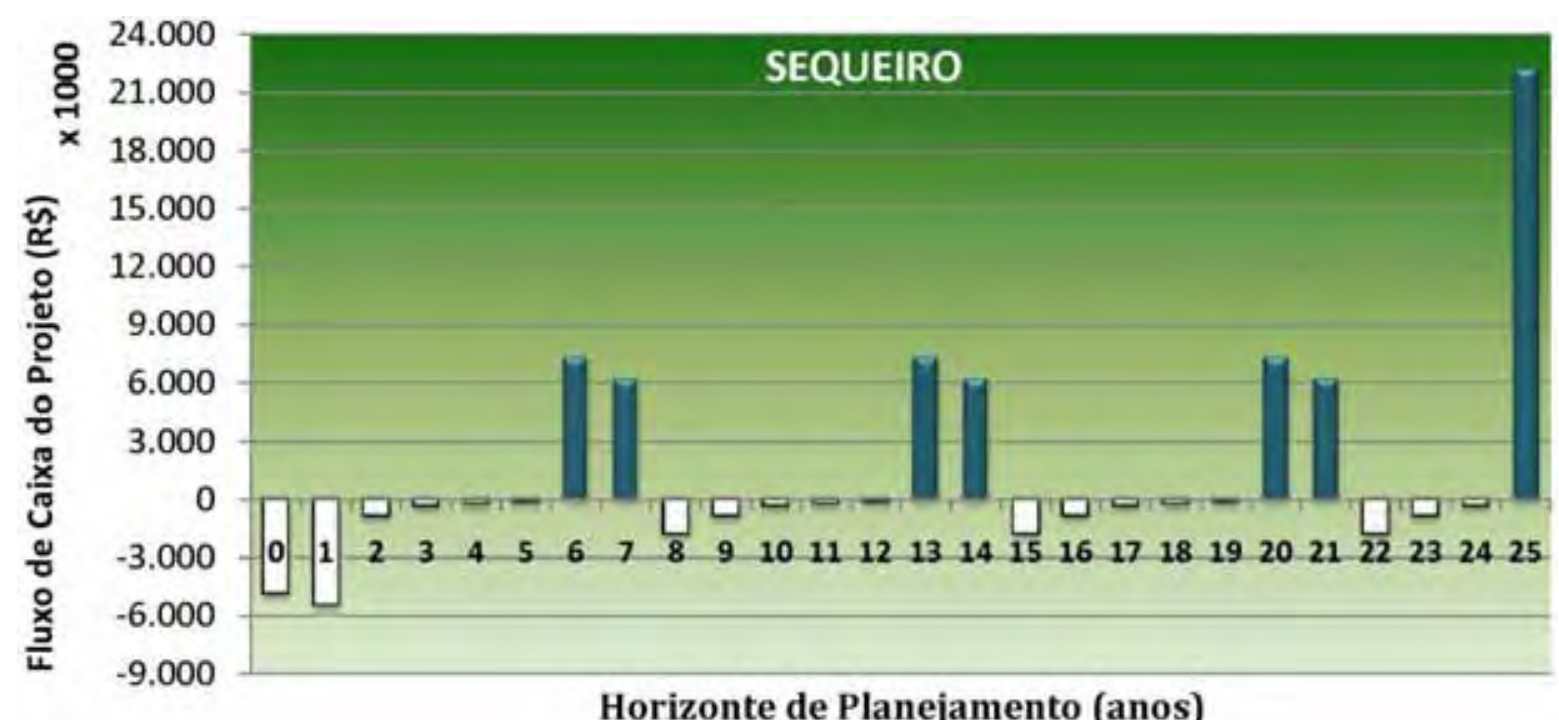

Figura 14. Fluxo de caixa do projeto na situação de sequeiro para produção de madeira de Eucalyptus spp da Empresa MMX Metálicos Corumbá Ltda.

Este fluxo de caixa apresentou um VPL de R \$ 4.994.275,11 e uma TIR de $11,44 \%$ para o horizonte de planejamento de 25 anos. O custo da madeira, calculado pela soma de todas as despesas operacionais do processo, dividida pela produção total ao longo do horizonte de planejamento foi de $\mathrm{R} \$ 20,47$.

Estes índices foram calculados considerando-se os investimentos em terra necessários ao sistema produtivo, sendo que no final do horizonte de planejamento (ano 25) a terra é vendida considerando a sua valorização no tempo, de acordo com a taxa de valorização da terra adotada de 5\% a.a.

A Figura 15 mostra o fluxo de caixa do projeto para a situação de fertirrigação, contabilizando as receitas e despesas inerentes ao processo de produção de madeira de Eucalyptus spp para dois módulos implantados de 250ha nos anos 2007 e 2008 , consecutivamente.

Nas condições em que as premissas foram assumidas, este fluxo de caixa apresentou um VPL de R $\$ 388.106,48$ e uma TIR de 8,26\% para o horizonte de planejamento de 25 anos. Embora esta TIR apresente-se baixa e muito próxima à taxa de oportunidade considerada $(8,00 \%)$, estes resultados indicam viabilidade do cenário definido, nos moldes em que foi concebido. 


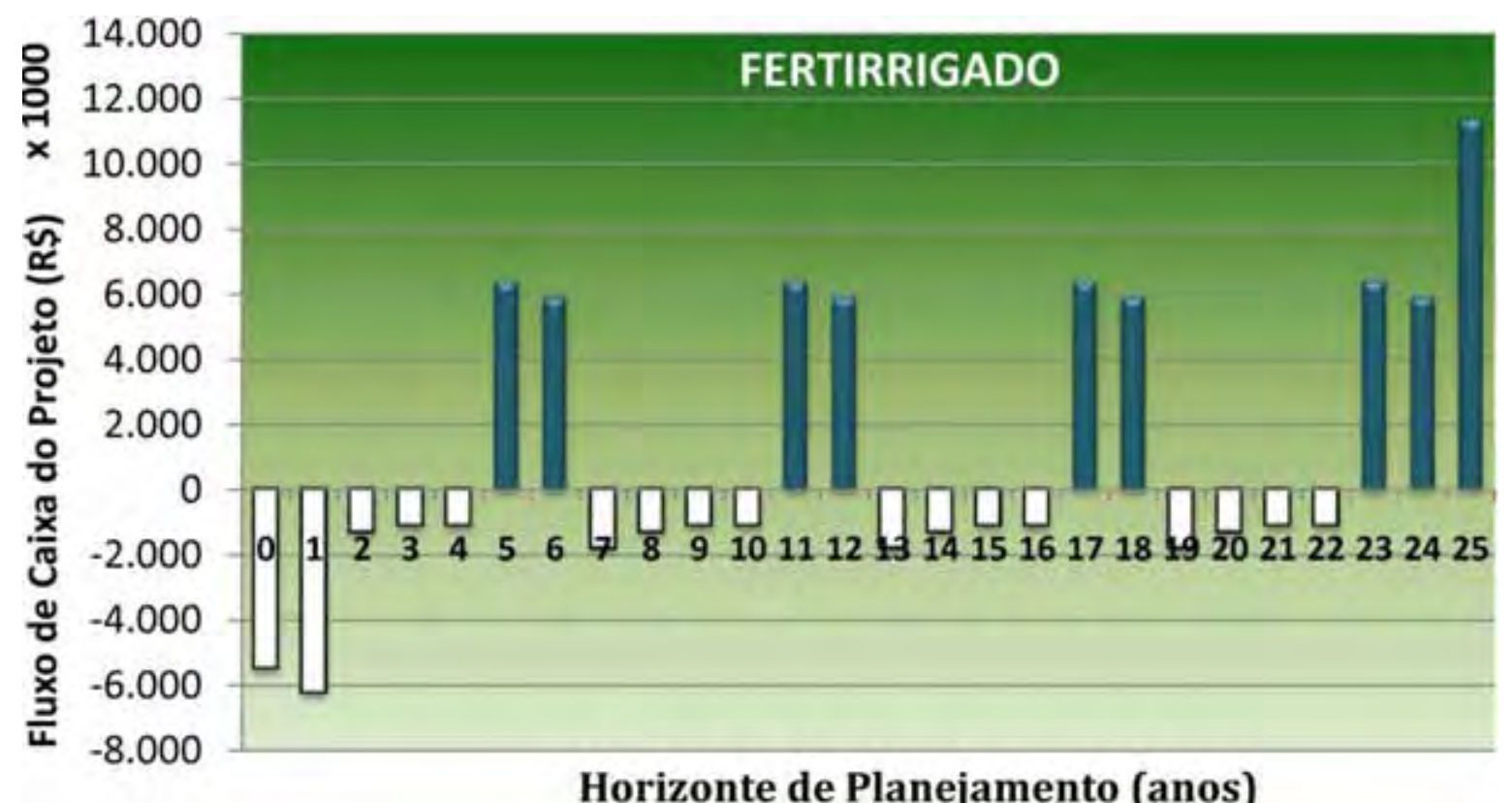

Figura 15. Fluxo de caixa do projeto na situação fertirrigado para produção de madeira de Eucalyptus spp da Empresa MMX Metálicos Corumbá Ltda.

O custo da madeira neste cenário foi de $\mathrm{R} \$ 28,77$, superior ao custo obtido no cenário de sequeiro e indicando que o custo de transferência do setor de produção da empresa para a fábrica se tornará maior, o que mostra que o cenário fertirrigado é menos indicado que o sequeiro, nas condições em que foram propostas. Entretanto, ao se analisar a diminuição do tempo em que ocorrerão as primeiras produções, esta pode se tornar uma importante questão de ordem estratégica para o processo produtivo.

\subsection{Análise de sensibilidade}

$\mathrm{Na}$ tentativa de se avaliar diferentes cenários em que o sistema fertirrigado pode se apresentar vantajoso, foram variadas as premissas de preço de venda ou transferência da madeira, custo da terra e nível de produtividade da floresta, avaliando-se novamente os índices econômicos: Valor Presente Líquido (VPL) e Taxa Interna de Retorno (TIR).

Durante a variação da premissa em estudo, todas as outras foram mantidas constantes, conforme os valores definidos na metodologia. 


\subsubsection{Sensibilidade do preço da madeira}

Com o objetivo de se avaliar a sensibilidade do empreendimento em função do preço da madeira foram realizadas simulações variando esta premissa no intervalo de $-50 \%$ a $+50 \%$ em torno do preço base, definido pela média dos últimos dois anos do CEPEA/ESALQ, conforme apresentado anteriormente nas premissas do modelo econômico.

A análise de sensibilidade demonstrou que o projeto de produção de madeira de Eucalyptus spp no cenário de sequeiro é viável e suporta uma variação negativa no preço da madeira de mais de $20 \%$, mantendo a atratividade do empreendimento (Figura 16). De modo inverso, a rentabilidade do projeto melhora bastante com um aumento no preço da madeira.

O valor crítico para o preço da madeira neste cenário é de $\mathrm{R} \$ 24,41$, ou seja, quando o valor da remuneração da madeira atinge valores inferiores a este, a remuneração do capital torna-se menor que a taxa de desconto e o empreendimento é considerado inviável.

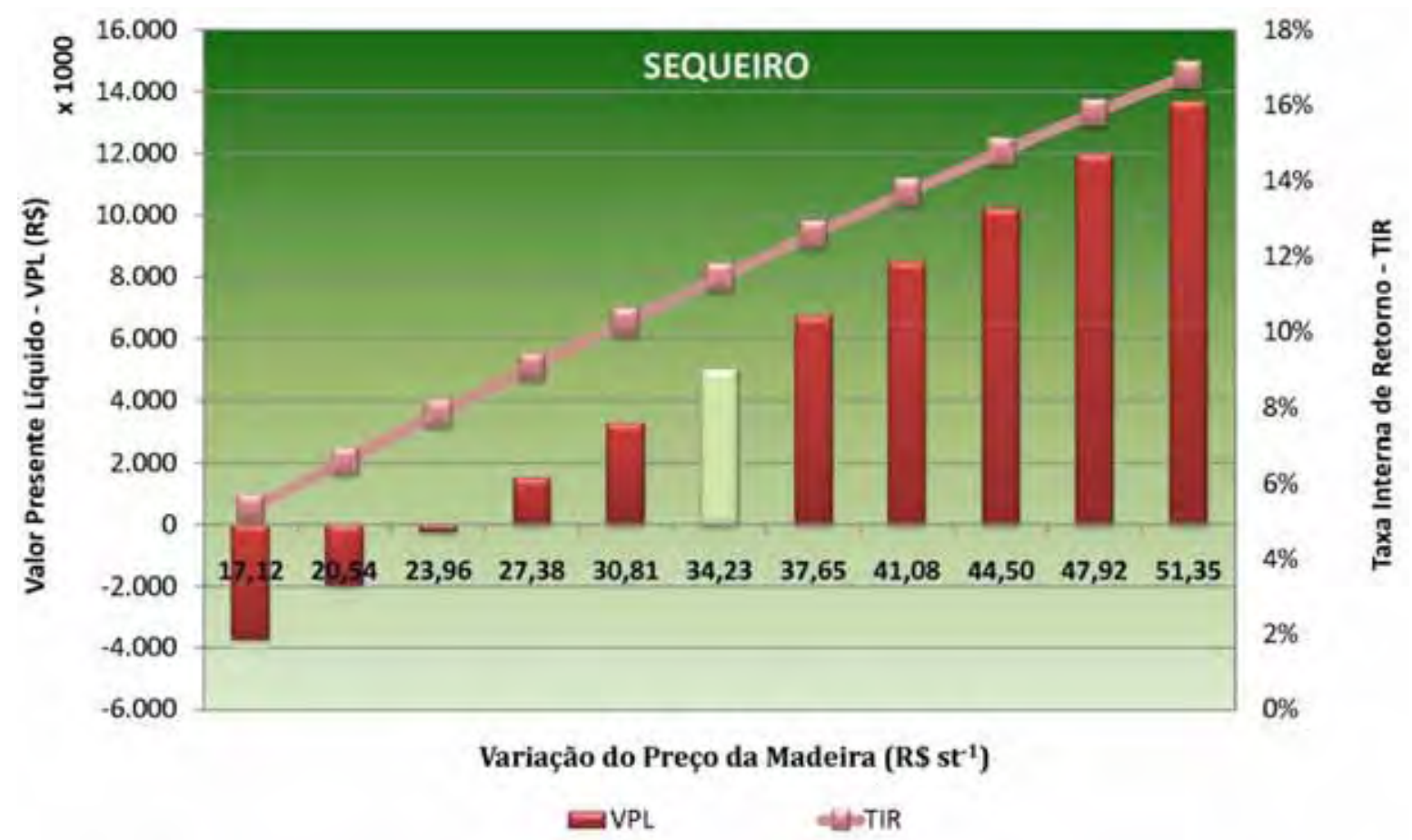

Figura 16. Análise de sensibilidade da variação do preço da madeira de Eucalyptus spp em condições de sequeiro. 
Esta mesma análise de sensibilidade pode ser realizada para o projeto de produção de madeira de Eucalyptus spp no cenário fertirrigado, porém demonstra neste caso que o cenário está marginal à inviabilidade, uma vez que um pequeno decréscimo no preço da madeira pode torná-lo inviável, conforme Figura 17. Valores inferiores $\mathrm{R} \$ 33,63$ tornam o empreendimento inviável.

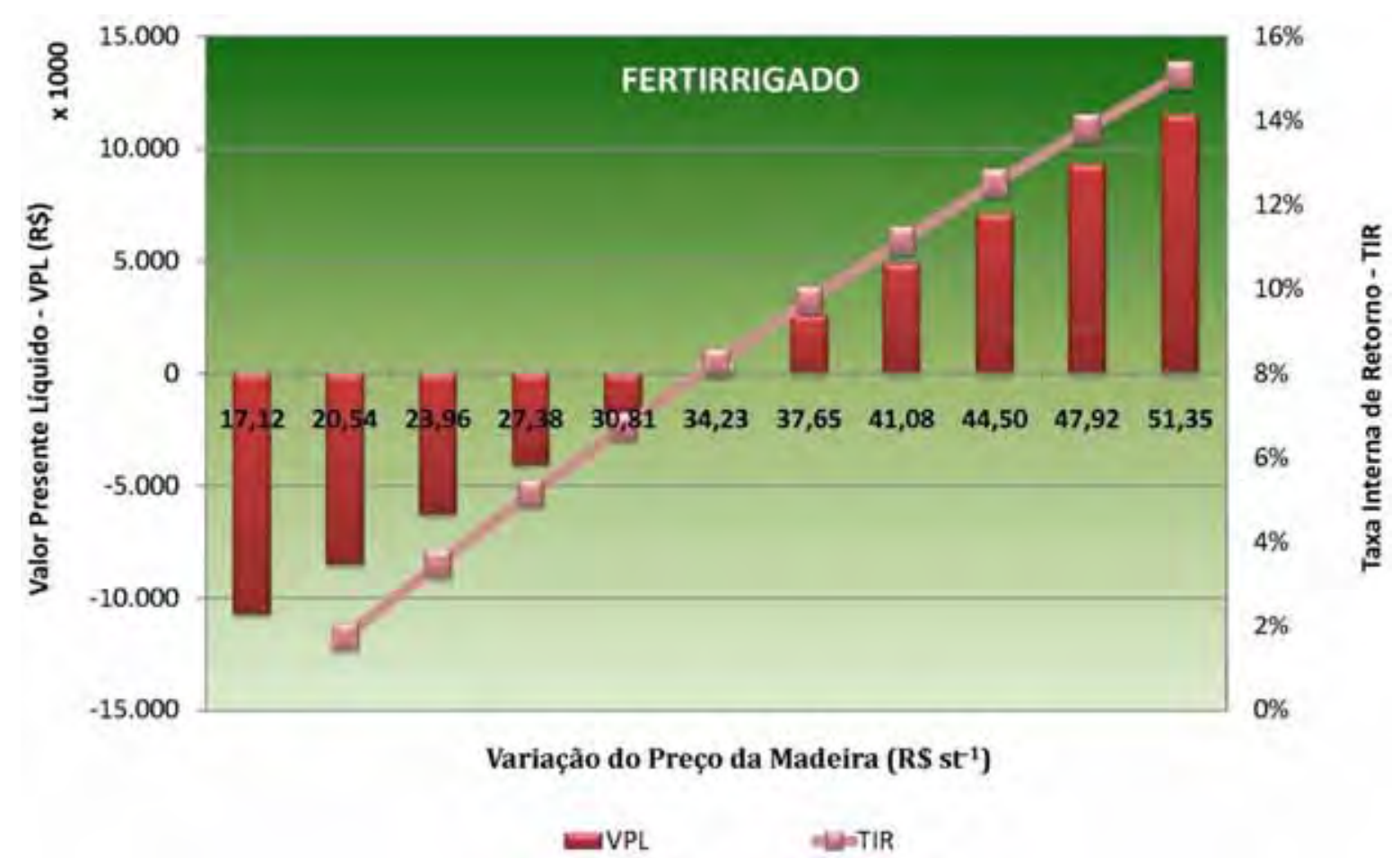

Figura 17. Variação do preço da madeira de Eucalyptus spp no cenário fertirrigado.

\subsubsection{Sensibilidade do preço da terra}

A variação no custo de aquisição da terra tem significativo efeito sobre o resultado econômico do projeto de produção de madeira de Eucalyptus spp no cenário de sequeiro, suportando uma variação de mais de $100 \%$ no valor da terra. O valor crítico para o preço da terra é de R $\$ 12.666,75$ por hectare, sendo este o valor que torna o VPL nulo.

De modo inverso, a rentabilidade do projeto melhora bastante com a diminuição do preço da terra, dando um VPL de R \$ 8.251.376,86 e uma TIR de 22,97\% no caso de não se considerar o custo de aquisição da terra, conforme Figura 18. 


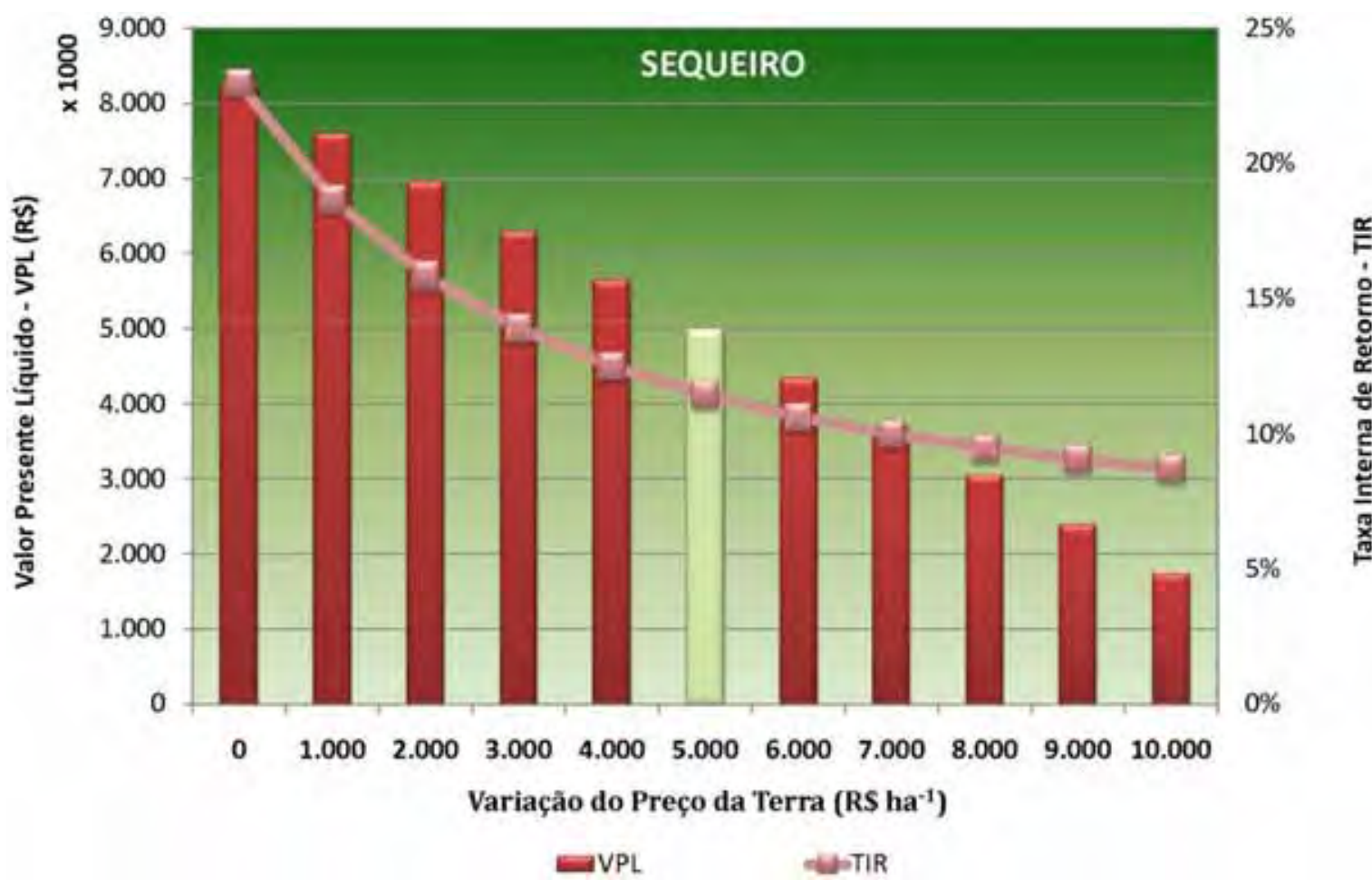

Figura 18. Variação do custo de aquisição da terra para produção de madeira de Eucalyptus spp no cenário de sequeiro.

No cenário em que a produção de madeira de Eucalyptus spp é realizada por fertirrigação, verificamos que os valores marginais para o custo de aquisição da terra são de $\mathrm{R} \$ 6.019,02$ por hectare, ou seja, custos superiores a estes tornam o empreendimento inviável.

Na situação em que o preço da terra não é considerado como custo de investimento, o cenário fertirrigado passa a ter um VPL de R 2.292.426,07 e uma TIR de 10,53\%, conforme podemos avaliar na Figura 19. 


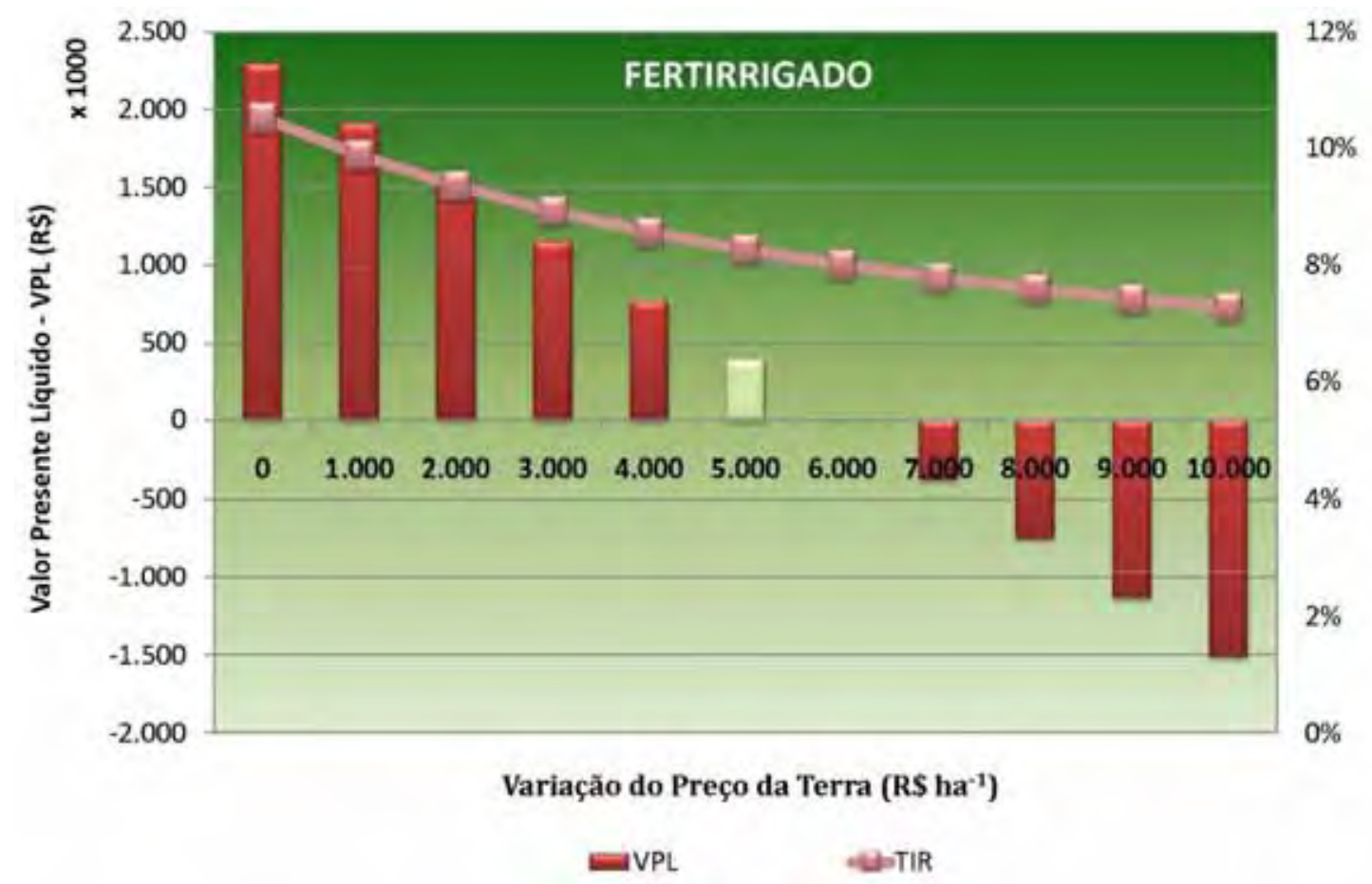

Figura 19. Variação do custo de aquisição da terra para produção de madeira de Eucalyptus spp no cenário fertirrigado.

\subsubsection{Sensibilidade da produtividade de madeira}

O nível de produtividade da floresta afeta diretamente as receitas do sistema produtivo, estando diretamente associado aos índices econômicos da análise financeira e aos retornos esperados pelo investidor.

Foi realizada uma análise de sensibilidade para o nível de

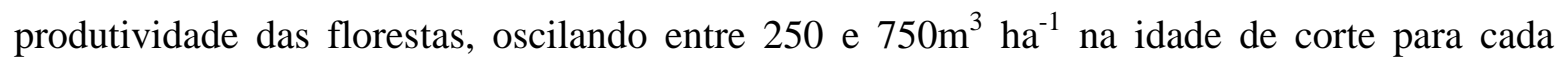
situação: sequeiro e fertirrigado, conforme apresentam a Figura 20 e a Figura 21.

Verificou-se que para as condições de sequeiro, produtividades superiores a $251 \mathrm{~m}^{3} \mathrm{ha}^{-1}$ tornam o empreendimento atrativo para a empresa, enquanto em condições fertirrigadas são necessários $590 \mathrm{~m}^{3} \mathrm{ha}^{-1}$.

Estes valores representam que embora a fertirrigação diminua em média um ano na idade de corte da floresta, são necessários um aumento de $135 \%$ na produtividade da floresta para que o sistema fertirrigado se torne mais vantajoso que o sistema de produção em sequeiro. 


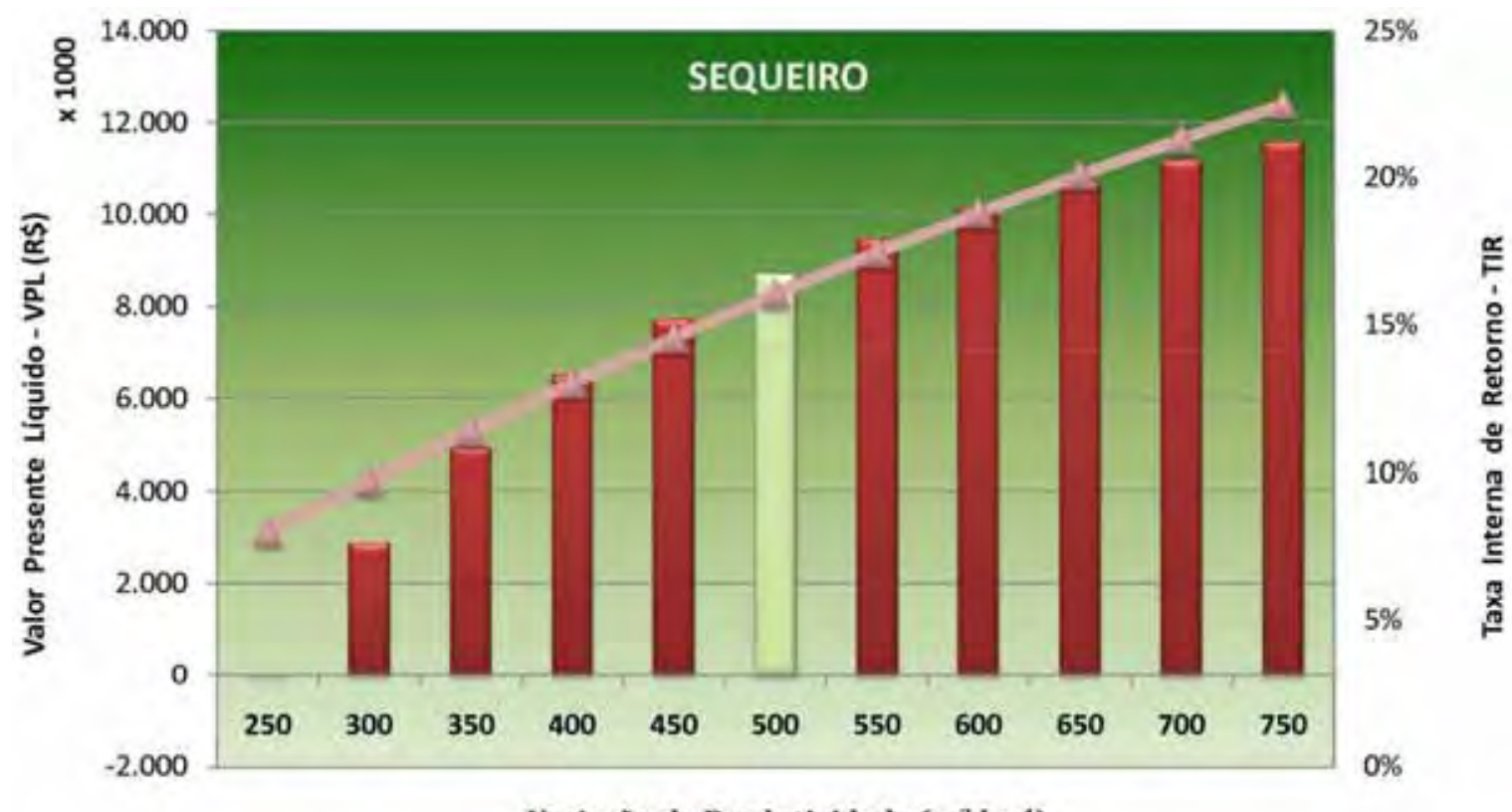

Figura 20. Variação da produtividade esperada da floresta para produção de madeira de Eucalyptus spp no cenário sequeiro.

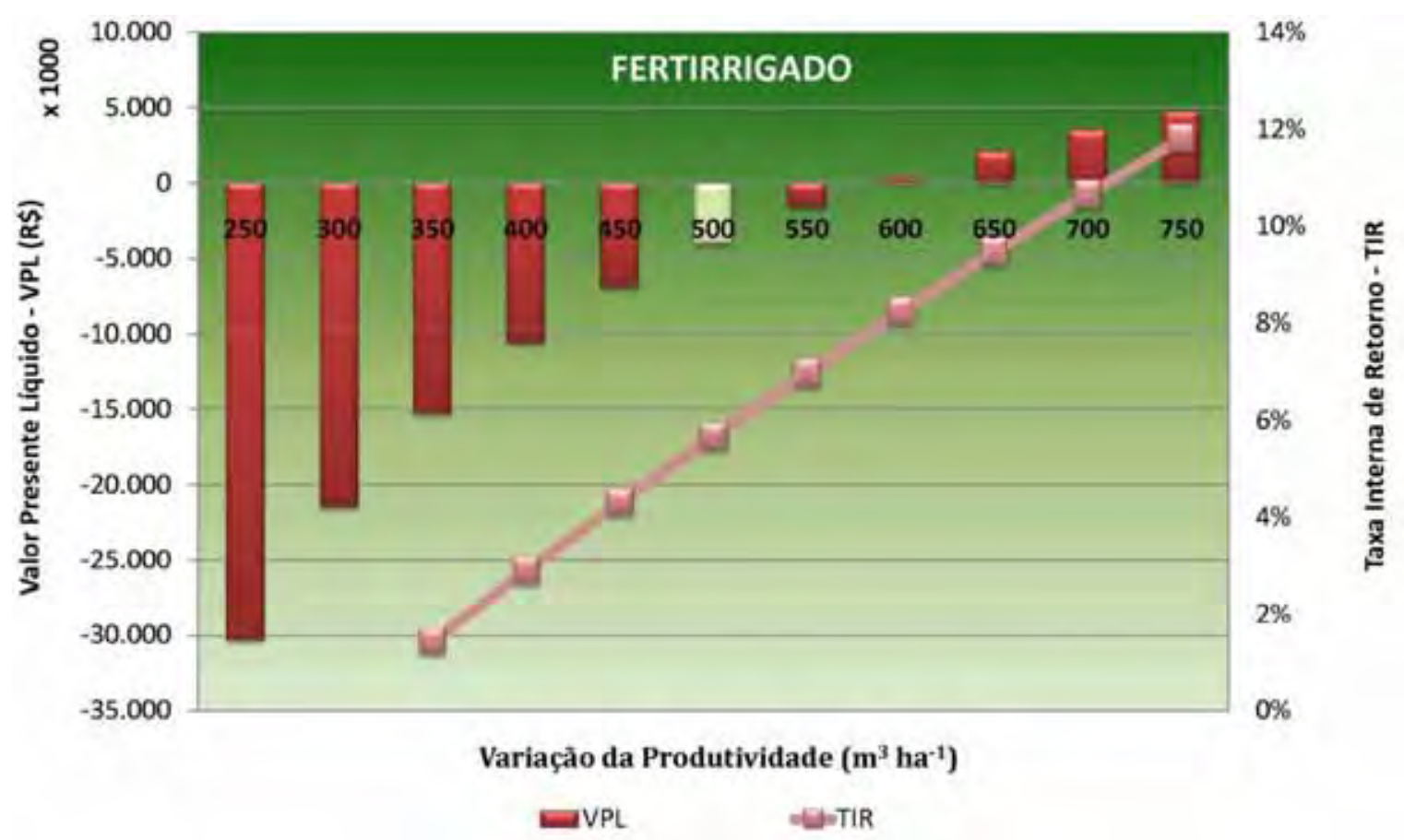

Figura 21. Variação da produtividade esperada da floresta para produção de madeira de Eucalyptus spp no cenário fertirrigado. 


\section{CONCLUSÕES}

Nas condições em que o sistema de produção de madeira de Eucalyptus spp foram aqui modeladas, nas situações de sequeiro e fertirrigada, pode-se concluir que ambas podem ser economicamente viáveis pelas análises de VPL e TIR, dependendo das premissas adotadas e implantadas para a unidade florestal.

Para os cenários em que o sistema foi montado na Empresa MMX Metálicos Corumbá Ltda, a condição de sequeiro apresentou um menor custo de transferência da madeira da unidade florestal para a unidade metalúrgica, comparada com a condição de fertirrigação, e portanto a opção de sequeiro deve ser adotada pela empresa como forma de diminuir os custos do sistema produtivo da unidade fabril, aumentando a lucratividade do setor.

De acordo com a análise de sensibilidade realizada pode-se concluir que o sistema de produção de madeira por meio da tecnologia de fertirrigação deve produzir um aumento no volume de madeira superior a 135\% com uma redução de um ano na idade de corte para se tornar mais vantajoso, do ponto de vista econômico, que os sistemas convencionais de sequeiro. Estas condições podem ser perfeitamente encontradas em locais de baixa pluviosidade, em que as produtividades convencionais são relativamente baixas.

O sistema fertirrigado pode se tornar interessante também em situações estratégicas de produção de madeira, na qual as reduções do percentual de área para atingir as mesmas demandas das unidades fabris passem a ser relevantes nas tomadas de decisão. Para as 
produtividades aqui prognosticadas esta redução de área foi de 41,6\%. O mesmo pode ser relacionado à redução de um ano na idade ótima de corte. 


\section{REFERÊNCIAS BIBLIOGRÁFICAS}

BELLI, P. et al. Economic analysis of investment operations: analytical tools and practical applications. Washington: World Bank Institute, 2000. 264 p.

BORGES, J. S. Parametrização, calibração e validação do modelo 3-PG para eucalipto na Região do cerrado de Minas Gerais. 2009. 77f. Dissertação (Mestrado em Solos e Nutrição de Plantas) - Universidade Federal de Viçosa, Viçosa, 2009.

BRASIL. Departamento de Produção Mineral. Projeto RADAMBRASIL: Levantamento de Recursos Naturais. Folha Corumbá (SE-21). Rio de Janeiro: editora, 1982. 452p.

BRIGAGÃO, E. N. Integração de análise econômica e financeira a sistemas de apoio a decisão de enquadramento, outorga e cobrança de Recursos hídricos: aplicação à bacia da Barragem do Descoberto no Distrito Federal. 2006.133 f. Dissertação (Mestrado em

Tecnologia Ambiental e Recursos Hídricos) - Departamento de Engenharia Civil e Ambiental, Universidade de Brasília, Brasília, 2006.

CALLLIEZ, F. Forest volume estimation and yield prediction: Volume estimation by Centre technique forestier tropical Nogent-sur-Marne. França: FAO, v.1, 1980.

CAMPOS, J. C. G.; LEITE, H. G. Mensuração florestal: perguntas e Respostas. Viçosa: UFV, 2002.

CHA, P. D.; ROSENBERG, J. J.; DYM, C. L. Fundamentals of moling and analysing engineering systems; Cambridge: Cambridge University Press, 2000. 466 p.

CLUTTER, J. L. et al. Timber management: a quantitative approach. New York: John Wiley \& Sons, 1983. 333p.

DUERR, W. A. Fundamentos de economia florestal. Lisboa: Fundação Calouste Gulbenkiam, 1972. 754p. (Trad.: Eugênio João Lamas da Silva). 
DU TOIT, B. Information requirements to fertilize plantations with greater precision in a dry country. In: PROCEEDINGS OF THE INTERNATIONAL PRECISION FORESTRY SYMPOSIUM, Stellenbosch University, South Africa, Mar. 2006.

GOODPASTURE, J. C. Quantitative methods in project management. Boca Raton: J. Ross Publishing, 2003. 257 p.

HIRSCH JUNIOR, L. M. Advanced management accounting. 2 ed. London: Thomson Learning High Holborn House, 2006. 712 p.

INSTITUTO DE PESQUISAS E ESTUDOS FLORESTAIS - IPEF. O eucalipto precisa de muita água? 2003. Disponível em: <http://www.ipef.br/hidrologia/eucaliptoeagua.asp>. Acesso em: 12 dez. 2009.

INSTITUTO NACIONAL DE METEREOLOGIA - INMET. Disponível em: <http://www.inmet.gov.br/html/clima/graficos/>. Acesso em: 19 mai. 2008.

INSTITUTO NACIONAL DE METEREOLOGIA - INMET. Disponível em: <http://www.inmet.gov.br/html/agro.php?lnk=Hídrico Climático>. Acesso em: 01 mar. 2010.

KLEMPERER, D. W.; KLEMPERER, D. Forest Resource Economics and Finance. 1995. $551 \mathrm{p}$.

LIMA, W. P. Impacto ambiental do eucalipto. 2 ed. São Paulo: Editora da Universidade de São Paulo, 1996. 301 p.

MACDONALD, L. H. Developing a monitoring project. Journal of soil and water conservation, Ankeny, p. 221-227, 1994.

MADEIRA, M. V. et al. Changes in carbon stocks in Eucalyptus globulus Labill plantations induced by different water and nutrient availability. Forest Ecology and Management, v. 171, n. 1-2, p. 75-85, 1 Nov. 2002.

MIAN, M. A. Project economics and decision analysis: deterministic models. Tulsa: PenWell Corporation, v. 1, 2002. 377p.

MIRANDA, I. et al. The influence of irrigation and fertilization on heartwood and sapwood contents in 18-year-old Eucalyptus globulus trees. Canadian Journal of Forest Research, n. 36, p. 2675-2683, 2006.

MMX METÁLICOS CORUMBÁ LTDA. Plano de manejo florestal sustentável - PFS. Anastácio: MMX, 2008.

MOORE, T. G. E.; LOCKWOOD, C. G., The HSG wood supply model: description and user's manual. Petawawa National Forestry Instit., Forestry Canada, Information Report PI-X98. 1990.31p. 
OLLITA, A. F. L. Os métodos de irrigação. São Paulo: Livraria Nobel, 1982. 267 p.

PINSON, L. Anatomy of a business plan: the step-by-step quide to building a business and securing your company's future. 7 ed. Tustin: Out of Your Mind...And Into the Marketplace, 2008. 352p.

REZENDE, J. L. P.; OLIVEIRA, A. D. Análise econômica e social de projetos florestais. Viçosa: Editora UFV, 2001. 389p.

RODRIGUEZ, L. C. E. Monitoramento florestal: iniciativas, definições e recomendações. Piracicaba: Série Técnica IPEF. v. 12, n. 31, p. 9-22, abr. 1998.

SANTANA, et al. Sistema de equações para simulação do crescimento e da produção em povoamentos de Eucalyptus grandis hill ex maiden. sem desbaste baseado no modelo de Clutter. Revista do Centro de Ciências Agrárias e Ambientais, v. 1, n. 2, jun-dez. 2005.

SCOLFORO, J. R. S. Manejo florestal. Lavras: FAEPE/UFLA, 1998. 438 p.

SPURR, S. H. Forest Inventory. New York: The Ronald Press Company, 1952.

TOMAZELLO FILHO, M. Efeito da irrigação e fertilização nas propriedades do lenho de árvores de eucalyptus grandis $\mathbf{x}$ urophylla. Tese apresentada à Escola Superior de Agricultura "Luiz de Queiroz", Universidade de São Paulo, para o Concurso de Livre Docência junto ao Departamento de Ciências Florestais; Piracicaba, 2006.

TONINI, H.; SCHNEIDER, P. R.; FINGER, C. A. G. Curvas de índice de sítio para povoamentos clonais de Eucalyptus saligna smith para a Depressão Central e Serra do Sudeste, Rio Grande do Sul. Ciência Florestal, Santa Maria, v. 16, n. 1, p. 27-43, 2006.

VANCLAY, J. K., Growth models for tropical forests: a synthesis of models and methods. Forest Science, Frederiksberg, v. 41, n. 1, p. 7-42, Feb. 1995.

WIMMER, R. Weather, water, wood: environmental effects on wood and fibre properties. Vienna: University of Agricultural Sciences, 2001. 
APÊNDICE 


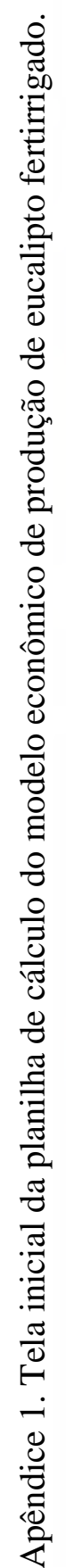

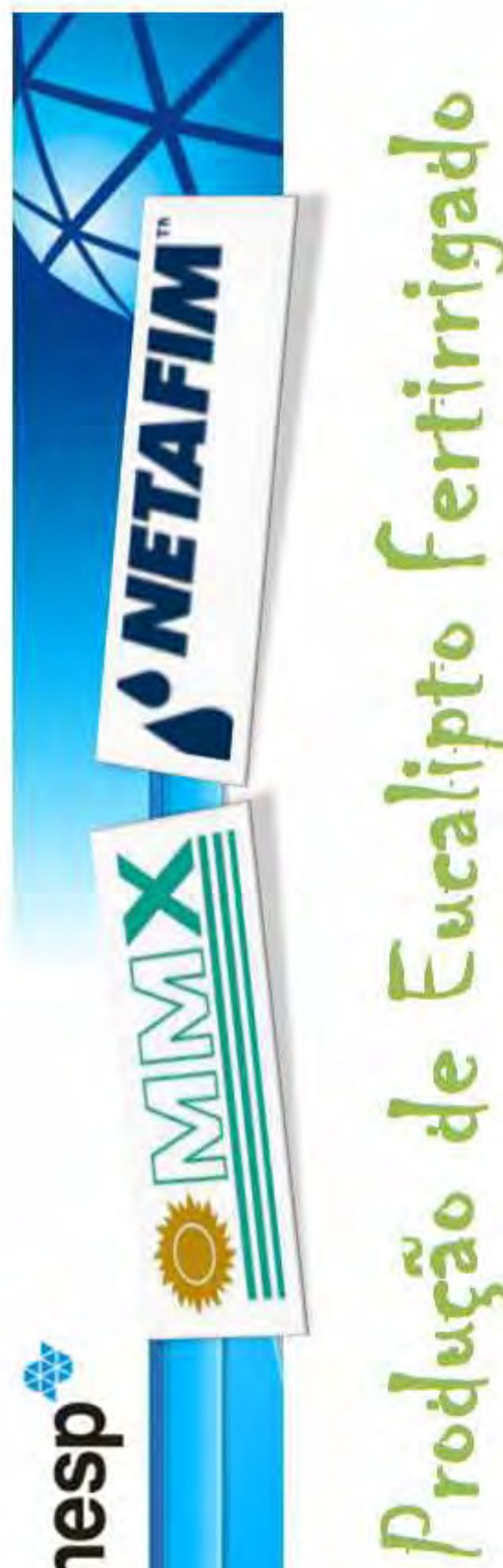


तิ

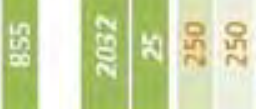

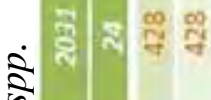

촐 해 $\mathrm{x}$ 웜

हैं 에 लवन

这

$\frac{1}{2}$

ชี

$\frac{\pi}{\frac{\pi}{\sigma}}$

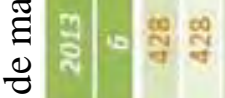

용

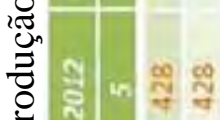

일

สำ

$\frac{3}{3}$

गี่

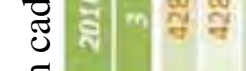

อ

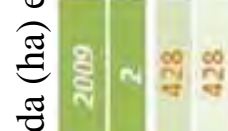

范

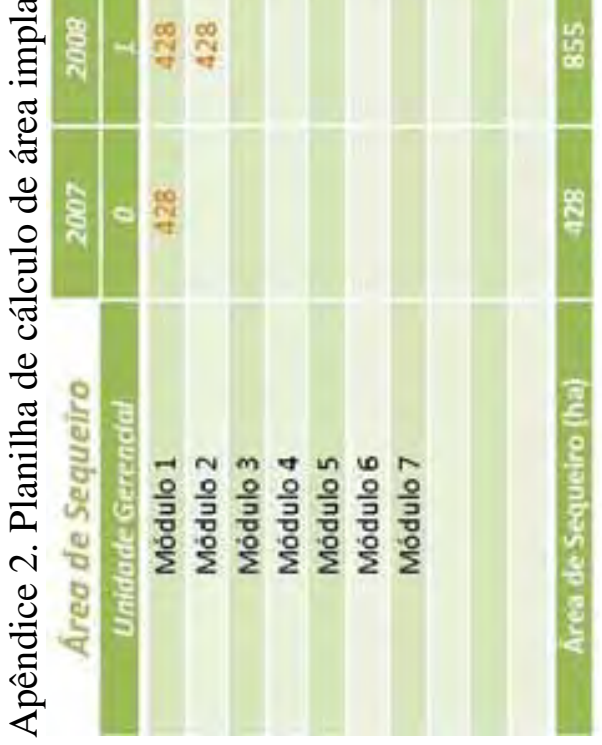

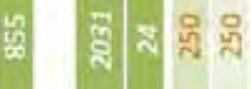

䓍 胥内品

迢

旨

녕

봄

落

苫

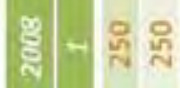

웡. 운

홍현 혼

$\overrightarrow{0} n m \in$

윽 윽 윽 윽윽음

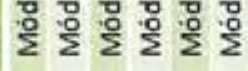




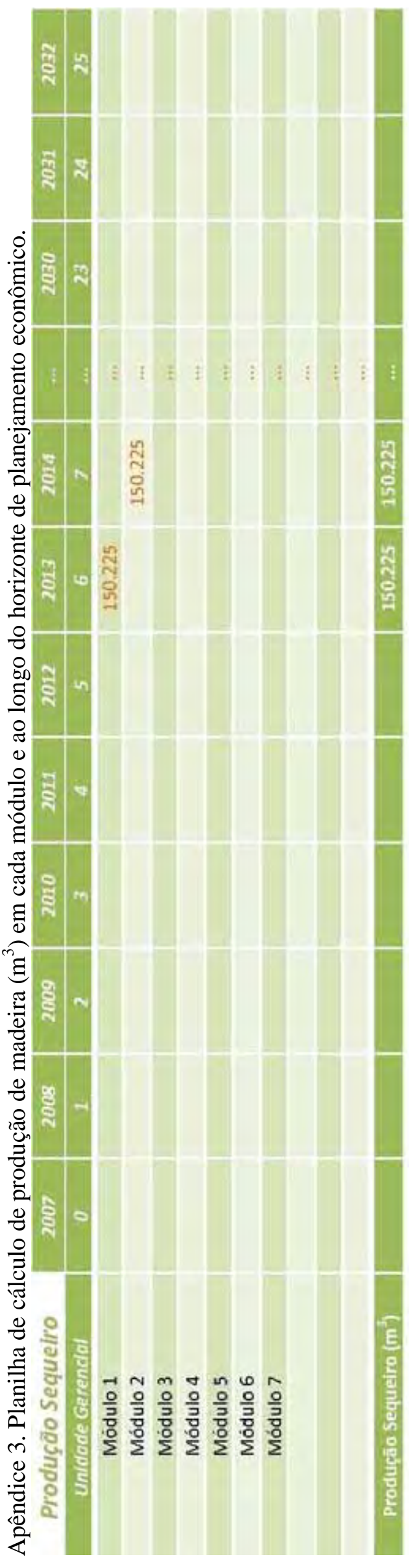

웡

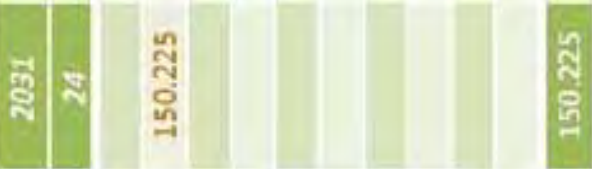

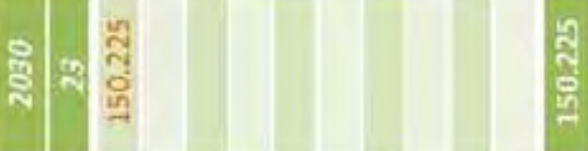

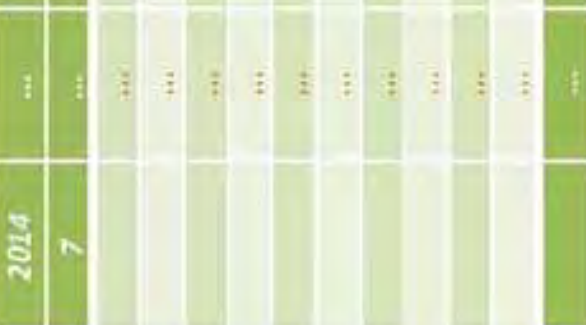

ㅎำ สู่

鱑

ㅊำ สี

萢

:

ㅊำ

ㅎํㅇ -

\$. -

\$ํ.

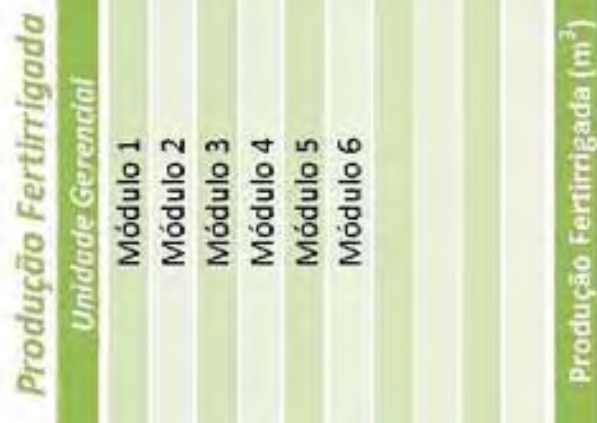




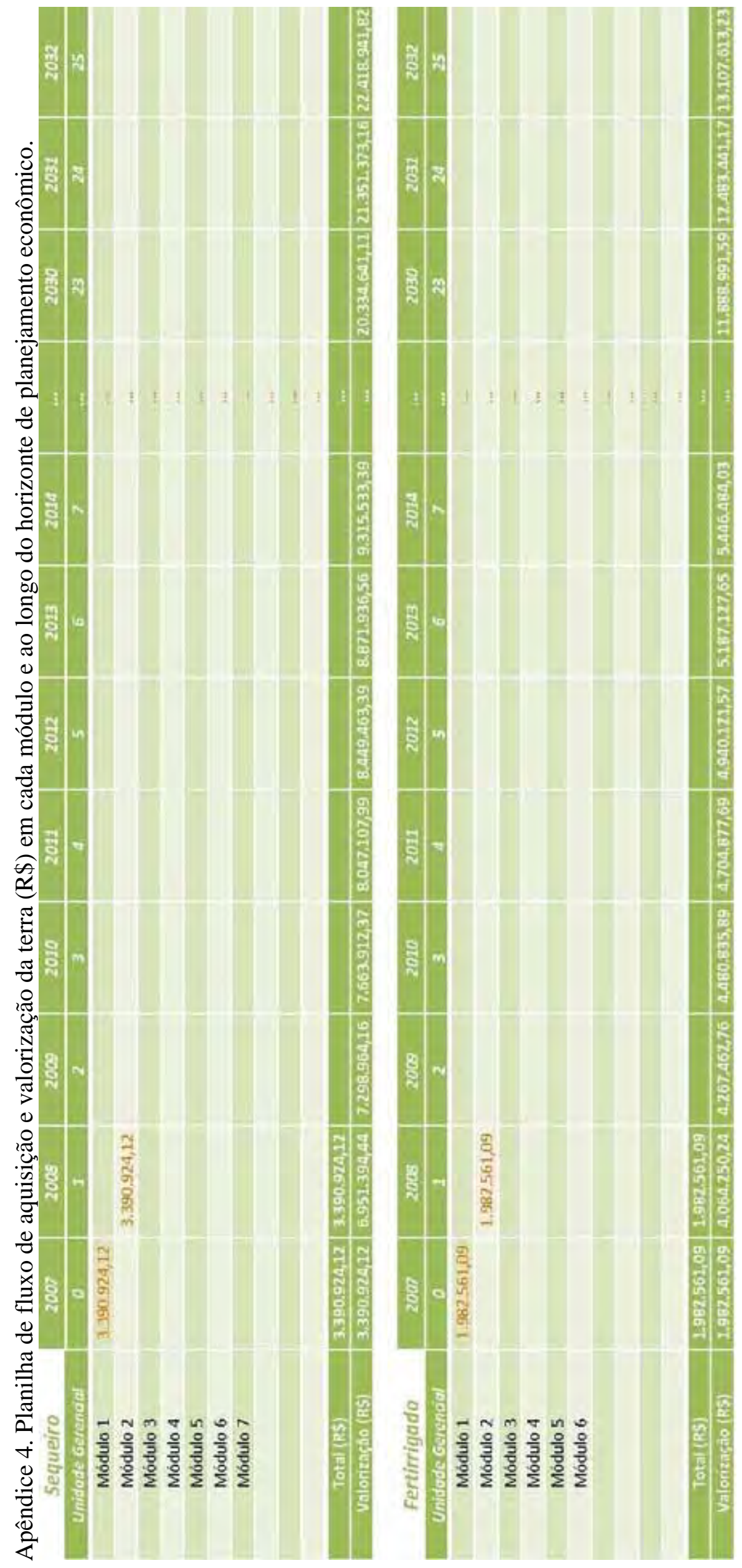




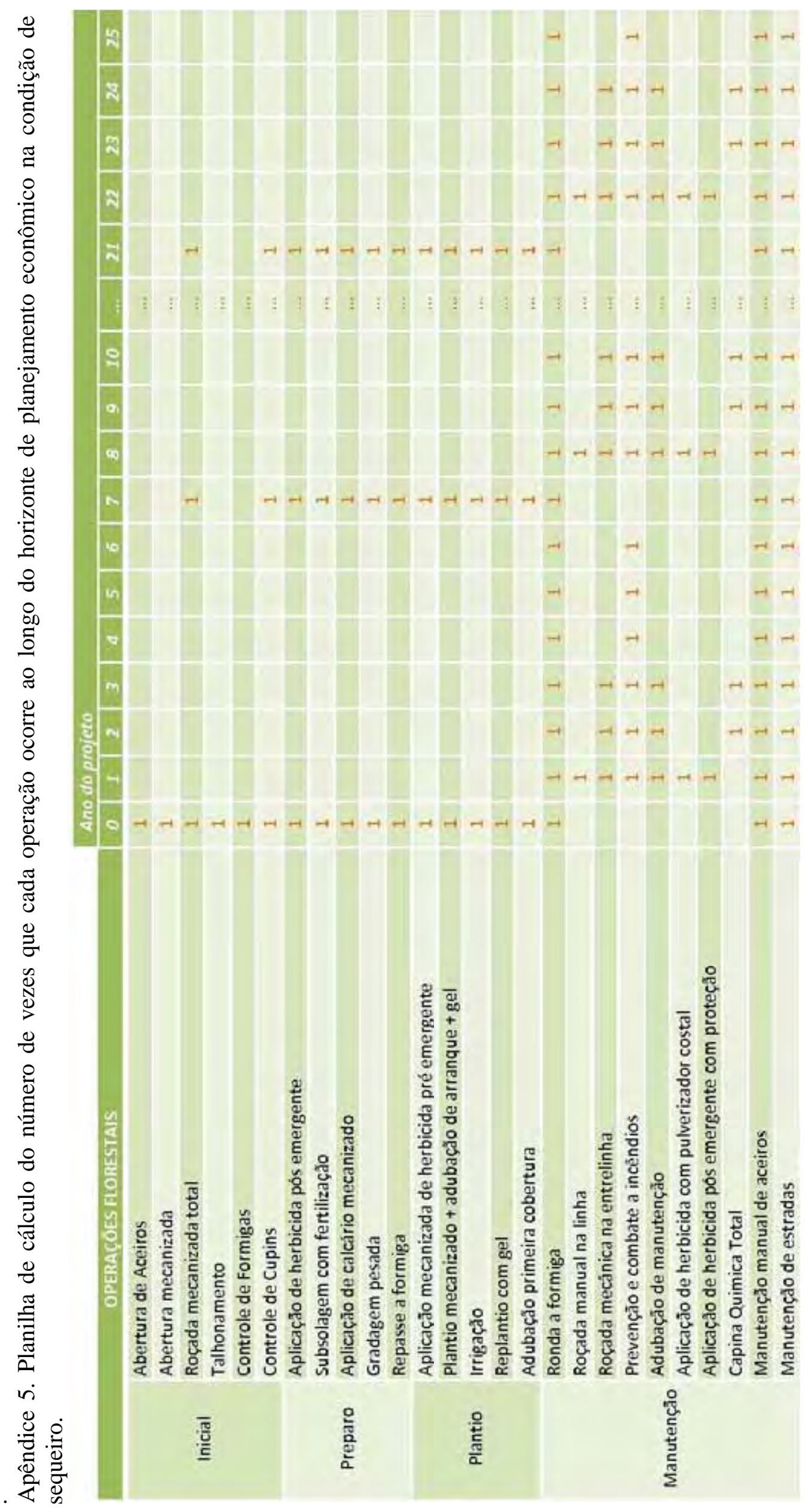




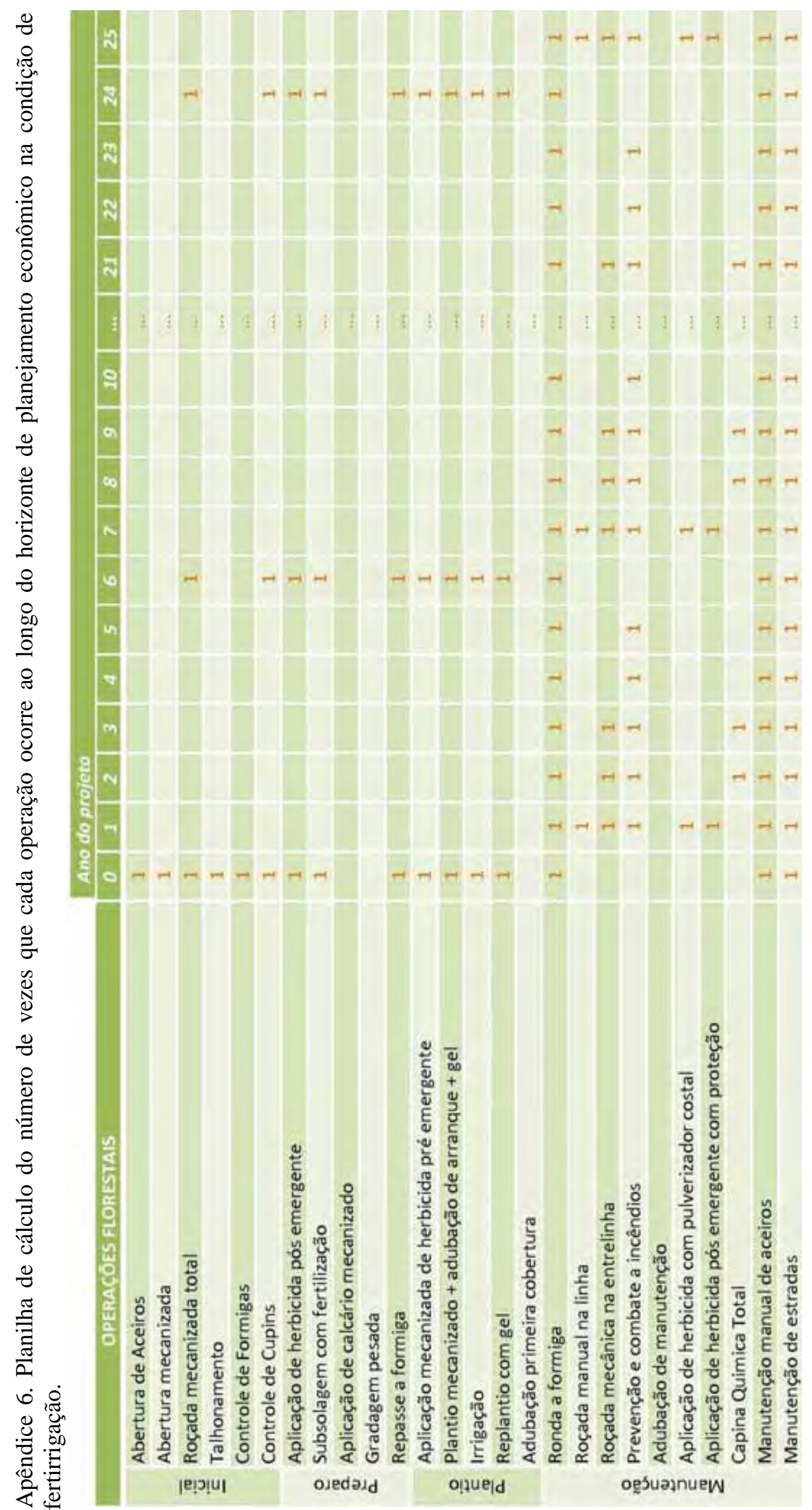




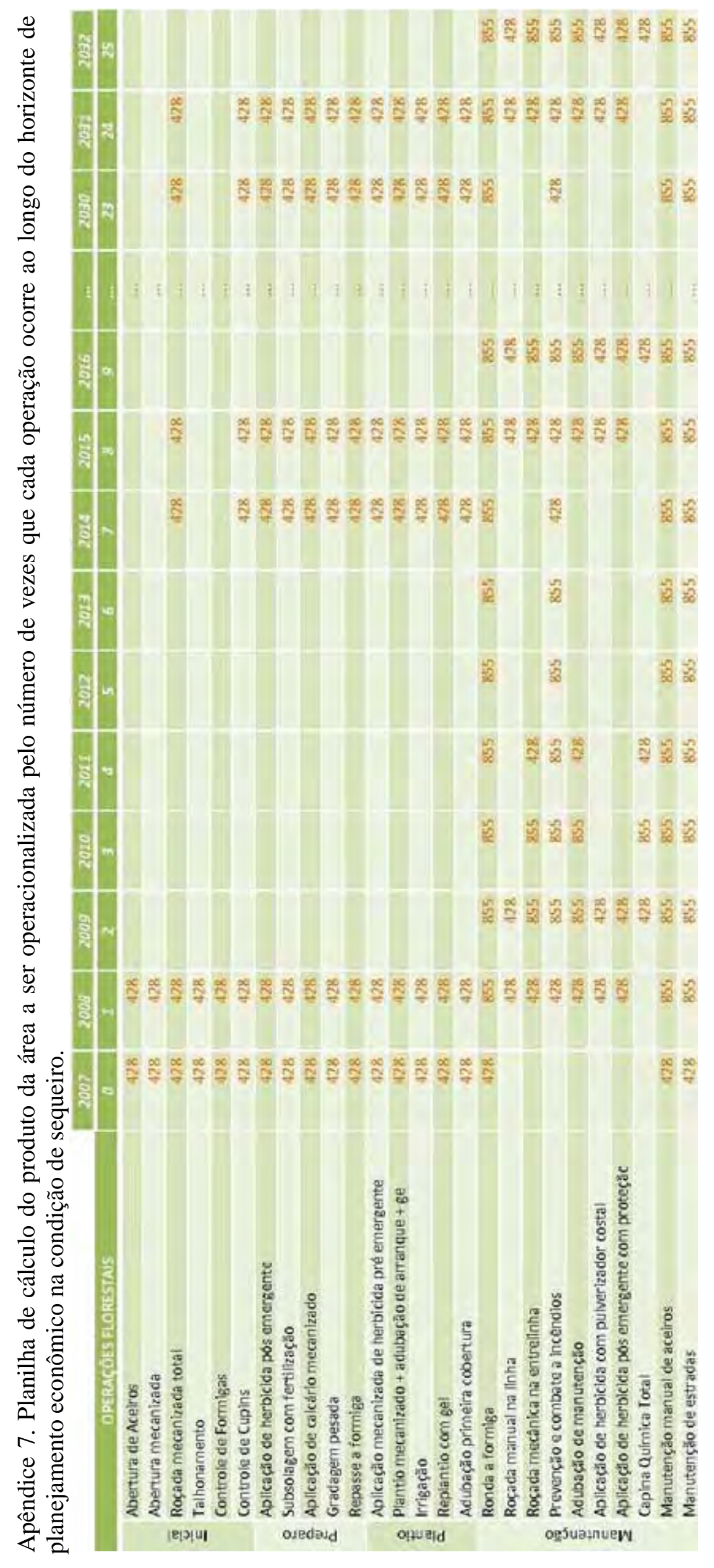




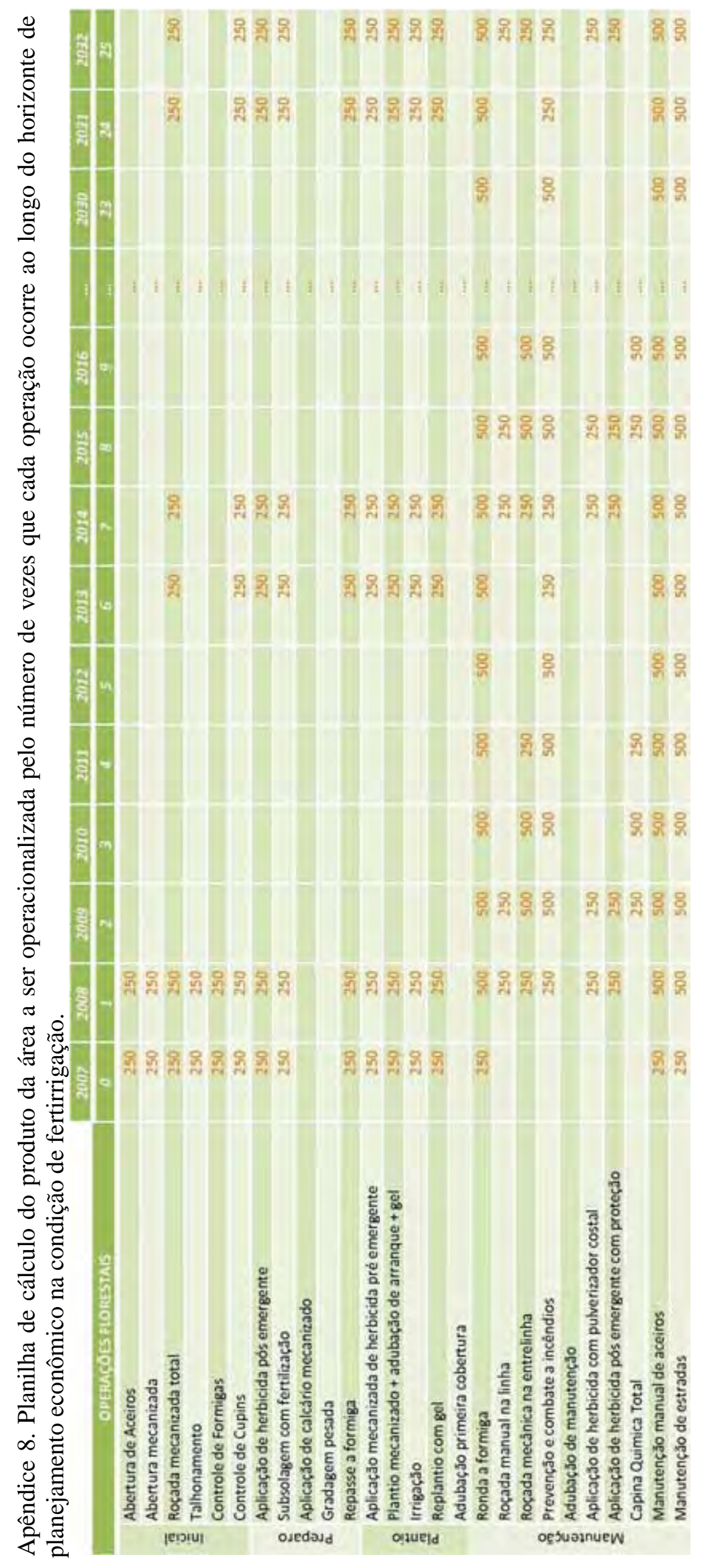




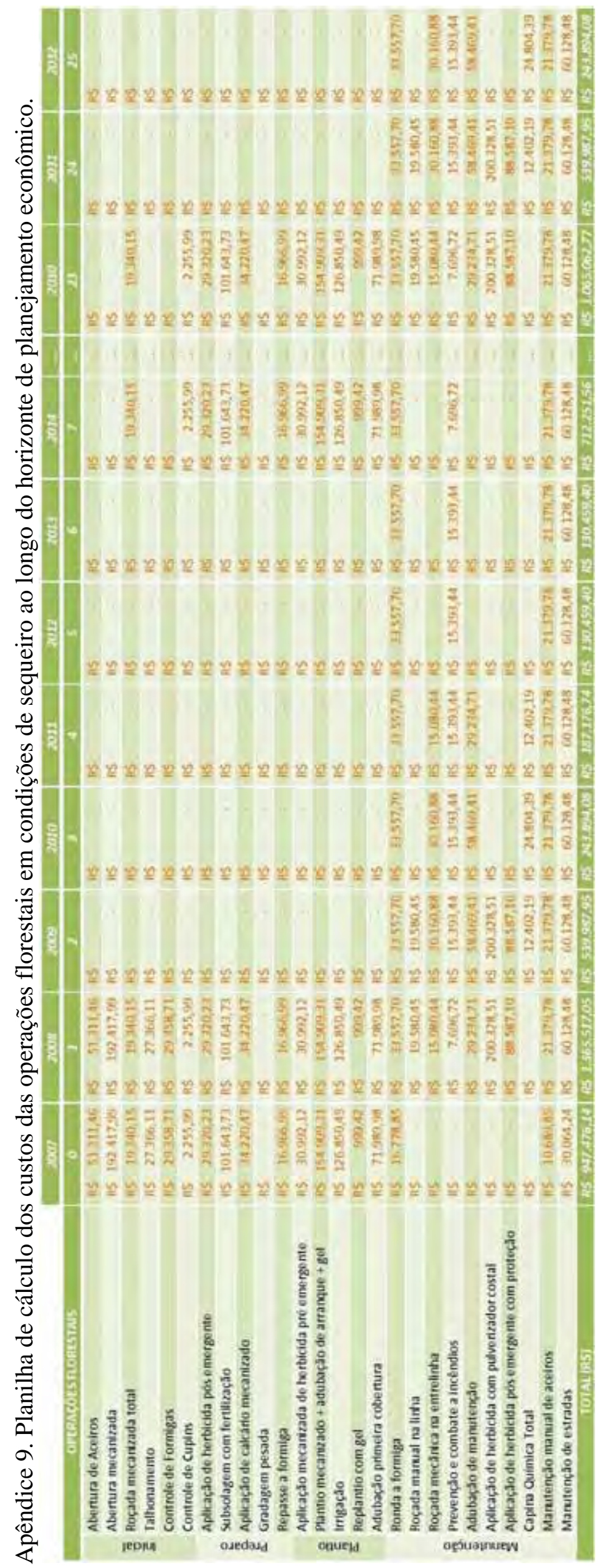




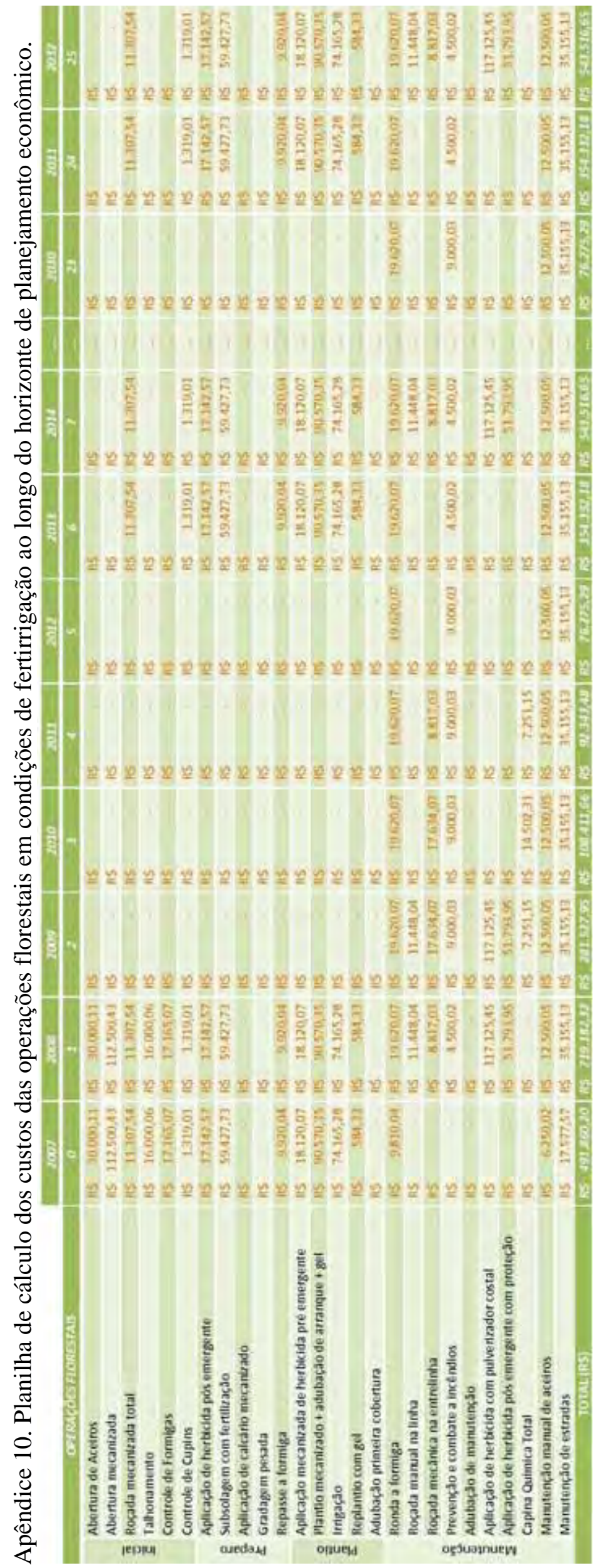



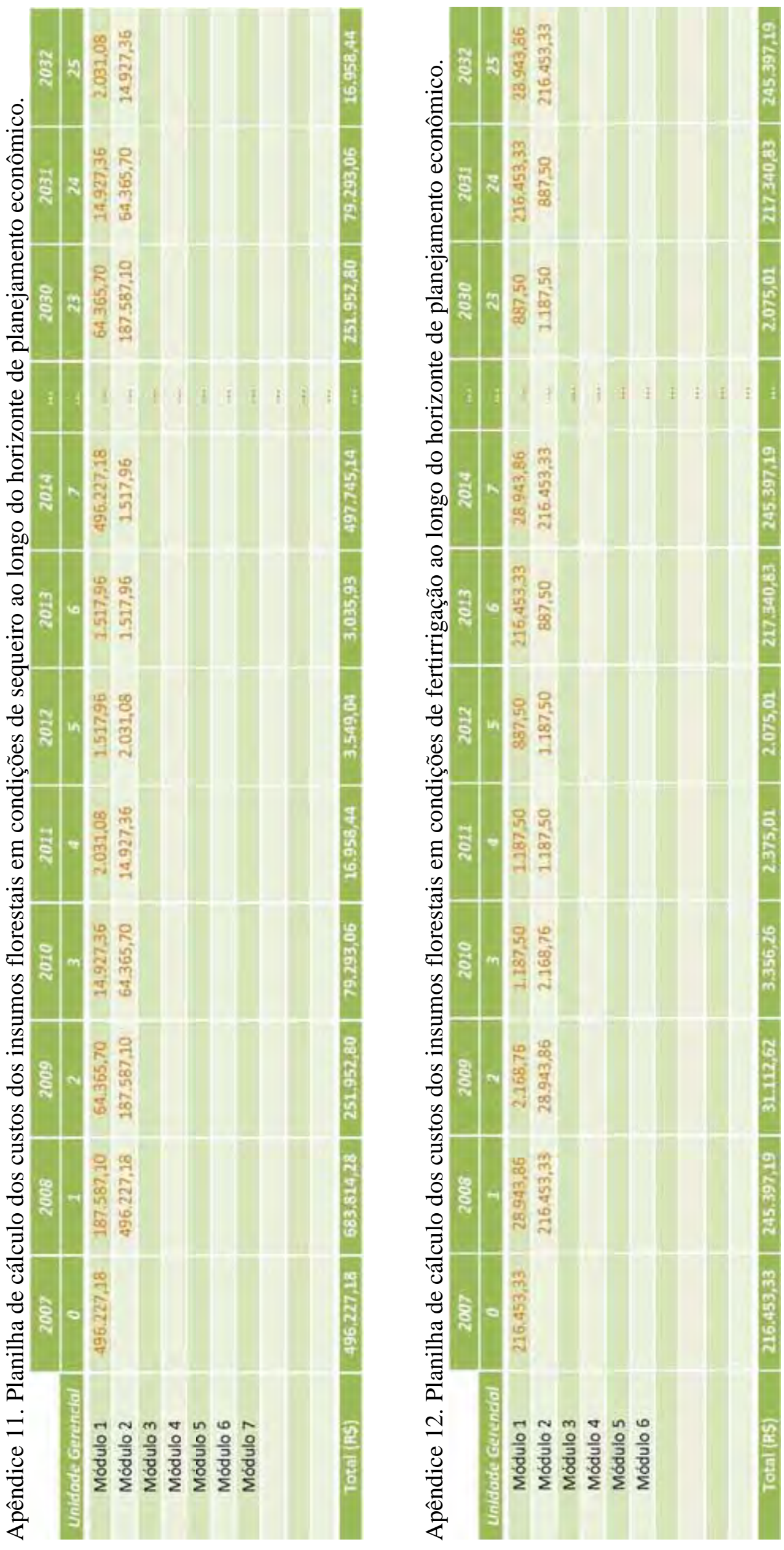


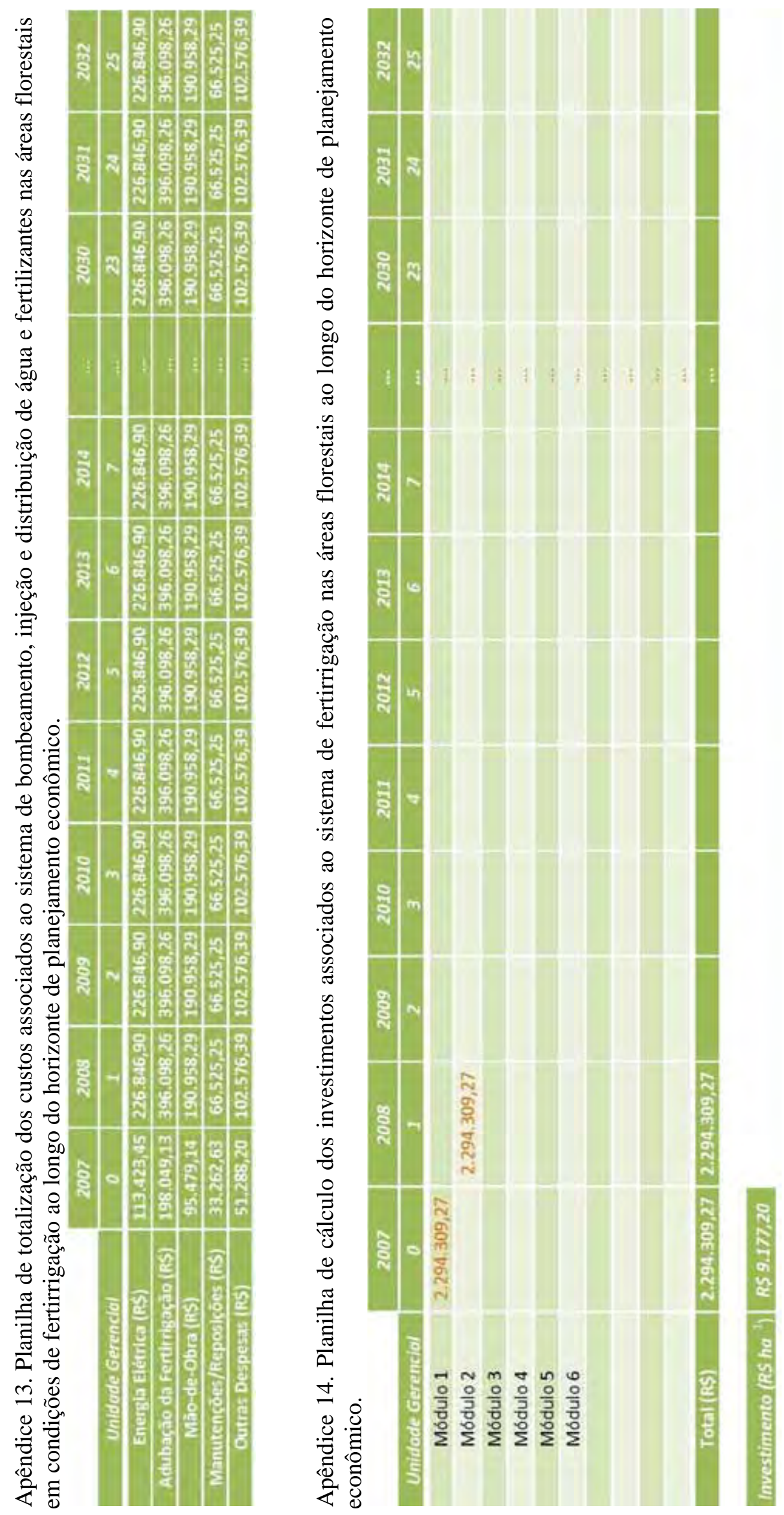



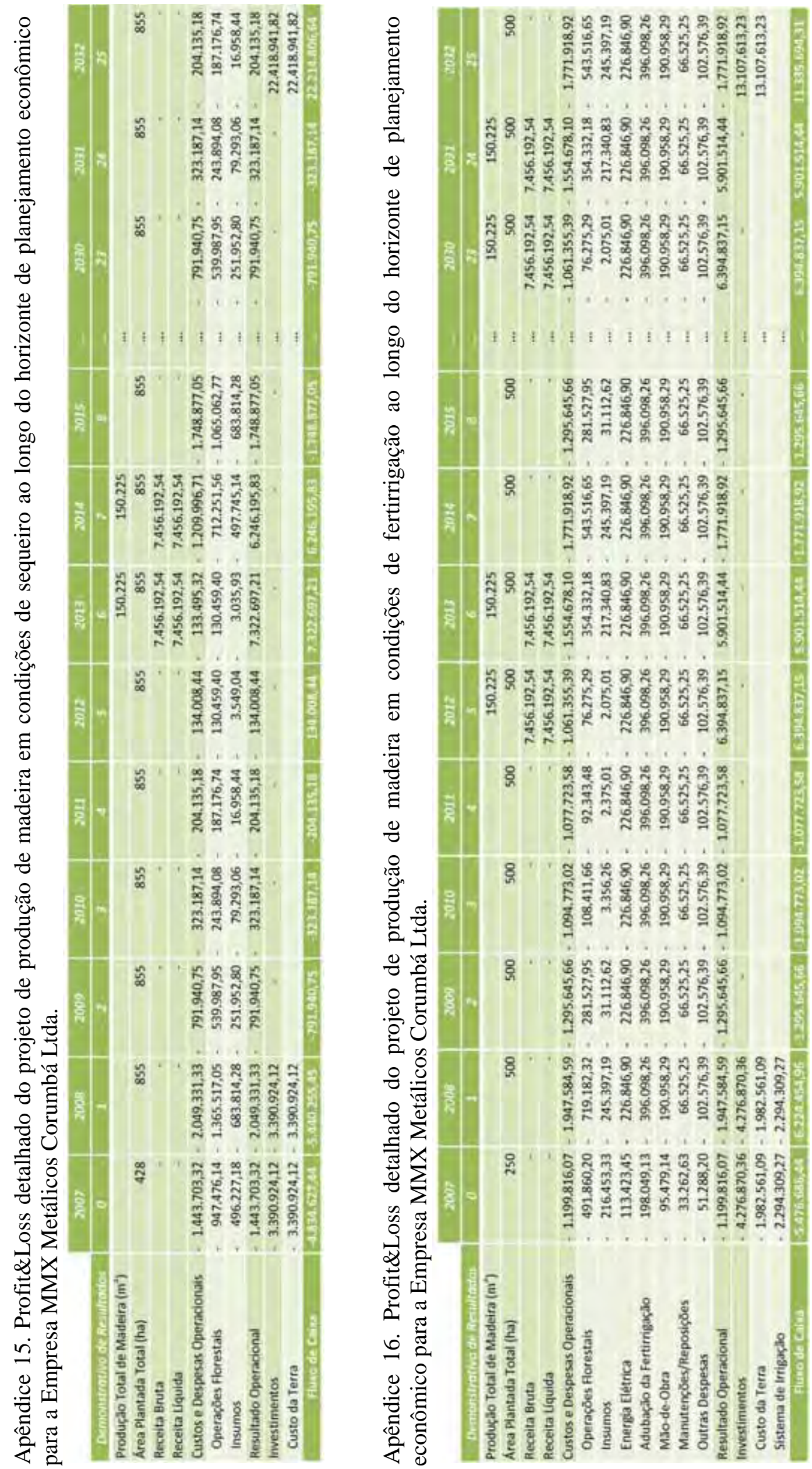